University of Redlands

\title{
GIS-Enabled California Agricultural Land Evaluation and Site Assessment Model
}

A Major Individual Project submitted in partial satisfaction of the requirements

for the degree of Master of Science in Geographic Information Systems

by

Dorothy Kathleen Watkins

Fang Ren, Ph.D., Committee Chair

Mark Kumler, Ph.D.

August, 2009 
GIS-Enabled California Agricultural Land Evaluation and Site Assessment Model

Copyright () 2009

by

Dorothy Kathleen Watkins 
The report of Dorothy Kathleen Watkins is approved.

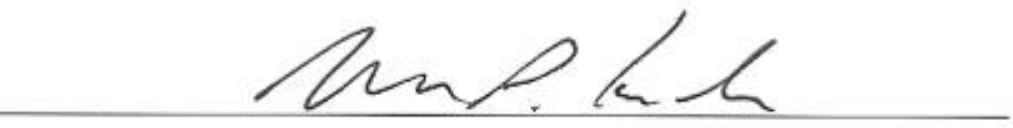

Mark Kumler, Ph.D.

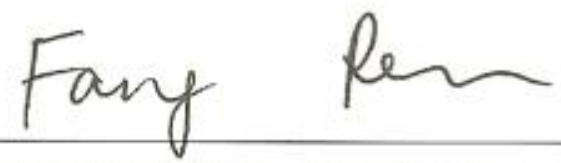

Fang Ren, Ph.D., Committee Chair

August 2009 



\section{Acknowledgements}

For my Mom, with all my love.

Thank you to Dr. June Morrison and her family for their generosity and support. I cannot begin to express my gratitude and pride. You have changed my life and I will use the investment wisely.

To Dr. Fang Ren, thank you for your guidance, support and encouragement. I couldn't have done it without you. It has been my honor to have you as my advisor and I hope you know how much all of Cohort 14 appreciates you as a person and as a professor.

To Dr. Mark Kumler for his encouragement, hard work helping me select an interesting and challenging agricultural topic, and for serving on my graduate committee from down under.

To Molly Penberth and the staff at the Farmland Mapping and Monitoring Program at the Department of Conservation thank you for working with me on this project. I have admired your work for years and it has been a pleasure to work with such a talented group of GIS professionals.

To Trevor and Jasper, my children and the ones who know me best, I thank you for all the sacrifices you have endured over the years that lead us here. You always kept me focused on what matters, and never doubted we would succeed. I hope I have given you courage and shown you how to make your own dreams come true.

To Dr. Eugenie Rovai, who empowered me as an undergraduate and became my mentor, friend, and confidant. The letters from home kept me grounded, and our annual autumn camping trip gave me something to look forward to all year long.

To my friends in Cohort 14, the greatest cohort of all time, we did it together and we are amazing! Working so hard has never been so much fun. Thank you all for your friendship, support, and making me feel a part of something special.

To Nate Strout for all the assistance with Python and those little gems of knowledge I will use the rest of my career.

To Lynn Flewelling and her purple pen, your talent and attention to detail is amazing. Thanks for helping me become a more confident writer.

To Debbie Riley thanks for all the early morning chats, being such a good listener, keeping us organized, and making all our problems go away.

To John, Brandon and Ruben for keeping me up and running all year, you are my heroes.

And a special thanks to the "Moms", Olga, Susan, Ashley, and Eva, the village who raised my child this year. The laps around the apartments, afternoons at the pool, goodnight kisses, trips to the library, and walks to the park made our apartments a real home. 



\begin{abstract}
GIS-Enabled California Agricultural Land Evaluation and Site Assessment Model

by

Dorothy Kathleen Watkins
\end{abstract}

Agriculture in California is an essential part of the state economy, which has a finite inventory of viable agricultural lands for production. California is also a highly urbanized state with an ever increasing population that requires housing and employment. Therefore, there is a need to balance conservation and development. The California Department of Conservation currently uses the California Agricultural Land Evaluation and Site Assessment Model (LESA) to plan rural land use, evaluate development projects, and review applications for long-term conservation easements. However, the entire decision-making process was completed manually, which was time-consuming and prone to spatial or classification errors. In order to improve the efficiency and consistency, a prototype application was developed in ESRI ModelBuilder to GIS-enable the California LESA model using Fresno County as the study area. The ModelBuilder application automates a workflow that can improve land use decisions in California and day-to-day operations of the Department of Conservation. 



\section{Table of Contents}

Chapter 1 - Introduction $\quad 1$

1.1 Client 2

1.2 Problem Statement 3

1.3 Proposed Solution 3

1.3.1 Goals and Objectives $\quad 4$

1.3.2 Scope of Work 4

1.3.3 Methods 5

1.4 Audience 5

1.5 Overview of the Rest of this Report 6

Chapter 2 - Background and Literature Review $\quad 7$

2.1 Use of the LESA Model at Local, State, and Federal Agencies in California 7

2.2 Rural Land Use Planning Applications and Studies 8

2.3 Agriculture Industry Solution Materials and Resources 10

$\begin{array}{lll}2.4 & \text { Summary } & 10\end{array}$

Chapter 3 - Systems Analysis and Design 13

3.1 Problem Statement 13

3.2 Requirements Analysis 13

3.3 System Design 14

3.4 Project Plan 16

3.4.1 Requirements Analysis Task 19

3.4.2 Manual LESA Modeling Task 20

3.4.3 Data Needs Task 20

3.4.4 Design and Load File Geodatabase Task 20

3.4.5 Development of ModelBuilder Applications Task 20

3.4.6 Project Presentations at CalGIS and ESRI Conferences Task 21

3.4.7 Project Conclusion Task 21

$\begin{array}{lll}3.5 & \text { Summary } & 21\end{array}$

Chapter 4 - Database Design 23

$4.1 \quad$ Conceptual Data Model 23

4.2 Logical Data Model 24

4.3 Data Sources 26

4.3.1 Study Area Layer 28

4.3.2 Natural Resources Conservation Service (NRCS) Soils Layer 28

4.3.3 Water Availability Layer $\quad 29$

4.3.4 Surrounding Agricultural Lands Layer 30

4.3.5 Surrounding Protected Lands Layer 30

4.4 Data Collection Methods 30

4.5 Data Preprocessing and Database Loading 31

$\begin{array}{lll}4.6 & \text { Summary } & 32\end{array}$

Chapter 5 - Implementation 33

5.1 Project Workspace 33

5.1.1 Portability 33

5.1.2 Project MXD 34

5.1.3 Toolbox Implementation 34 
5.1.4 Python Scripts $\quad 35$

$5.2 \quad$ Modeling 36

5.2.1 Land Capability Classification (LCC) Factor 37

5.2.2 Storie Index Factor 38

5.2.3 Project Size Factor 38

5.2.4 Water Availability Factor 39

5.2.5 Surrounding Agricultural Lands Factor $\quad 40$

5.2.6 Surrounding Protected Lands Factor $\quad 42$

$5.3 \quad$ Reporting the LESA Model Results 43

5.4 Model Documentation $\quad 43$

$\begin{array}{lll}\text { 5.4.1 Tool Help } & 43\end{array}$

5.4.2 Metadata 44

5.5 Summary 44

Chapter 6 - Results and Analysis $\quad 45$

6.1 The LESA Tools Toolbox $\quad 45$

6.2 Weighing and Interpreting the Model Results 47

6.3 ModelBuilder Model Report $\quad 48$

6.4 Model Consistency $\quad 49$

6.5 Model Efficiency 51

6.6 Summary $\quad 52$

Chapter 7 - Conclusions and Future Work $\quad 53$

7.1 Review of Requirements 53

7.1.1 Ease of Use $\quad 53$

$\begin{array}{ll}7.1 .2 & \text { Light Data Storage } \\ 7.1 .3 & 53\end{array}$

7.1.3 Scalability 53

7.1.4 User Documentation $\quad 54$

7.1.5 CEQA Compliant $\quad 54$

7.2 Review of Scope $\quad 54$

7.3 Challenges 54

$\begin{array}{lll}\text { 7.3.1 Data } & 55\end{array}$

7.3.2 Consistency with 1997 Instruction Manual 55

7.4 Future Work $\quad 55$

7.4.1 Web GIS

7.4.2 Batch Processing 56

7.4.3 Replace Agricultural and Water Layers with DWR Land and Water Use Study Layers 56

7.4.4 Incorporate LESA Model Results in UPlan Model 56

$\begin{array}{lll}7.5 & \text { Summary } & 57\end{array}$

Works Cited $\quad 59$

Appendix A - List of URLs $\quad 61$

Appendix B - ESRI System Specifications $\quad 62$

Appendix C - Information Product Description 64

Appendix D - Project Tasks and Schedule $\quad 67$

Appendix E - ArcGIS Diagrammer Database Schema $\quad 68$

Appendix F - ArcGIS Diagrammer Data Report $\quad 73$ 
Appendix G - Fresno County Soil Survey Pre-processing

Appendix H - Python Script Samples $\quad 77$

Appendix I - Model Diagrams $\quad 81$

Appendix J - Project Size ModelBuilder Model Report $\quad 87$

Appendix K - Manual Methodology $\quad 111$

Appendix L - Instruction Manual $\quad 112$ 



\section{List of Figures}

Figure 1-1: Location of Fresno County study area within California........................ 2

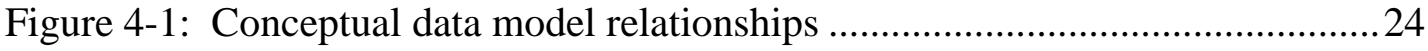

Figure 4-2: ArcGIS Diagrammer geodatabase schema ...................................... 25

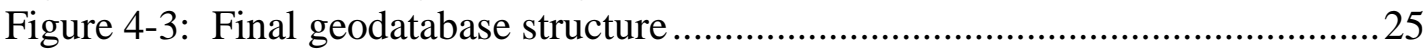

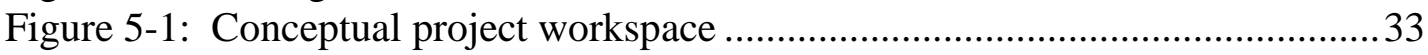

Figure 5-2: Calculate Field dialog box for embedding scripts .............................. 36

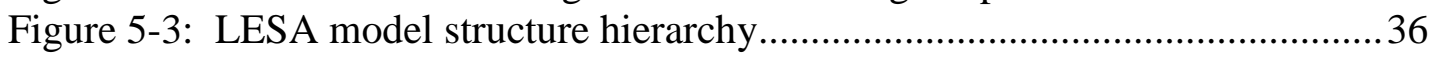

Figure 5-4: Bounding box for an irregular polygon............................................ 40

Figure 5-5: Buffered bounding box with study area removed .................................41

Figure 5-6: Custom tool Edit Documentation dialog box........................................ 44

Figure 6-1: LESA Tools toolbox contents ......................................................... 45

Figure 6-2: Example of empty space in a data layer..............................................46

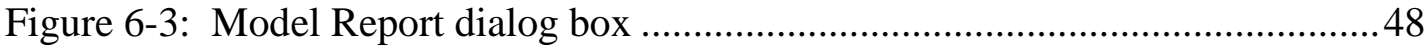

Figure 6-4: Model Report variable excerpt......................................................49

Figure 6-5: Model Report processes excerpt ..........................................................49

Figure 6-6: Comparison of extents used to model surrounding land factors ............50 



\section{List of Tables}

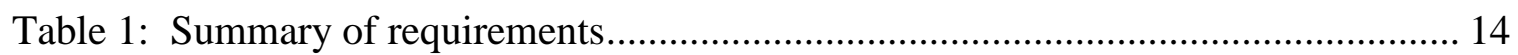

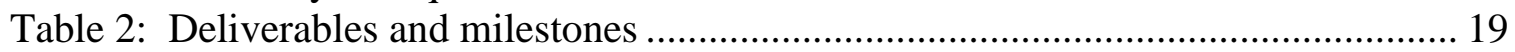

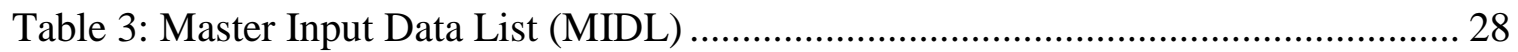

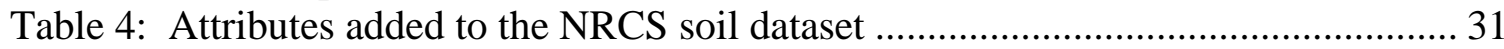

Table 5: LCC classification conversion to LCC rating.............................................. 37

Table 6: Summary of LCC rating associated with Bins I, J, and K.............................. 39

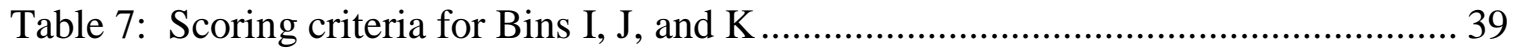

Table 8: Scoring criteria for the Surrounding Agricultural Lands factor ...................... 42

Table 9: Scoring criteria for the Surrounding Protected Lands factor ............................ 43

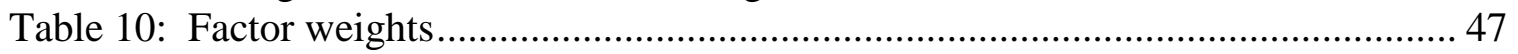

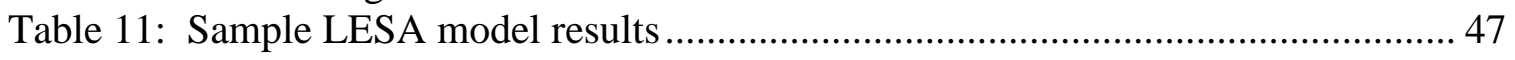

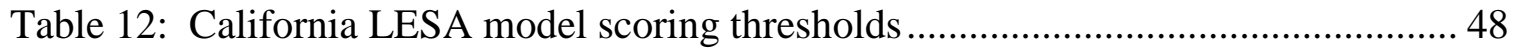

Table 13: Summary of the amount of deviation from 1997 manual ............................... 51 



\section{List of Acronyms and Definitions}

$\begin{array}{ll}\text { CALES } & \text { NRCS Computer-Aided Land Evaluation System } \\ \text { Caltrans } & \text { California Department of Transportation } \\ \text { CaSIL } & \text { California Spatial Information Library } \\ \text { CEQA } & \text { California Environmental Quality Act } \\ \text { DOC } & \text { California Department of Conservation } \\ \text { DWR } & \text { California Department of Water Resources } \\ \text { ESRI } & \text { Environmental Systems Research Institute } \\ \text { FMMP } & \text { DOC Farmland Mapping and Monitoring Program } \\ \text { ICE } & \text { Information Center for the Environment, University of California Davis } \\ \text { IPD } & \text { Information Product Description } \\ \text { LCC } & \text { NRCS Land Capability Classification of soil units } \\ \text { LESA } & \text { Land Evaluation and Site Assessment model } \\ \text { NRCS } & \text { United States Natural Resources Conservation Service } \\ \text { MIDL } & \text { Master Input Data List } \\ \text { SSURGO } & \text { NRCS Soil Survey Geographic Database }\end{array}$





\section{Chapter 1 - Introduction}

Agriculture is an essential part of California's economy. In 2006 California was the top producing and exporting state in the nation. Nine of the top 10 producing counties in the United States were located in California (California Department of Food and Agriculture, 2006). Farm and ranch lands are also an important conservation resource, which protects groundwater recharge areas, provides open space, and promotes soil conservation. At the same time California is an urbanized state whose residents need adequate housing and access to employment (United States Census Bureau, 2009).

Decisions made at the local, state, and federal level affect agricultural land inventories and development projects. Decision makers need tools to efficiently and consistently evaluate land use proposals. The Farmland Mapping and Monitoring Program (FMMP) is responsible for participating in the initial study phase of California Environmental Quality Act (CEQA) environmental reviews of real estate development projects, as well as long-term agricultural conservation agreement proposals. The FMMP program is part of the California Department of Conservation's Land Resource Protection Division.

The California Agricultural Land Evaluation and Site Assessment model (LESA) is one of the tools available for these types of assessments. These assessments help to form land use decisions, which may result in land use changes. The LESA modeling process results in a single score which ranks how agriculturally viable a property is, based on multiple factors including soil quality, water resources and surrounding land uses.

The California Agricultural LESA model was adopted in 1997 by the California Department of Conservation (DOC) and has always been a manual process. In 1997, GIS was just beginning to be incorporated into the workplace at the state level in California. Most of the data inputs required for the LESA model were available only in hard copy form. Therefore, in the past the DOC relied on LESA modeling results submitted by consultants or local planning agencies and did not have an efficient way of substantiating these submittals. This project aimed to develop a GIS-enabled LESA model which would provide the California Department of Conservation with an automated workflow, in order to more efficiently and consistently determine future uses of California's agricultural resources.

A prototype application and file geodatabase were developed using Fresno County as the study area. Fresno County was selected as the study area because it is a rich agricultural region and one the California's fastest growing counties (County of Fresno, 2009). Figure 1-1 illustrates the location of Fresno County with the state of California. 


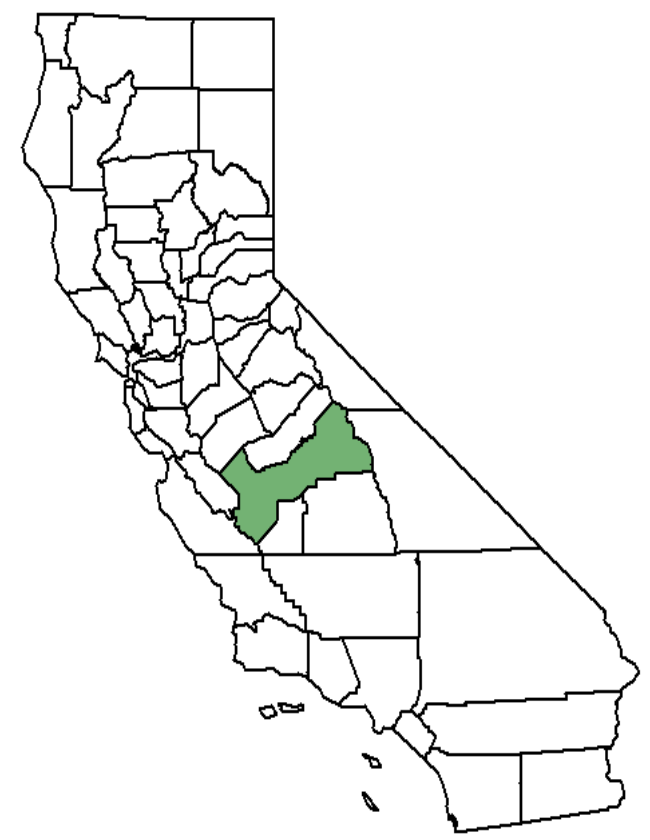

Figure 1-1: Location of Fresno County study area within California

The remainder of this chapter provides an introduction of the client, and defines the problem statement and proposed solution. Included in the project solution are the goals and objectives, scope of work, and methodology employed to develop and implement the project. It concludes with a discussion of the intended audience for this report, followed by an overview of topics remaining in the rest of the report.

\subsection{Client}

The California Department of Conservation, Division of Land Resource Protection has five programs, including the Farmland Mapping and Monitoring Program (FMMP). The other four programs that fall under the Division of Land Resource Protection at the California Department of Conservation are: the California Farmland Conservancy Program, the Resource Conservation District Assistance Program, the Williamson Act Program, and the Watershed Program.

A fundamental purpose of FMMP is to collect, update, and distribute statistical and geographic data of the statewide inventories of agricultural lands in California. FMMP was an early user of GIS technology at the state level, and has mapped and analyzed California's agricultural lands since 1982. The first Important Agricultural Lands map was published in 1984. Since then, the program has evolved to include urban land uses so that agricultural land conversions can be mapped and analyzed statistically. The map series is updated every two years and is available for download from the Department of Conservation's FMMP website (Appendix A).

Molly Penberth is the FMMP manager and responsible for overseeing the collection of statistical data and developing map documents of agricultural land statewide, as well as for reviewing environmental documents submitted by developers or property owners. 
California Environmental Quality Act (CEQA) environmental reviews may include LESA modeling results.

\subsection{Problem Statement}

The underlying problem is that California has a finite inventory of viable agricultural lands, and an increasing population which requires housing and employment. Two California Department of Conservation (DOC) goals are to identify strategic farmland resources, and to develop useful tools for conservation planning. However, the existing methods of using LESA models are time-consuming, require a comprehensive understanding of the manual procedures, and can introduce bias as well as spatial and classification errors. Therefore, the challenged faced by DOC was to improve the existing approach to evaluating land use proposals.

To address this issue DOC intended to automate the LESA modeling workflow for determining the agricultural viability of lands under CEQA environmental review for development, or for long-term protection. This would allow FMMP staff to identify high-value agricultural lands for conservation, and low-value agricultural lands for development, thus enhancing their ability to perform their duties and improving the decision making process. As a result, FMMP staff would be able to better critique environmental reviews and to conduct evaluations of their own for properties of interest.

\subsection{Proposed Solution}

An application automating the workflow of the DOC's LESA model using GIS would make it possible for FMMP to substantiate the accuracy of LESA model submittals, as well as to prepare evaluations of their own. Therefore, this project proposed to develop a GIS-enabled LESA model for the Department of Conservation, Division of Land Resource Planning, Farmland Mapping and Monitoring Program (FMMP).

The GIS-enabled LESA model automated the workflow of the six factors contained in the 1997 California Agricultural LESA model instruction manual using Environmental Systems Research Institute (ESRI) ModelBuilder software available with ArcGIS. The URL for viewing or downloading the 1997 instruction manual is provided in Appendix A. The LESA model yields an overall score for a property that is between 1and 100, with 100 being the most viable for agriculture. ModelBuilder allows functions and outputs to be created in a GIS platform, and to be repeated for different study areas. It also provides the user with the means to vary parameters such as input data layers, and provides graphic instructions in the form of flowcharts. Automated workflows built and shared using the ModelBuilder format allow the user to vary or update the model without requiring programming skills. ArcGIS ModelBuilder was used to automate the set of applications, and a file geodatabase was developed to house the project data. A project workspace was used to store the data and applications that make up the GIS-enabled LESA model. 


\subsubsection{Goals and Objectives}

The overall project goal was to develop a GIS application for the LESA modeling workflow which would aid and improve the process by which agricultural land use decisions by the California Department of Conservation are made. It was important that the GIS application developed in the project improve the day-to-day operations of those who work to balance the needs of land conservation and real estate development, and enhance the tools for more efficient property assessments of agricultural viability.

The first objective was to develop a file geodatabase containing the regional and statewide GIS data used by the ModelBuilder applications automating the LESA model. Successful completion of this project would demonstrate the ability of GIS to solve complex problems related to agriculture using GIS technology, as well as the ability to document and communicate processes and solutions within ModelBuilder. The goals and objectives identified below guided the development of the scope of work and project plan that would result in a GIS-enabled LESA model for FMMP. Project specific objectives included:

- Develop a set of GIS models to automate the workflow of the six LESA model factors that make up the complete model

- Identify and incorporate appropriate datasets for use in the model and database

- Compile the results of the LESA model results in a single table

- Develop clear instructions which would allow FMMP staff to use a GIS-enabled LESA model easily and efficiently

- Demonstrate that the GIS-enabled model requires less time to determine LESA scores than the manual procedure

\subsubsection{Scope of Work}

This project was designed to automate each of the six factors of the LESA model described in the 1997 instruction manual. The 1997 manual is divided into two parts: the Land Evaluation section, and the Site Assessment section. The Land Evaluations section includes the Land Capability Classification (LCC), and the Storie Index factors. The Site Assessment section includes the project size, the water availability, the surrounding agricultural land, and the surrounding protected land factors.

The products resulting from this project were a set of nine GIS models developed for use by FMMP to calculate LESA scores. The final result of the complete model is a single, weighted score with values between 1 and 100. The ModelBuilder applications, Python scripts and file geodatabase containing the study area data were stored in a project workspace for portability.

Fresno County was chosen as the study area and the prototype was limited to that area. It was beyond the scope of this project to compile and aggregate all the datasets necessary to implement a statewide LESA model. Therefore, the project was limited to a single county for development and testing.

In addition, the project was limited to the use of data available from state and federal agencies, though various data sources and criteria have been used in different versions of 
LESA models since 1997. The Farmland Mapping and Monitoring Program (FMMP) agreed to facilitate the acquisition of datasets, such as the Natural Resources

Conservation Service (NRCS) soil data layer. Additionally, FMMP prepared the Land Capability Classification (LCC) and Storie Index attributes for the NRCS soils data layer.

Project documentation included a summary report of the project, metadata and instruction materials for the GIS user, a PowerPoint presentation at a professional conference and project defense, as well as a DVD containing the file geodatabase and associated ModelBuilder applications for the study area.

\subsubsection{Methods}

The approach to GIS-enabling the California Agricultural Land Evaluation and Site Assessment (LESA) was to develop a project workspace that would house the file geodatabase and the set of ModelBuilder applications, including Python scripts automating the LESA model workflow. Python scripting was used to leverage ModelBuilder's functionality when the system tools were unable to fully automate the workflow described in the 1997 instruction manual.

ESRI ModelBuilder is a graphic interface for accessing and combining geoprocessing tools within the ArcGIS ArcToolbox module. Geoprocessing is a fundamental task in GIS in which spatial and/or non-spatial data are manipulated in order to derive new data. Common geoprocessing tasks are data extraction, transforming map projections and manipulating attribute tables. A completed ModelBuilder workflow is a reusable model that can be altered to accept different variables and is itself a tool within ArcToolbox. This feature of ModelBuilder makes it a good choice for automating the LESA model, as the LESA model would be able to be reused for different land use proposal evaluations.

Since some functions required to automate the LESA model workflow in ModelBuilder are not available, Python scripting was used to create customized geoprocessing tools such as running batch processes or performing complex calculations inside existing system tools. Python scripting was implemented within ModelBuilder's visual programming interface and within system tools.

An additional consideration of the project methods was data preprocessing. Data preprocessing includes tasks to refine or aggregate data attributes and features, including calculating new values based on existing attribute values, and standardizing each data layer's projection, datum and units for geodatabase loading. Data preprocessing is a common task performed to ensure the data attributes and features are formatted appropriately and consistently prior to importing to a GIS map document for labeling, symbolizing, or analyzing.

\subsection{Audience}

The topics presented in this document are intended to be of interest to a range of readers, including those interested in rural land use planning, agricultural land use decisions, water resources, agricultural conservation, and the use of GIS technology to improve the 
decision-making process. This audience includes readers who have professional experience in the subject matter, and are familiar with GIS.

\subsection{Overview of the Rest of this Report}

The upcoming chapters will lead the reader through the development, implementation and conclusion of this project. Chapter 2 provides the reader with the background and literature reviewed for this project. The literature review encompasses three primary topics. The first explores the existing use of LESA modeling at local state and federal agencies in California. Next is a review of rural land use planning application and studies. The review concludes with a summary of agricultural GIS industry solutions, materials, and resources available.

Chapter 3 provides the project systems analysis and design. This includes a discussion of the requirements analysis, as well as the functional and nonfunctional requirements, system design, and the project plan. The system design is also presented graphically in this section. Database design is presented in Chapter 4. It includes text and graphics describing the conceptual and logical data models, data sources and collection methods used to acquire the data. Data preprocessing and loading of the geodatabase are also discussed in this chapter.

Project implementation is described in Chapter 5. Project implementation provides a detailed discussion of how the project was developed. Chapter 6 provides the analysis and the results of the implementation process, leading to the project findings. In Chapter 7 the project findings are presented, as well as recommendations for future work. 


\section{Chapter 2 - Background and Literature Review}

As stated in Chapter 1, balance between land development and land conservation is one of the key factors for promoting sustainable land use in California. In order to efficiently and consistently evaluate land use proposals, decision makers need easy to use tools or land assessment models to aid in the process. Among these various land assessment models, the California Agricultural Land Evaluation and Site Assessment (LESA) model has been widely used. Despite its popularity and usefulness, the automation of this model still needs improvement. A background of existing LESA models at local, state and federal agencies is provided in this chapter. In addition to the LESA models, a broader range of studies relevant to agricultural land use changes will also be examined along with a summary of GIS resources available for the agriculture industry.

\subsection{Use of the LESA Model at Local, State, and Federal Agencies in California}

The LESA model is used to evaluate the environmental impacts on agricultural lands being considered for development or long-term conservation during the initial study phase of the CEQA review process. The California LESA model quantifies a property's soil quality, water resources, and neighboring land use to gauge how viable it is for agriculture. This is accomplished by scoring and weighing six factors to determine a single overall score for the property.

Use of LESA models is widespread and there are numerous versions in use. A nationwide inventory conducted in 1990 found more than 200 different models in use nationally (Pease \& Coughlin, 1994). The original LESA model was designed by the federal government in 1981 and distributed by the Natural Resources Conservation Service (NRCS). It was intended to be adapted to reflect local policies and values. As a result, there may be different criteria evaluated and scored in the various models reflecting local values and circumstances. The model was originally used to quantify the impacts of federal projects, such as freeways, on agricultural lands.

In California, LESA modeling is used in rural land use planning during the initial study phase of the environmental review process to determine if a project will be subject to the California Environmental Quality Act (CEQA) (California Department of Conservation, 2008a). If it is determined to be subject to CEQA, a project would require additional investigation, and likely require mitigation measures prior to development.

At the local level, the City of Davis has developed a GIS-enabled LESA model for their agency, based on the 2002 Yolo County Local Agency Formation Commission LESA model. The Davis model is used to evaluate lands proposed for long term agricultural conservation. This vector-based model was developed using ArcObjects programming and provides a separate score for each factor measured, as well as the overall weighted score. The City of Davis found a separate factor score useful for comparing specific criteria across multiple properties, which allows the user to determine which properties in a group rated higher or lower for a certain criteria (Boyd, 2008). 
In 2008 the City of Davis model was shared with the Yolo County, California, office of the Natural Resources Conservation Service (NRCS), which adapted it to run using countywide datasets. No programming changes were planned by this local NRCS office at that time. They planned to extend the projects extents to include all of Yolo County, but not alter the applications functionality (Rash, 2008).

NRCS also has a form-based application on their national website, known as the Computer-Aided Land Evaluation System (CALES), which was originally developed by the United States Army Corps of Engineers. This application allows the user to enter property data into an online form and provides a score based on the NRCS version of the model, but it is not implemented in a GIS environment (Natural Resources Conservation Service, 2009). This form is useful for performing computations. However, like the manual process, it requires the user to compile the input data prior to entering in the application and it requires a comprehensive understanding of the model. A GIS-enabled LESA model application is superior to the form based application because it simplifies and automates the evaluation process, eliminating the need to have a comprehensive understanding of the modeling process in order to evaluate a property. It also allows the user to visualize and map the property being evaluated.

A GIS-enabled LESA model application is available to counties in Pennsylvania that participate in the regional Farmland Preservation Program. The Farmland Preservation Program works to identify viable agricultural properties for the purchase of development rights from farmers. This model was developed by the Pennsylvania State University Land Analysis Lab and Cooperative Extension, and has been available for download since 2000. It was developed using ArcView 3.2 and produces maps and tables for each of the criteria evaluated, and a summary table (Pennsylvania State University, 2008). The ability to produce multiple layouts from a single project is a benefit of using the older software version, ESRI ArcView 3.2.

The online form available from NRCS automates the LESA modeling process in a limited manner, but lacks the spatial and visual components of GIS. The city and county applications made use of GIS to automate the model but both required the user to have programming skills in order to adapt to a new region or different datasets. This is a specialized skill set not all GIS users possess. For these reasons ESRI ModelBuilder was selected for this project. Using ModelBuilder, a GIS user may repeat the analysis for a different region or different dataset without specialized programming skills.

\subsection{Rural Land Use Planning Applications and Studies}

To date, a number of studies and projects have been conducted to address rural land use planning issues, some of which used LESA modeling or incorporated aspects of the model. For example, in the mid 1980s an early GIS land use study, the Metropolitan Landscape Planning Model, incorporated LESA components. Using the City of Westfield, Massachusetts, as the study area, planners developed a vector-based GIS to identify "alternative nonagricultural lands for development" (Lindhult, Fabos, Brown, \& Price, 1988). The LESA model was not used in its entirety in the study and had to be adapted because agriculture in Westfield was mostly cattle and dairy, while the federal LESA model criteria used in this study placed an emphasis on crop growing land uses. 
The California Urban Futures Project is another early GIS urban land use model (Landis \& Zhang, 1998). The study provided the basis for the California Central Valley Alternative Futures Model, which modeled the impacts of rural land conversion on residential and commercial uses in California's Central Valley (Bradshaw \& Muller, 1998). Fresno County is located in the Central Valley. Using GIS data available from governmental agencies, the Central Valley Project analyzed the locations where development was taking place, and the consequences of rural development. One objective was to identify "demographic, political, and geographic factors associated with conversions" (Bradshaw \& Muller, 1998) in order to identify areas that had a high probability of growth. These areas were then modeled with low and high density growth scenarios.

A common issue the above studies addressed was how to manage and plan the urban-rural interface, commonly called a conflict zone (negative), or transition zone (neutral) by land use planners. Areas where agriculture activities are taking place in close proximity to urban activities can be a source of frustration for both parties. A farmer expects to be able to spray fertilizer and operate the equipment needed to produce and harvest crops. Homeowners in both urban and rural areas expect to enjoy their homes without pollution, noise, and smells invading their personal environment.

Farming on the urban edge doesn't have to be a conflict zone. There are many examples of adaptive farmers who work in or near urban areas (Arendt, 1994). These farmers are characterized by the intensive farming practices they use to produce more crops on less land, compared to their traditional counterparts in more rural locations. They may also use their proximity to urban areas to improve their markets and reduce shipping costs by selling to urban markets and restaurants (Arendt, 1994). The Inland Orange Conservancy in San Bernardino County, California is a good example of adaptive farming. The Conservancy farmers market their produce directly to the consumer, resulting in higher profits for the farmers while providing consumers with fine local produce (Inland Orange Conservancy, 2009).

In California, integrated land use and transportation planning performed on a regional basis is known as blueprint planning. This integrated planning is gaining popularity because land use decisions and transportation networks affect each other. Change a land use to allow development, and new homes or industries will need transportation improvements. Build a freeway interchange and new housing or commercial developments will move in.

Highly urban areas such as San Diego and Sacramento have already completed urban blueprint plans. In 2008 the California Department of Transportation (Caltrans) provided blueprint planning grants to rural planning agencies for the first time. The Information Center for the Environment (ICE) at the University of California, Davis, is under contract with Caltrans to provide technical support and training for blueprint planning software named UPlan. UPlan is a raster based extension for ESRI ArcGIS software that allows the user to model growth scenarios by varying geographic attractors and discouragers within the model, such as residential land use zoning and transportation infrastructure (Roth, 2007). Geographic attractors are land uses that encourage development, such as residential zoning or proximity to transportation networks. Discouragers are land uses 
that prevent or inhibit development, such as open space zoning, prime farmland designations, or water bodies.

The UPlan software allows the user to vary inputs such as population, housing density, and the location of land uses to explore "what if" scenarios. These scenarios can reflect policies or values, such as discouraging development in wilderness areas or on prime farmland, or encourage high density housing on low value soils. The ability to model different scenarios is valuable because it will show the user where the development is likely to occur, once the available inventory of land intended for development is exhausted. Like the Central Valley study, this application is used to demonstrate the effect of high, medium or low density land uses on land inventories. Output from the LESA model could be used as an input to UPlan in the future. High scoring agricultural properties could be made unavailable or discouraged for development in the UPlan model. Low scoring lands could be added to the inventories of land available for development in the model.

\subsection{Agriculture Industry Solution Materials and Resources}

There is an abundance of literature available on agricultural applications with an emphasis on precision farming practices. Precision farming is defined as, "farm management at a level that allows input be tailored to variable conditions across short distances in a single field" (Organization for Economic Co-Operation and Development, 2001). One example of precision farming is applying the minimum amount of agricultural chemicals only at the locations that need them, instead of treating the entire property.

ESRI has published industry solution literature, case studies, and electronic media to address the needs of the agriculture community. Much of this literature addresses precision farming practices. The ESRI website includes an Agricultural Industry section which provides animated demonstrations, software brochures, case studies, news releases and information on best practices (ESRI, 2008). Promotional CDs are also available from ESRI. GIS Solutions for Agriculture (ESRI, 2001) provides information on the software products available, publications by ESRI Press, online training, and where to find data. ESRI's GIS Solutions for Agricultural Government (ESRI, 2002) provides an overview of the benefits of GIS for agricultural uses and how agencies have implemented GIS with various agricultural organizations, including 14 agricultural case studies.

Case studies are available from sources other than ESRI. In 2007, a collection of case studies was compiled to highlight the use of GIS in precision farming (Pierce \& Clay, 2007). This collection is not software specific and provides the reader with detailed methodologies for implementing the GIS practices at a farming operation. Examples of the case studies and methods include measuring crop yields, soil conservation, and precision spraying of pesticides and herbicides.

\subsection{Summary}

In this chapter existing LESA models were researched in order to understand what approaches have been used to automate the model, as well as to understand the evolution 
of the modeling process. The earliest GIS-enabled LESA model discovered was the Pennsylvania State University application, which has been available since 2000 and continues to use ESRI ArcView 3.2 software. All of the approaches explored were GISenabled, with the exception of the Natural Resources Conservation Service (NRCS) form-based online application. Additionally, all the GIS-enabled approaches required programming skills in order to adapt to new regions or datasets.

Rural land use planning applications and studies were reviewed to provide context for how GIS is used to improve planning practices in these areas, and to understand how this use has evolved in the past two decades. In the studies reviewed there was an emphasis on identifying where new growth might occur by modeling various growth density scenarios. Management of the urban-rural interface and adaptive farming practices was also of interest because the LESA model is often employed to evaluate properties on the urban fringe that are being considered for development.

Agricultural industry solutions materials and resources available from ESRI place an emphasis on precision farming practices. While these materials were not used directly in the development of this project, they did provide industry context.

Based on the previous work, it seems GIS technology has gained recognition in rural and agricultural land use planning because of its capability for managing and analyzing geographic and non-geographic data. Therefore a GIS application for the California LESA model was developed in this project to facilitate decision makers in evaluating land use proposals. However, unlike the previous studies and projects, the implementation of the GIS applications in this project is not dependent on advanced programming language skills. Instead it makes use of the geoprocessing and modeling functionality in ESRI's ModelBuilder and it leverages Python scripting to extend this functionality in order to automate the LESA model for FMMP. 



\section{Chapter 3 - Systems Analysis and Design}

Systems analysis and design were developed using the methods and practices presented in Roger Tomlinson's Thinking about GIS: Geographic Information Systems Planning for Managers (Tomlinson, 2003). This chapter will first restate the problem to be solved and introduce the associated project requirements in section 3.2. The remaining sections describe the conceptual and logical design of the system, and provide a detailed discussion of the project plan tasks.

\subsection{Problem Statement}

The LESA model is used to evaluate the agricultural viability of a given property by scoring and weighing multiple factors such as soil quality, water resources, and surrounding land uses. It is prepared and submitted to the Farmland Mapping and Monitoring Program (FMMP) for review as part of mandated California Environmental Quality Act (CEQA) environmental reviews for real estate development projects and for proposed long-term conservation contracts. Previously, FMMP relied on LESA scores submitted by consultants or property owners, and did not have an efficient and consistent method for evaluating the accuracy of these manually prepared submittals. FMMP wished to validate the submittals they received in a consistent manner, thereby improving the environmental review process. They also wished to use the LESA model to screen properties throughout the state to help identify good candidates for various conservation funding programs.

\subsection{Requirements Analysis}

A requirements analysis was conducted to identify and evaluate the nonfunctional and functional requirements of this project. The nonfunctional requirements are the "what" of a project, and the functional requirements are the "how". It was conducted to ensure the client's needs were met and to ensure the project was compatible with existing systems and processes. This was accomplished through communication with the client in order to achieve consensus or a mutual understanding of necessary compromises. Summarizing the functional and nonfunctional requirements also ensured the completeness of a project through documentation and review.

Table 1 provides a summary of the functional and nonfunctional requirements which resulted from client coordination during the project development. The functional requirements identified to meet the nonfunctional requirements of the project included designing a set of ModelBuilder applications and a file geodatabase located in the project workspace. The file geodatabase and applications needed to be designed using existing statewide datasets. The ModelBuilder applications were required to produce a table that could be used to prepare a LESA model report for use in CEQA reviews. 
Table 1: Summary of requirements

\begin{tabular}{|l|l|}
\hline Nonfunctional (What) & Functional (How) \\
\hline \hline Ease of Use & ModelBuilder to Automate Workflow \\
\hline Light Data Storage & File Geodatabase Storage \\
\hline Scalable & Use Existing Statewide Data \\
\hline User Documentation & Instruction Manual \\
\hline $\begin{array}{l}\text { Useful for CEQA } \\
\text { Reviews }\end{array}$ & LESA Model Results Table \\
\hline
\end{tabular}

As for the nonfunctional requirements, FMMP required a simple-to-use application and a lightweight file geodatabase that could be expanded to include additional counties in the future. They needed the workflow to be easy to use so staff unfamiliar with GIS could be trained to run the model, freeing up FMMP management to evaluate the results and make land use recommendations. The file geodatabase was required to house only the layers and associated applications absolutely necessary to run the model. This was because the data used for the model was already available in its entirety on FMMP's data servers. This included FMMP agricultural land use layers for each county in California, Natural Resources Conservation Service (NRCS) soils data, the Protected Lands database, as well as federal and private irrigation district layers. In addition to the nonfunctional requirements of ease of-use, data storage, and scalability, FMMP required instructions documenting the use of the model. It also required the model result in a table that could be used to prepare a report of the LESA model results to be submitted for CEQA reviews.

\subsection{System Design}

The project's conceptual design for the GIS-enabled LESA model was to launch ESRI ArcGIS 9.3 desktop, input the study area polygon, and select the application for LESA modeling. The user would then run the model and use the resulting table to complete a form suitable for submittal to CEQA. Optionally, the user could also print a hardcopy map showing the location and situation of the study area using the soil and land use data from the model database. Due to the low volume of modeling performed by FMMP, batch processing capabilities were not included in the design, but may be considered for future work. Batch processing is commonly employed when there are a number of study areas to be evaluated in a row. Batch processing can be designed to run the process during non-peak times, such as overnight, freeing up resources during the day.

The development environment for the application was ESRI ModelBuilder, supplemented by Python scripting. Python scripting was used in two ways. It was used to group sets of repeated processes, such as adding or deleting multiple fields. This was valuable for decreasing the number of steps within the model. Python scripting was also used to develop custom tools for use inside ModelBuilder. The Project Size tool is an example of Python scripting used to expand the functionality of ModelBuilder. The ModelBuilder applications are discussed further in Chapter 5. Figure 3-1 provides an overview of the system design. 


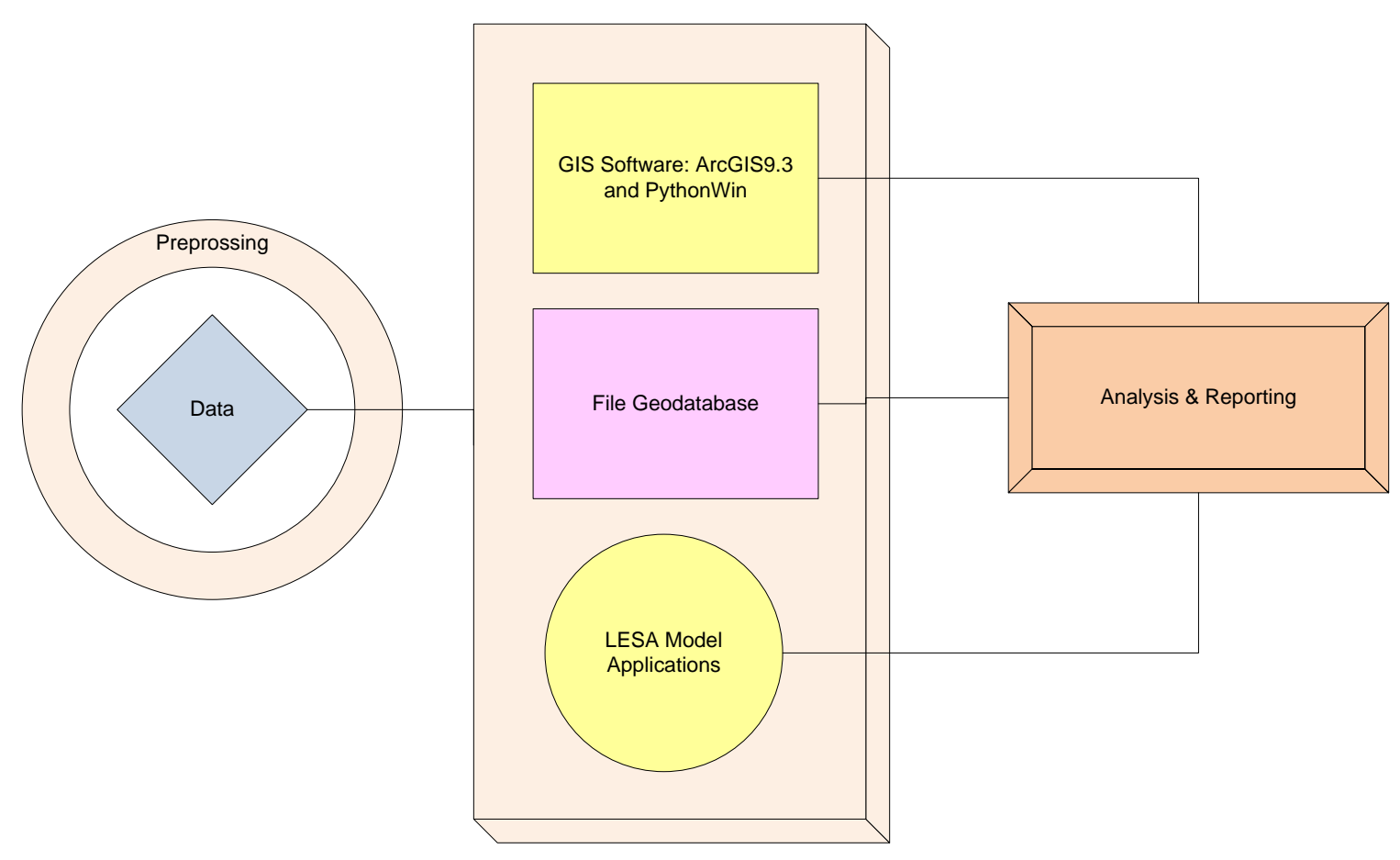

Figure 3-1: System design diagram

In addition to Python scripting, Visual Basic.Net programming and Visual Basic 6 were considered for use in the LESA model. Visual Basic.Net requires more advanced programming skills than Python scripting. Visual Basic 6 was avoided because ESRI is discontinuing support of this programming language, and like Visual Basic.Net, it requires more programming skills than Python scripting.

The system was also designed to be compatible with FMMP's GIS system that included GIS data servers, ESRI ArcGIS (ArcView and ArcInfo license levels), and ArcGIS Server software. FMMP's GIS data layers are organized using file geodatabases on the data servers. FMMP provided public access to current and archival shapefiles and metadata via the Internet using ftp download. The URL for the FMMP ftp site is provided in Appendix A.

Hardware and software requirements were evaluated using ESRI Help documentation, which provides a matrix listing all the geoprocessing tools available in ArcToolbox for use in ModelBuilder, as well as the ESRI license level required to access the tool. The license levels available for ESRI ArcGIS are ArcView, ArcEditor and ArcInfo, with ArcInfo providing the most functionality. In order for FMMP to use the ModelBuilder applications it is necessary for them to have highest license level required by all of the tools within the application. For example, the tool used to generate a bounding box polygon (envelope) in the surrounding agricultural land use and surrounding protected land use models requires an ArcInfo license, so FMMP must have an ArcInfo level license installed at the workstation running the model. Additionally, PythonWin must be installed in order to run the Python scripts. The PythonWin software is available on the ESRI installation disks for all license levels. 
The hardware requirements for this project were minimal. The estimate for a statewide geodatabase was not more than 2 GB (gigabytes). This means if FMMP wishes to run the project from an individual workstation, as opposed to their GIS server, it is highly likely any workstation capable of running ESRI ArcGIS software will be capable of using the GIS-enabled LESA application and database. Appendix B provides a summary of ESRI system requirements for hardware, software and Python scripting. While the project could be stored and used from an individual workstation, FMMP indicated they will house it on their GIS data server so it is accessible to all. This configuration was preferred because it provides access to the floating ArcInfo license necessary to run the ModelBuilder applications.

The application and data will be delivered at the conclusion of the project for deployment by FMMP IT staff. Once deployed, FMMP will be responsible for loading the additional datasets required for a statewide application. This project does not require any additional software or hardware purchases by FMMP. Please refer to Appendix B for additional information regarding the specifications for operating systems and minimum hardware required for ESRI software licensing.

Policies and standards were considered while developing the form to be used for compiling the model results for submittal to CEQA. The form was formatted to replicate the form provided in the 1997 manual as closely as possible so they would have a familiar look to users handling the newly automated results. The report provides the overall score and the individual scores from the land valuation and site assessment evaluation. This allows the staff evaluating the results to understand the study property more fully. This is useful when assessing a number of properties that are competing for grant funded conservation contracts. Properties with similar scores can be compared for individual strengths and weaknesses based on local priorities.

The Information Product Description (IPD) matrix provided in Appendix C was prepared during the system design phase and summarizes the functional utilizations within the project. An IPD describes what is being produced, what data is essential, the existing steps taken to produce the product, and for whom the product is prepared (Tomlinson, 2003). The functional utilization table within the matrix shows how often each tool within the application is used during the modeling process.

\subsection{Project Plan}

The concept for this project was simple: automate an existing manual process using GIS technology. The steps, procedures, data inputs, and data outputs were all defined in the 1997 manual. Although what was to be done had already been established in the instruction manual, how it was to be accomplished in a GIS environment was not. Working from an existing set of instructions meant each of the six procedures in the model was well defined, so it was clear from the beginning what was to be accomplished. However, this could be limiting in practice because the goal was to recreate the existing model in GIS, not to develop a new version of the model. Deviation from the model was avoided unless there was a compelling reason, such as lack of data. A diagram of the final project plan workflow is provided in Figure 3-2. The primary tasks for this project were: 
- Requirements Analysis

- Learn LESA Model Manually

- Database Design

- Build ModelBuilder Applications/Python Scripting

- Project Analysis

- Project Documentation

- Public Presentations

- Project Conclusion

The project plan and workflow diagram were used throughout the project development to measure progress and to evaluate the planning process for future projects.

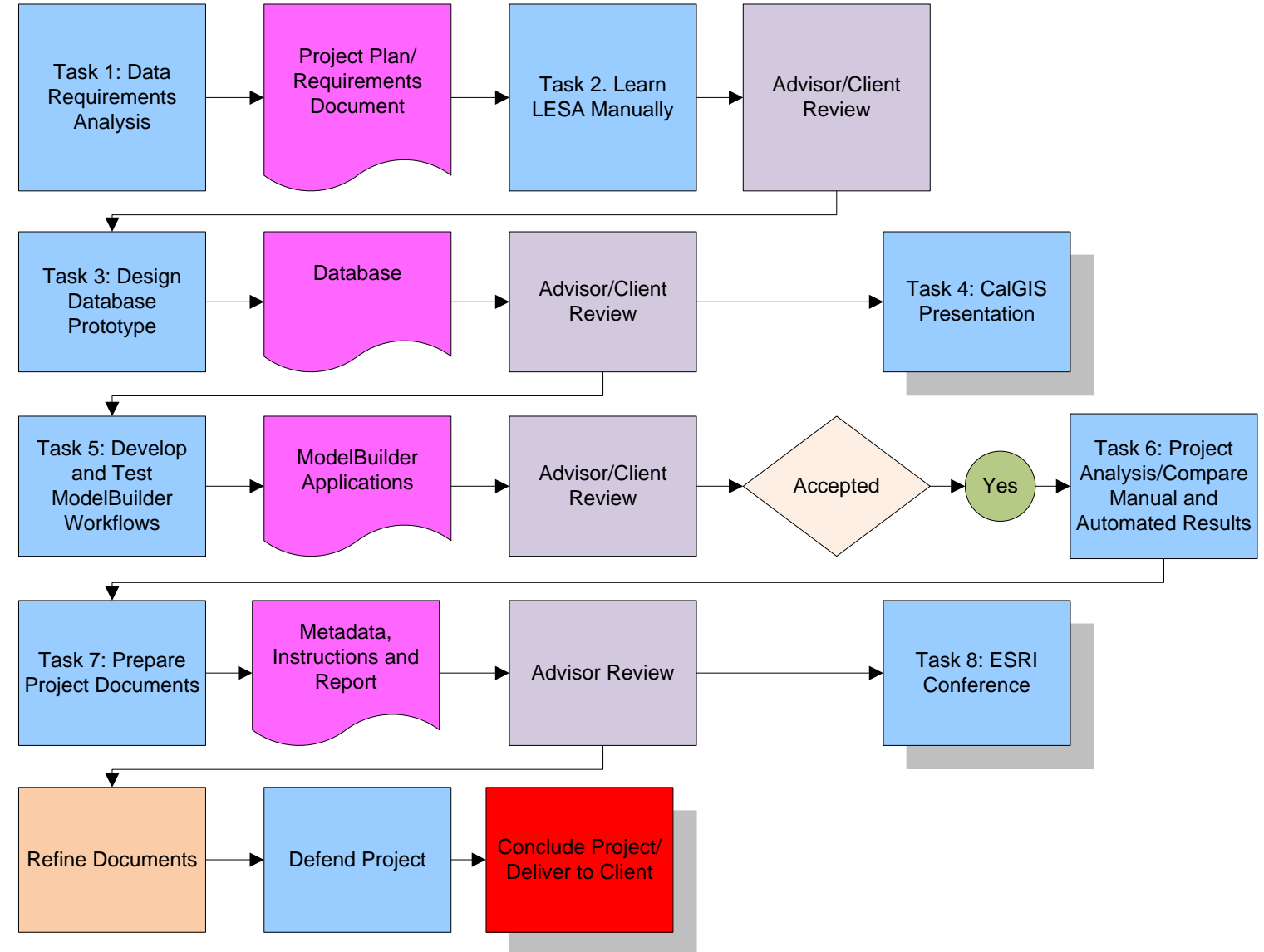

Figure 3-2: Final workflow diagram

The original project plan included a list of seven assumptions that were made during the development of the project plan. Of those seven assumptions, two were false and resulted in deviations from the original project plan. The assumptions that proved false were: 1) the project can be developed using existing data available from public agencies, and 2) the project applications can be developed using ESRI ModelBuilder without additional programming. The assumption regarding the availability of data was incorrect for the water resource component of the model. Neither of these false assumptions prevented the completion of this project, but both resulted in a change of approach. Data availability impacted the water resources component of the model, and is discussed 
further in Chapter 4. ModelBuilder provided most functionality needed to automate the LESA model in GIS; however, Python scripting was required to completely automate the process. The use of Python scripting is discussed further in Chapter 5.

Each task in the project plan had an associated deliverable or milestone, as well as client and advisor review and comment. Table 2 provides a summary of the deliverables and milestones completed during the project development, execution, and conclusion. 
Table 2: Deliverables and milestones

\begin{tabular}{|l|l|c|c|}
\hline \multicolumn{1}{|c|}{ Task } & \multicolumn{1}{|c|}{$\begin{array}{c}\text { Deliverable or } \\
\text { Milestone }\end{array}$} & \multicolumn{1}{c|}{ To } & Media \\
\hline $\begin{array}{l}\text { Prepare Scope \& } \\
\text { Project Plan }\end{array}$ & $\begin{array}{l}\text { Scope of work/ project } \\
\text { plan }\end{array}$ & Advisor/Client & Hard copy \\
\hline Requirements analysis & $\begin{array}{l}\text { Data requirement } \\
\text { matrix }\end{array}$ & Advisor/Client & Digital \\
\hline Design database & Demo database & Advisor & Digital \\
\hline $\begin{array}{l}\text { Develop ModelBuilder } \\
\text { applications }\end{array}$ & Demo models & Advisor & Digital \\
\hline $\begin{array}{l}\text { CalGIS/ESRI } \\
\text { conferences }\end{array}$ & $\begin{array}{l}\text { Presentation/client } \\
\text { coordination }\end{array}$ & Attendees/client & PowerPoint \\
\hline $\begin{array}{l}\text { Prepare project } \\
\text { documents }\end{array}$ & $\begin{array}{l}\text { Draft project } \\
\text { documentation }\end{array}$ & Advisor & $\begin{array}{c}\text { Digital/hard } \\
\text { copy }\end{array}$ \\
\hline Project defense & Project defense & Grad Committee & $\begin{array}{c}\text { PowerPoint/ } \\
\text { project } \\
\text { documents }\end{array}$ \\
\hline Deliver project to client & Project documents & Client & $\begin{array}{c}\text { Digital/hard } \\
\text { copy }\end{array}$ \\
\hline
\end{tabular}

In addition, a project plan, schedule, and budget were prepared during the planning phase of the project. The tasks remained the same throughout the project. The schedule and budget were adjusted to reflect a better understanding of the project which impacted the time available to complete tasks. The final project schedule is provided in Appendix D. The following sections are the further discussion of each task listed in Figure 3-2.

\subsubsection{Requirements Analysis Task}

This task required coordination with FMMP to gather information about their business methods and products. Because the client is based in Sacramento, California, the majority of communication took place via e-mail and phone conferences. The client participated in the data requirements analysis and data survey, system analysis, facilitated introductions to key staff at other agencies, provided all data layers used in the models, and provided feedback on the modeling process.

In April 2009 an on-site visit to the FMMP offices took place in order to meet with management and staff. This provided an opportunity to better understand the client's work environment, staffing, and technological capabilities. The requirements analysis included coordination with federal and local agencies such as the United States Natural Resources Conservation Service (NRCS) and the City of Davis, California, GIS department. The purpose of the requirements analysis was to determine the client's GIS capabilities, prepare a survey of existing data, and identify existing hardware, software, and data storage capacities. 


\subsubsection{Manual LESA Modeling Task}

The LESA model needed to be understood in its manual form prior to designing workflows using ModelBuilder applications to automate it. To accomplish this, LESA scores were developed using the 1997 instruction manual for sample properties. The time to complete the manual process was tracked so it could be compared to the automated process at the end of the project. Performing this task helped identify specific datasets called out in the processes, as well as the steps to be automated in ModelBuilder, which guided the data needs.

\subsubsection{Data Needs Task}

Data requirements analysis was conducted early in the project. A survey of data identified in the manual process was conducted and sources identified. FMMP provided the most current datasets for soils, land use, water resources, and protected lands. The available statewide water resource data was identified as inadequate for developing the automated application exactly as described in the existing LESA manual. This resulted in an alternative approach discussed further in Chapter 5.

The instruction manual named specific datasets for use when preparing the model by hand, with the exception of water resources. With FMMP's assistance, a survey was conducted to identify the equivalent GIS datasets and source agencies. This survey was used to compile the Master Input Data List table provided in Chapter 4.

\subsubsection{Design and Load File Geodatabase Task}

The project database was designed based on the requirements analysis and datasets identified in the instruction manual. The file geodatabase was loaded with the statewide data for the Fresno County study area. The requirement analysis was prepared using GIS planning practices developed by Tomlinson (2003). A file geodatabase was chosen for development because it is the database standard for the Department of Conservation. With the exception of water resource data, all of the datasets named in the instruction manual are available in GIS format statewide. Database design and development were completed as expected. FMMP provided the GIS datasets identified in the requirements analysis. This GIS data database ready and did not require pre-processing prior to loading into the geodatabase. During the modeling process various fields were added, populated using field calculations, and deleted, but because they were intermediate data they were not added to the permanent data. Intermediate data is derived information that has a temporary purpose within ModelBuilder, such as a statistical summary of area used to calculate a proportion of the whole study area. The geodatabase schema allows for additional county datasets to be loaded. The approach for database scalability is discussed further in Chapter 4.

\subsubsection{Development of ModelBuilder Applications Task}

The LESA model process consists of six factors. There were also intermediate and summary steps that needed to be modeled in order to automate the entire process as described in the instruction manual. Intermediate steps included the use of Python 
scripting to create custom tools for use in ModelBuilder and calculating the total area of the property. Summary steps included compiling the results from modeling the six factors into a single table so the client could prepare the results for CEQA reviews.

This task involved learning ESRI ModelBuilder and applying that knowledge to the project. Functions available in ArcToolbox were matched to the extent possible with the steps identified in the manual. Steps that did not have corresponding tools in ArcToolbox required custom tools which were created using Python scripting.

The approach to the ModelBuilder applications was to first develop a single, complete model that would allow the GIS user to run the entire model in one event. The single application was then divided between the Land Evaluation section and the Site Assessment sections, allowing the GIS user to conduct independent investigations of the two primary sections of the model. Finally, both the Land Evaluation section and Site Assessment section were broken down into the six individual factors in LESA modeling.

The development and testing of the ModelBuilder applications required a number of options to be considered, including how to input the study area boundary, what programming language to use to supplement the functionality of ModelBuilder, and what approach to take to allow scaling the database schema. Developing and testing the applications was completed concurrently with the project documentation. Project analysis was conducted to interpret the final score based on CEQA scoring thresholds, to evaluate the consistency of the automated workflow with the manual workflow, and for efficiency.

\subsubsection{Project Presentations at CalGIS and ESRI Conferences Task}

A PowerPoint presentation was prepared and presented at the California GIS Conference (CalGIS) in Sacramento in April, 2009. This CalGIS presentation provided the opportunity to garner input and comments from GIS professionals while the project was still in development, as well as to meet with the client on location at their offices. Near the conclusion of this project it was presented again at the ESRI International User Conference in July, 2009. The ESRI presentation provided the opportunity to present the completed project to a professional GIS audience.

\subsubsection{Project Conclusion Task}

This project was concluded upon the delivery of a DVD to the client containing the final approved report, prototype file geodatabase, all ModelBuilder applications, metadata, and instruction manual. Project documentation included the project report, metadata for the geodatabase layers and applications, and instructions for using the GIS-enabled LESA model.

\subsection{Summary}

Project planning and execution benefit from a well-defined scope of work. A scope of work clearly defines the work products and deliverables of a project, as well as the roles and responsibilities of the parties involved. A project plan describes how this will be accomplished. The scope of work of a well thought out project will remain intact 
throughout the life of project. The project plan required more flexibility than the scope of work in order to accommodate or mitigate unforeseen events that affected the satisfactory completion of the project.

The requirements analysis and system design revealed two false assumptions in the project planning that were not conceived of during the risk assessment of the project plan. As a result, adjustments were necessary to the project plan to mitigate inadequate water resources data and to include Python programming to extend ModelBuilder functionality to meet the geoprocessing needs of the model. This project benefited from a well-defined scope of work. What was to be created and delivered to the client remained the same throughout the life of the project, but the project plan provided enough flexibility to accommodate changes in how this was accomplished. 


\section{Chapter 4 - Database Design}

Two common approaches to geographic databases are the GIS data library and the GIS project database. A data library is a repository for an organization's archival data, as well as data under development or maintenance. A project database, on the other hand, is prepared for a specific job and can house the data, applications, and map documents associated with that job. A file geodatabase was developed specifically for this project. The design considerations for the project database are discussed in the following chapter. Presented first in this chapter are the conceptual and logical data models, followed by a narrative of the data sources which includes a description of the data layers used in the model, as well as the methods used for data collection. This chapter concludes with data preprocessing and database loading.

\subsection{Conceptual Data Model}

The design of the conceptual data model was based on the data recommended in the 1997 instruction manual. It names hard copy datasets for four of the six factors to calculate and suggests datasets or sources for the remaining two factors. The conceptual data model for this LESA model is not typical of many data models because of the low occurrence of interdependencies between different datasets. In this case, there is a single user defined data input related to all other data layers, which is the study area. The user defined study area is used to determine the extent and proportions of the six individual factors that are evaluated and scored in the model. With the exception of the project size factor, which is an additional calculation derived from the soil data's LCC rating attribute, none of the data is related or dependent on the other. Each of the model's data inputs is needed to calculate an independent score for that factor, which is later weighted to determine the final overall score for the study area. The six factors evaluated in the LESA model and their associated data layers are:

1. Land Capability Classification (LCC): Study Area and Soils

2. Storie Index: Study Area and Soils

3. Project Size: Study Area and LCC rating derived from Soils

4. Water Availability: Study Area and Irrigation Districts

5. Surrounding Agricultural Lands: Study Area and Agricultural Lands

6. Surrounding Protected Lands: Study Area and Protected Lands

Figure 4.1 illustrates the relationship and dependencies between the data layers required for the LESA model. The study area is the hub and each of the remaining data layers radiate from the hub, interacting only with the study area layer, but not each other. 


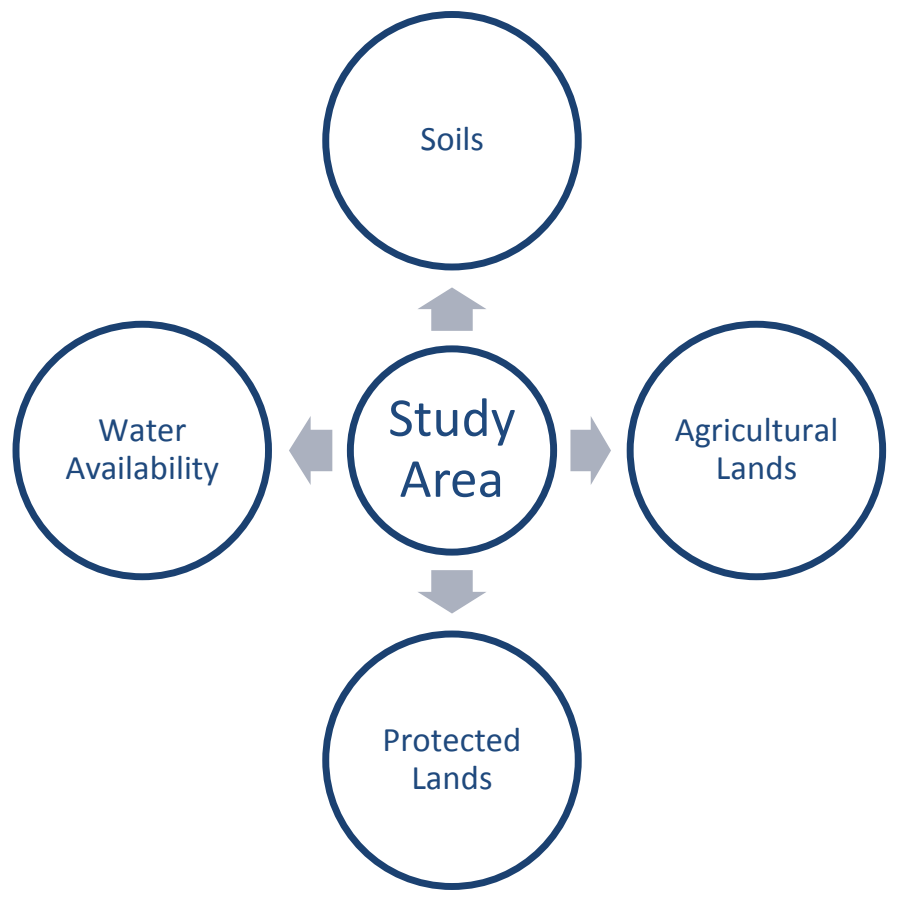

Figure 4-1: Conceptual data model relationships

\subsection{Logical Data Model}

The logical data model was derived from the conceptual data model to graphically represent the specific data inputs, their attributes, and relations. ArcGIS Diagrammer was used to prepare and diagram the database schema. ArcGIS Diagrammer is a geodatabase design tool available for download from the ESRI support webpage (ESRI Application Protoype Lab, 2009). The URL is provided in Appendix A. Figure 4-2 provides an illustration of the logical data model schema prepared using ArcGIS Diagrammer. The schema includes the data layers, the data type, and the attribute fields present in the layer. 

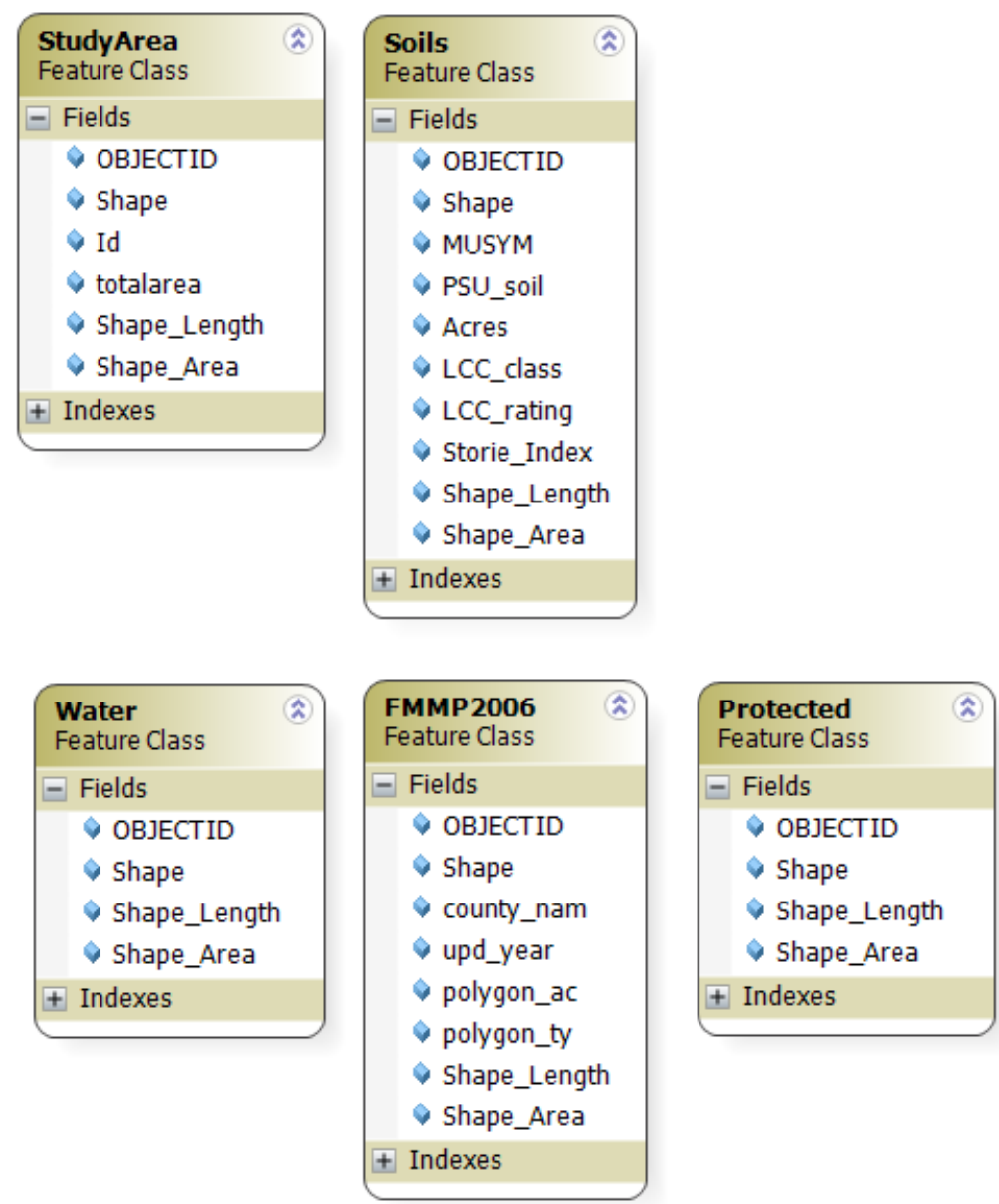

\section{Figure 4-2: ArcGIS Diagrammer geodatabase schema}

The project database was compiled into an ArcGIS 9.3 file geodatabase located in the project workspace. All the data containing required attributes were loaded into the ArcGIS Diagrammer schema. The final geodatabase schema is shown in Figure 4-3.

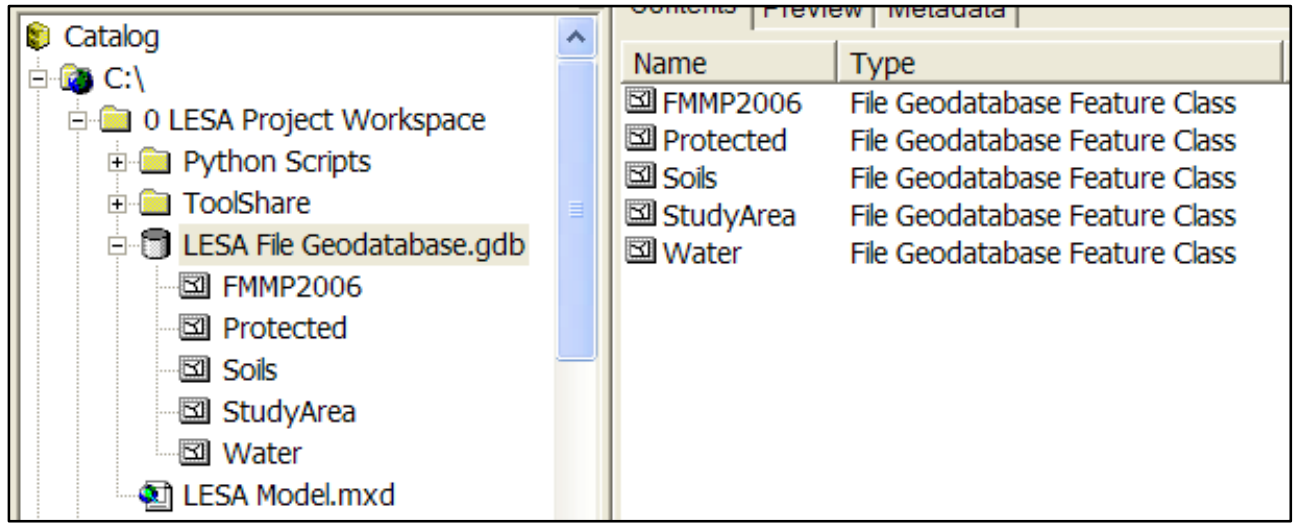

\section{Figure 4-3: Final geodatabase structure}

The project workspace included a Toolshare folder which contains the ModelBuilder toolbox and a folder for the associated Python scripts tools. The database schema is 
simple and scalable. Since all the data used in the mode share the same custom projection and datum, feature datasets were not included in the schema in order to reduce complexity. Scaling the database can be accomplished in the future by loading the remaining counties for each of the statewide datasets used in the model. This approach was chosen to provide the easiest and fastest data loading or data replacement possible to the client, and allows the data layer extents to be expanded to include additional counties without creating new layers or groups for the individual counties. In addition to the ArcGIS Diagrammer diagram illustrated in Figure 4-2, the tool was used to prepare a database schema and data report. Appendix E provides the ArcGIS Diagrammer database schema. Appendix F provides the ArcGIS Diagrammer data report.

All data layers loaded into the project database use the same custom projection: California Teale Albers, NAD 27, meters. This is the standard projection and datum used by the Department of Conservation and is commonly used by State agencies. The California Teale Albers projection is the custom projection developed by the California Teale Data Center. The Teale Data Center is the predecessor to the California Spatial Information Library (CaSIL). The URL for CaSIL is provided in Appendix A.

For the Land Evaluation portion of the model, all of the data required for calculating the Land Capability Classification (LCC) and Storie Index factor scores are identified and are currently available in a GIS format. The Site Assessment portion of the model suggests data sources for the Project Size factor and the Surrounding Agricultural Lands factor. The Project Size is derived from an additional calculation performed on LCC rating attributes and the Surrounding Agricultural Lands calls for FMMP land use type attributes.

\subsection{Data Sources}

In order to transfer the data model from the manual process to an automated workflow, it was necessary to acquire digital datasets equivalent to the hard copy datasets from the manual. The project scope limited the data sources to those that were available on a statewide basis. One purpose of this was to ensure that the database could be easily and efficiently scaled to include additional counties in the future. The other reason is that statewide datasets, available from state and federal sources, follow standards for attributes and metadata, which results in efficient data loading when scaling a dataset to include another region. When the attributes are the same, additional features may be added to expand the geographic extents without changing the database schema.

Another consideration for using statewide datasets was maintenance cycles. For example, FMMP map layers are updated and released every two years and Williamson Act maps are updated annually to document protected lands. Working with data that has regular maintenance cycles improves the planning process for updating the LESA model database, because major release dates for the data inputs can be scheduled on a regular basis, thereby improving the currency of the database.

Prior to designing and developing the project database, various data sources were identified and evaluated for use in this project. In some cases there was only one option while in others there was more than one choice. Each data source that was selected for use in the GIS-enabled LESA model is discussed in the following sections, as well as 
data sources that were considered and rejected for this project. Primary attributes are identified in the sections below and secondary attributes that are a result of the modeling process are discussing in Chapter 5.

The data inputs named in the manual LESA model are: project study area, soils, agricultural parcels, protected parcels, and water resources. Table 3 provides a summary of the data layers used in the project in the form of a Master Input Data List (MIDL). A MIDL should include all datasets required to prepare an information product. If a dataset is not used to prepare an information product it should not be included in the Master Input Data List (Tomlinson, 2003). In this case, the MIDL reflects the datasets selected for use in the GIS-enabled LESA model which are the most useful digital equivalents to the datasets named in the instruction manual. 
Table 3: Master Input Data List (MIDL)

\begin{tabular}{|c|c|c|c|}
\hline & Factor & Layer & Source \\
\hline \multirow{3}{*}{ Study Area } & Study area extent & Study Area & User input \\
\hline & Soil mapping unit types & SSURGO & NRCS \\
\hline & Soil mapping unit acres & SSURGO & NRCS \\
\hline \multirow{2}{*}{$\begin{array}{c}\text { Land } \\
\text { Evaluation }\end{array}$} & $\begin{array}{l}\text { Land Capability } \\
\text { Classification (LCC) }\end{array}$ & SSURGO & NRCS \\
\hline & Storie index & SSURGO & NRCS \\
\hline Project Size & Project size & SSURGO/ Study Area & $\begin{array}{l}\text { NRCS/ User } \\
\text { Input }\end{array}$ \\
\hline $\begin{array}{c}\text { Water } \\
\text { Resources }\end{array}$ & Water availability & $\begin{array}{l}\text { Federal and Private } \\
\text { Irrigation Districts }\end{array}$ & FMMP \\
\hline \multirow{2}{*}{$\begin{array}{l}\text { Zones of } \\
\text { Influence }\end{array}$} & $\begin{array}{l}\text { Surrounding agricultural } \\
\text { lands }\end{array}$ & FMMP 2006 & FMMP \\
\hline & Surrounded protected lands & Williamson Act Lands & FMMP \\
\hline $\begin{array}{l}\text { Compile } \\
\text { Results }\end{array}$ & Final weighted score & All Outputs & User input \\
\hline
\end{tabular}

\subsubsection{Study Area Layer}

The study area layer is the only data source that is user defined. It is a simple polygon feature with a single required attribute of total area. The study area is an input to all six factor scoring processes. The study area is edited by the user prior to running the ModelBuilder applications to delineate the extents of the property under investigation. The ModelBuilder application provides enough flexibility to allow the user to add a preexisting polygon layer of the study area to the model, if desired.

A third option that was investigated, modeled, and rejected was the use of ESRI feature sets to draw the study area boundary on-the-fly. Feature sets are a ModelBuilder parameter option that allow interactive drawing, but have unusual behavior. They are a virtual feature and do not persist after the application is run. An example of unusual behavior when using ModelBuilder feature sets is when a feature set is used as an input for a selection set, the resulting selection doesn't display until the user either refreshes the map view, or zooms to the extent of the map view.

\subsubsection{Natural Resources Conservation Service (NRCS) Soils Layer}

Sixty-five percent of the final overall score for a property is based on NRCS Soil Survey Geographic (SSURGO) Database attributes. This includes the LCC factor (25\%), the Storie factor (25\%) and the Project Size (15\%). Automating the LESA model would not be possible if the NRCS data were not available in a GIS format. No alternative dataset was identified during the project planning. NRCS soil data was not available statewide in California until the past few years. For example, soil data in northern California was not 
available from NRCS in GIS until 2005. This is a likely reason why the LESA model was not considered for GIS automation until recently.

NRCS soil data has a complex tabular structure and requires subject matter knowledge to fully utilize. Soil data is available for download at the NRCS Soil Data Mart website (Appendix A); however the data layer for Fresno County used in this project was preprocessed and provided by FMMP. NRCS soil data is made up of contiguous polygons which represent the soil unit types within a soil study area. A complete soil dataset would include dozens of attribute tables. However, the only attributes of interest in this model are the LCC and Storie Index attributes prepared by FMMP using the NRCS soils attribute tables. LCC and Storie are two different agricultural classifications which measure how viable a soil unit type is for agricultural purposes. The LCC scale is from I to VIII, and the Storie Index is scaled from 1-100.

\subsubsection{Water Availability Layer}

Specific datasets for the Water Availability and Surrounding Protected Lands are not named in the manual, but are suggested. The Water Availability factor in the instruction manual uses inputs that are subjective and might require an interview with the property owner to determine. Examples of inputs requiring firsthand knowledge of water availability include: the location of water infrastructure, specifically groundwater well locations within the study area; what cost for water delivery the owner considers economically feasible during drought conditions; and would or could the owner change crops to others that require less water during drought conditions as opposed to fallowing the land.

In this project federal and private irrigation district boundaries were used in the model as surrogates for water infrastructure data. The irrigation district layers are available for download from the California Spatial Information Library (CaSIL) and were provided by FMMP for use in this project. They are polygon features with attributes describing the water contracts with the Bureau of Reclamation and private contracts to deliver water to the districts.

The California Department of Water Resources (DWR) Land and Water Use datasets were evaluated and rejected for use in this project primarily because of inconsistencies in the datasets from region to region. The most problematic inconsistency was missing data from one region to the next. It was found that the database schema was consistent from region to region, but not all regions were completely attributed. Specifically, the Water Source attribute is not collected and populated for all areas. The Water Source attribute of DWR Land and Water Use datasets indicates if a property is serviced by groundwater, surface water, or both. Two other issues that emerged during the evaluation of DWR Land and Water Use data were how current the datasets were and access to the data. DWR standards in some regions provide for a countywide update every five to seven years, depending on how urbanized the county is. However, it was found that even some urbanized counties had not been updated in more than ten years, making the data obsolete. Additionally, DWR data has access constraints on any datasets which include groundwater well locations. This is because groundwater well information is confidential in California and protected by law. 


\subsubsection{Surrounding Agricultural Lands Layer}

The Surrounding Agricultural Lands layer is the 2006 FMMP Important Farmland Map layer for Fresno County. It is a continuous polygon layer used to calculate the amount of agricultural lands near and adjacent to the property under investigation. The primary attribute for the dataset is the Polygon Type, which identifies urban, rural, and agricultural land uses and has a minimum mapping unit of ten acres. Land use polygons smaller than ten acres are aggregated into the surrounding polygons. During the modeling process the layer was queried for any agricultural land uses, eliminating the need for pre-processing.

Other sources of agricultural land use data suggested in the 1997 instruction manual included the DWR Land and Water Use studies, locally derived maps, or field inspections. Use of the DWR Land and Water Use layer in ModelBuilder would have provided a better result for the automated workflow. This is because the DWR Land and Water Use data layer is a parcel based layer, while the FMMP is based on NRCS soil units. The methodology provided in the 1997 instruction manual requires a parcel based input; however, the DWR data was rejected because of inconsistencies described in section 4.3.3. Additionally, the inclusion of county assessor parcel data in the model was rejected by the client because of the burden of updating and maintaining the layer. Locally derived maps and field inspections were also rejected for use in this model due to the nonfunctional requirement of the database to be scalable, resulting in the use of only statewide datasets.

\subsubsection{Surrounding Protected Lands Layer}

The datasets for use in the Surrounding Protected Lands factor are not named specifically in the LESA manual because there are a variety of datasets that could be used, which vary from region to region. The Surrounding Protected Lands layer was provided by FMMP in this project. It is a non-continuous parcel based layer of the Williamson Act Lands database maintained by the Department of Conservation. The Williamson Act is a Californian agricultural conservation act that provides significant property tax discounts to rural property owners who enter into long term contracts with the state (California Department of Conservation, 2008b). This layer is used to calculate the amount of protected lands near and adjacent to the property under investigation.

Other data sources suggested for evaluating the influence of surrounding protected lands include: publicly owned lands, parks, open spaces, natural habitat easements, and any other land use designations that protect the property from development. Additional data layers could be merged with the Williamson Act Lands layer to refine the presence of protected lands. A single layer was used in the model because it is a prototype project to automate the workflow and acquiring the additional layers would not alter the performance of the applications.

\subsection{Data Collection Methods}

As provided for in the project plan and scope of work, all data layers for use in the project were procured by FMMP, with the exception of the user input study area layer. In 
addition to the datasets required for modeling, basemap layers such as local streets were provided by FMMP for reference and orientation. The basemap layers are not discussed in the following sections as they are not included in the modeling process.

Data used in the model that are developed and maintained by FMMP are the Important Farmlands Map layer and the Williamson Act Lands database used for the Surrounding Agricultural Lands factor and the Surrounding Protected Lands factor. The soil data layer and irrigation district data layers were acquired from NRCS and CaSIL for use in this project. The data transfers were accomplished using the FMMP website ftp download. With the exception of the Williamson Act database lands, all of the data layers are available for download via ftp on the internet from the source agencies. A list of URLs for downloading the data is provided in Appendix A.

\subsection{Data Preprocessing and Database Loading}

Data preprocessing was performed on the NRCS soil data layer by FMMP staff prior to providing it for use in this project. Preprocessing included table joins, adding new fields to the table, and calculating values for the new fields. The tabular data acquired from the National Soil Information System (NASIS) and joined to the Fresno soils layer included: the California Revised Storie Index rating; irrigated and non-irrigated yields by map soil unit, which includes the irrigated and non-irrigated LCC classifications; important farmlands; and the Storie Index rating. Table 4 summarizes the fields and associated attributes added to the soil data layer by FMMP staff for use in the automated LESA model. Please refer to Appendix $G$ for additional information on the field calculations performed by FMMP staff.

Table 4: Attributes added to the NRCS soil dataset

\begin{tabular}{|l|l|}
\hline Field added & Description \\
\hline Acres & Calculation: Shape_Area/4046.856422 \\
\hline LCC_class & Land Capability Classification (LCC) \\
\hline LCC_rating & Land Capability Classification (LCC) point rating :0-100 \\
\hline PSU_soil & Prime (P), Statewide Importance (S) or Unique (U) farmland \\
\hline Storie_Index & California Revised Storie Index rating \\
\hline
\end{tabular}

The Federal and Private Irrigation Districts layers were merged prior to database loading resulting in a single layer indicating the presence or absence of irrigated water infrastructure at a location. Changes to the attribute fields of the resulting layer were not necessary because the layer is used only for area overlays. The remaining data manipulations were automated as part of the modeling process. This includes adding and calculating fields, deleting fields, and attribute queries. Data attribute manipulations handled within the model do not persist after the modeling is finished. Data attribute manipulations are discussed further in Chapter 5. This approach was chosen to reduce preprocessing requirements and to reduce data redundancy. 


\subsection{Summary}

Due to the requirements and tasks involved in the project, the database was designed for simplicity and scalability. An ArcGIS file geodatabase was developed for storing, organizing and retrieving the statewide data layers which were used to ensure future expansion or maintenance of the database. Some datasets, such as the Water Availability layer and Protected Lands, are simple data representations for use in the model. It is expected that additional data layers will be merged with them to expand the extent and increase the accuracy of the model. Preprocessing was minimized by incorporating temporary manipulations into the applications so they do not persist after the model has been run. 


\section{Chapter 5 - Implementation}

Chapter 5 provides a detailed discussion of how the LESA model was reproduced in a GIS system. The first topic covered is the project workspace, and includes project portability, the project map document, and toolbox implementation. An understanding of the project workspace considerations is the foundation for the modeling process. The second topic covered is the modeling process. According to the LESA manual, there are six factors that play a role in the study area evaluation. Therefore, each of the six factor workflows was modeled and combined to form the complete GIS-enabled LESA model. Finally, this chapter concludes by summarizing the key components of implementing the LESA model in ArcGIS.

\subsection{Project Workspace}

The project workspace consists of all the data, applications, and documentation necessary to install and run the GIS-enabled LESA model at a new location. The LESA model project workspace is a folder which contains the file geodatabase, the project .mxd, the Toolshare folder for storing ModelBuilder tools, and the Python script files used to create custom tools used in ModelBuilder. Figure 5-1 illustrates the conceptual file structure of the project workspace for the LESA model project.

\begin{tabular}{|c|c|c|}
\hline \multicolumn{3}{|l|}{ Address $\square$ C:|OOLESA Model } \\
\hline Folders & $x$ & Name $\triangle$ \\
\hline 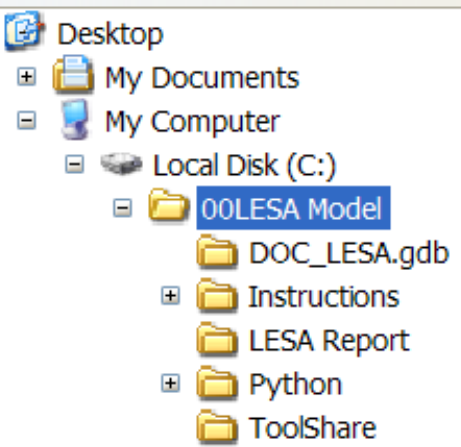 & $\hat{=}$ & $\begin{array}{l}\text { GOC_LESA.gdb } \\
\text { DInstructions } \\
\square \text { LESA Report } \\
\square \text { Python } \\
\text { ToolShare } \\
\text { CEQA report template.xltx } \\
\text { alESA Model.mxd }\end{array}$ \\
\hline
\end{tabular}

Figure 5-1: Conceptual project workspace

\subsubsection{Portability}

It is not sufficient to place all the data and tools in a single directory. The project workspace must also be able to be moved from one computer system to another, or ported, and retain its functionality. In order for a project to be ported seamlessly, it is necessary to understand the difference between absolute and relative file paths. Absolute file paths are fixed locations on a computer drive. It is the full (entire) path to a location on a drive. Relative paths, on the other hand, are partial paths indicating where the data is stored relative to the drive it has been placed on. By default, ESRI software uses absolute paths. In order to ensure a project maintains its links to data and tools, it is necessary to inform the system that relative paths are needed so that connections to data 
and tools can be re-established when a project is moved to another directory. Relative path settings applied for this project included:

- Data sources (layers) within the map document

- ModelBuilder model properties

- Python script tool properties

\subsubsection{Project MXD}

The LESA project .mxd is a map document within ArcGIS ArcMap. ArcMap provides a place to view, symbolize, label, and manipulate the feature classes used in the model. The map document is also where the user accesses and interacts with the applications in the LESA Tools toolbox. The project environment settings were configured at the ArcMap level. Environment settings can be configured at different levels within the software. The ability to set the environments at different levels allows the GIS user to control where the settings take effect. By setting the environments at the ArcMap level, the settings do not override the user's default settings, which are set in ArcCatalog. This means these environment settings apply only to a given project's map document and will not be changed in any other map documents.

Environment settings were limited to the general settings options which are exposed to the user by right clicking in the ArcToolbox panel within ArcMap. The general settings applied for this project include the workspace and scratch workspace location, and coordinate systems settings. The scratch workspace is the location where any data derived from geoprocessing is to be stored, and was set to the project file geodatabase. The coordinate system settings include the projection and datum defaults. The coordinate system setting was set to the custom projection, California Teale Albers, NAD 27, meters which is the standard for the California Department of Conservation. The map document uses a single data source, which is the project file geodatabase. Layer symbology was kept simple, as the primary output of this system is a table.

\subsubsection{Toolbox Implementation}

In order to automate the California LESA model in GIS, a set of applications was developed using ESRI ModelBuilder within ArcGIS ArcToolbox. A custom toolbox was prepared within the map document and saved to the Toolshare folder in the project workspace. Toolboxes are used to organize tools used for geoprocessing and two types are available: system toolboxes and custom toolboxes. System toolboxes are the standard sets of geoprocessing tools, organized by theme, that come with ArcGIS. The system tools available will vary depending on the license level of ArcGIS. The higher the level of software, the more system tools are available. Custom toolboxes are ones that are developed by the user to organize tools, scripts, and models that extend the functionality of the system tools.

Custom tools are also dependent on the license level of the software. For example, if a model is developed which incorporates a tool requiring an ArcInfo license and then shared with another user, the other user must have an ArcInfo license to run the model. Sometimes simple programming, such as Python or Visual Basic, is also necessary to 
extend the functionality of a tool or to roll up a series of geoprocesses into a single tool. The use of Python scripting to extend the functionality of the geoprocessing tools required to automate the LESA model workflow is discussed in the next section.

Similar to the way environments can be set at different levels, a custom toolbox can be added to ArcCatalog, ArcMap, or placed within a geodatabase. A toolbox added to ArcCatalog is at the top of the hierarchy and is available whenever the ArcCatalog or ArcMap modules are launched. Toolboxes added to ArcMap are available only after being added to the project and are not exposed in other map documents, unless they are added. Finally, toolboxes can be stored within a geodatabase. A toolbox stored within a geodatabase is similar to one at the ArcMap level, except that it is stored inside a geodatabase and is only available for use to those who have access to that geodatabase.

The custom toolbox for this project was stored at the ArcMap level and is located within the project's Toolshare folder. The project's custom toolbox was not stored at the ArcCatalog level for two reasons. The first reason is because the user would need to know how to add the toolbox to ArcCatalog, which does not facilitate use by non-GIS staff. The second reason is because each user would be required to add it to their ArcCatalog before using. By placing it in the project workspace Toolshare folder, and adding it to the project's map document, which serves as the model interface, any user who opens the map document has access to the models.

The custom toolbox could have been placed inside the geodatabase to allow portability but this choice was rejected because it would be accessible only from within the LESA geodatabase. By placing the toolbox in the Toolshare folder, at the ArcMap level, access is not limited to a single location within a geodatabase. This configuration makes it available to the user when the map document is opened, and available to share with those who have access to the project workspace. The Toolshare folder is also easier to distribute, such as via email, than inside in a geodatabase.

\subsubsection{Python Scripts}

Scripting languages that have been used to extend the functionality of ESRI software during the past decade have evolved from Avenue, which was used in ArcView 3.x to Visual Basic Application (VBA) macros in 8.x to Python scripting in 9.x. What all of these languages have in common is their ability to allow the user to customize tools to perform additional tasks that are not implemented in the software package. In this project, Python scripting was used to perform repetitive tasks, loop through a series of datasets, and evaluate attributes based on criteria.

Python scripts were included in the model using two methods. Custom script tools were created and added to the LESA Tools toolbox, or the scripts were embedded inside the Calculate Field system tool. A custom script tool can be used by itself, or graphically added to a model workflow, just like any other system tool. Scripts can also be embedding inside the Code Block section of a system tool that accepts expressions such as the Calculate Field tool (Figure 5-2). Embedding the scripts inside an existing tool extended the functionality of the tool and eliminated the need to create a new custom tool. This also simplified the model by reducing the number of tools needed to create the workflow. 


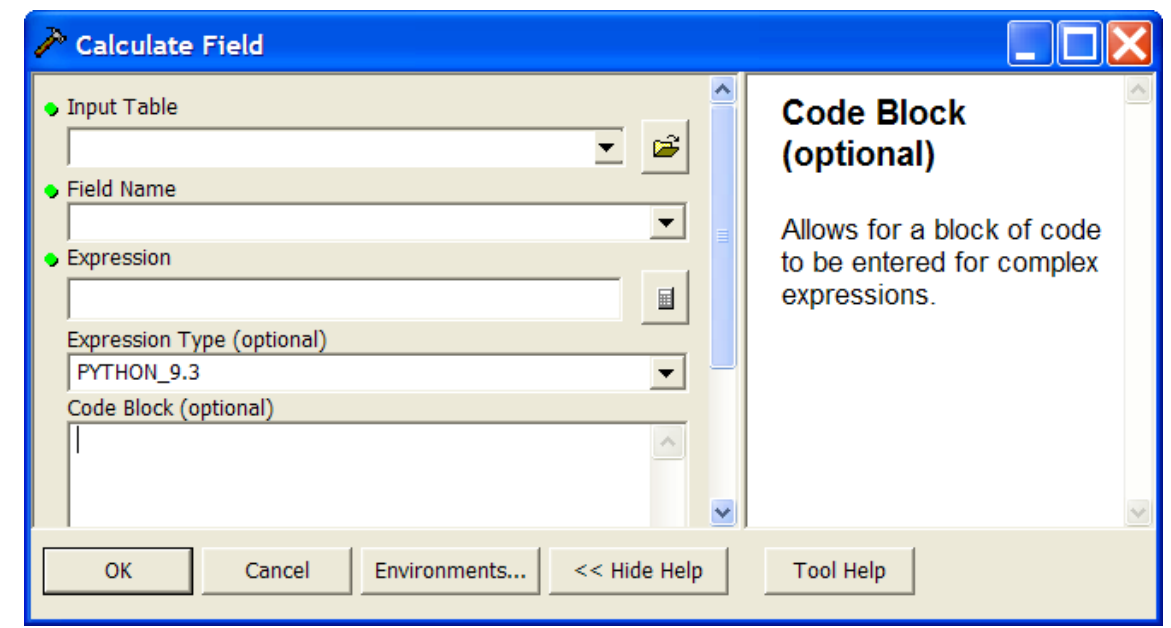

Figure 5-2: Calculate Field dialog box for embedding scripts

\subsection{Modeling}

The LESA model results in a single weighted score that summarizes the evaluation of six quantifiable factors. The model can be broken down into two primary sections: Land Evaluation and Site Assessment. Both of these sections can be further broken down into individual factors. The Land Evaluation section quantifies the soil properties and the Site Assessment section quantifies the situational properties of the study area. The Land Evaluation section has two factors: Land Capability Classification (LCC) and Storie Index. The Site Assessment section has four factors: Project Size, Water Availability, Surrounding Agricultural Lands, and Surrounding Protected Lands. Figure 5-2 illustrates the model hierarchy, starting with the model as a whole, and progressing down to the individual factors.

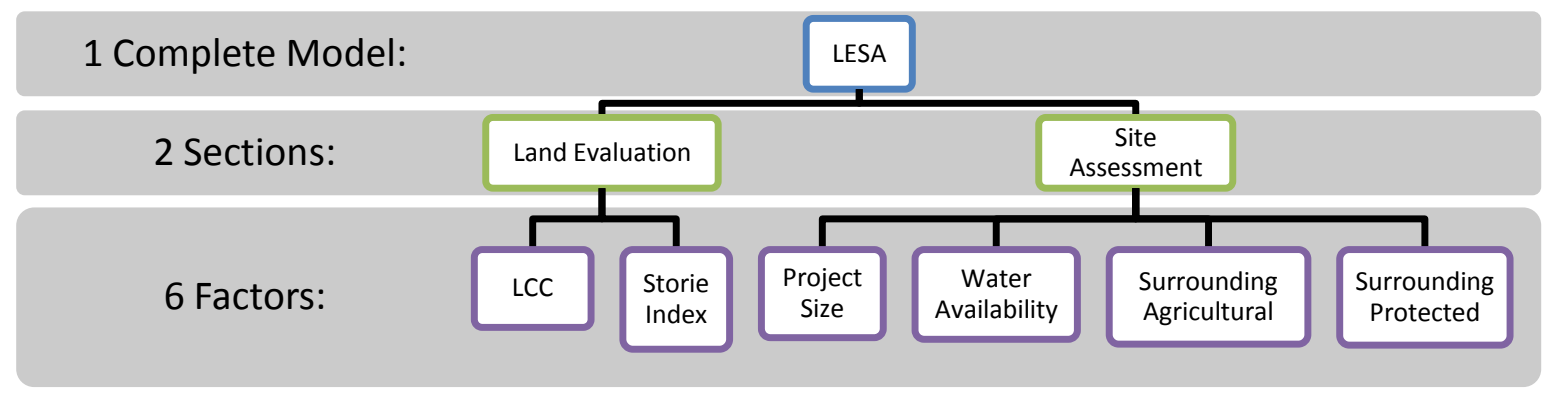

\section{Figure 5-3: LESA model structure hierarchy}

In order to provide flexibility to the user, a set of models using the structure illustrated in Figure 5-2 were developed for the project. The complete model includes all six factors and results in a single weighted score. Next are section level models for the Land Evaluation or Site Assessment. Finally, there is a model for each of the individual factors. Model diagrams for each of the factors are provided in the Appendix I. 
The individual factor models are described in the following subsections and combine to make up the more complex models. Provided is a description of the factor, its data inputs and weight value, followed by the modeling process and an explanation of how closely the GIS method replicates the manual process. System tools used during modeling often require a specific data type as an input, or result in a specific output. Therefore, it is necessary to convert data layers from one type to another in order to make the model work. Examples of these data requirements include: select by attribute and select by location, which require a feature layer input, or the summary statistics tool which outputs a table.

\subsubsection{Land Capability Classification (LCC) Factor}

The Land Capability Classification (LCC) is one of the agricultural classification systems used by the Natural Resources Conservation Service (NRCS) to assess soils for agricultural uses. LCC classes indicate the limitations of a soil unit for growing crops. Classes range from 1 to 8 (with letters e, s, and w used to indicated soil subclasses), with Class 1 having the least limitations for crop choice and Class 8 being the least viable for growing crops. LCC classes have an associated rating from 0-100 assigned to them in the 1997 instruction manual which was used to calculate the factor scores. Table 5 provides a summary of the LCC class conversion to a rating. The LCC has a weight of $25 \%$ in the overall score.

Table 5: LCC classification conversion to $\mathrm{LCC}$ rating

\begin{tabular}{|c|c|}
\hline LCC Classification & LCC Rating \\
\hline 1 & 100 \\
\hline $2 \mathrm{e}$ & 90 \\
\hline $2 \mathrm{~s}, 2 \mathrm{w}$ & 80 \\
\hline $3 \mathrm{e}$ & 70 \\
\hline $3 \mathrm{~s}, 3 \mathrm{w}$ & 60 \\
\hline $4 \mathrm{e}$ & 50 \\
\hline $4 \mathrm{~s}, 4 \mathrm{w}$ & 40 \\
\hline 5 & 30 \\
\hline 6 & 20 \\
\hline 7 & 10 \\
\hline 8 & 0 \\
\hline
\end{tabular}

The data inputs for the LCC portion of the model are the study area and NRCS soils. Feature class attributes that were modified during the preprocessing task were the addition of the LCC_rating field and the field calculation of the LCC_rating attributes, based on the conversion table provided in the 1997 instruction manual. Attribute fields that were added to the data layers in the model, using a custom tool derived from Python scripting are proportion, unit acres, LCC factor, and weighted LCC.

The LCC factor score workflow was modeled in GIS by the following procedures. The study area was first delineated by the user and the total area of the study area calculated. Soils are clipped to the study area. The proportion of each soil unit to the entire study area is calculated and the soil unit areas are converted to acres. The soil unit 
proportions are then multiplied by the LCC rating. The results are recorded in the LCC score fields and summarized. The sum of the LCC score field is the un-weighted LCC factor. The LCC factor is multiplied by 0.25 and the value is recorded as the weighted factor score. This model is consistent with the 1997 instruction manual.

\subsubsection{Storie Index Factor}

The Storie Index is another agricultural classification systems used by the NRCS to assess soils for agricultural use. The Storie Index is based on a variety of soil properties including: soil profile, slope, drainage, fertility, salt content, and erosion (California Department of Conservation, 2009). The Storie Index values range from 0-100, with 100 being the best value. The Storie Index has a weight of $25 \%$ in the overall score. The data inputs for the Storie Index portion of the model are: study area and NRCS soils. No feature class attributes were modified during the preprocessing task. Attribute fields that were added to the data layers during processing using a custom tool derived from Python scripting are proportion, unit acres, Storie Index factor, and weighted Storie Index.

The Storie Index factor score workflow was modeled by the following procedures. The study area was delineated by the user and the total area of the study area is calculated. Soils are clipped to the study area. The proportion of each soil unit to the entire study area is calculated and the soil unit areas are converted to acres. The soil unit proportions are then multiplied by the Storie Index. The results are recorded in the Storie Index score fields and summarized. The sum of the Storie Index score field is the Storie Index factor. The Storie Index factor is multiplied by 0.25 and the value is recorded as the weighted factor score. This model is consistent with the 1997 instruction manual.

\subsubsection{Project Size Factor}

Project Size is the first of four factors in the Site Assessment section of the California LESA model. Although it is included in the Site Assessment section, the modeling itself is an extension of the Land Evaluation section model, and uses the same data inputs of study area and NRCS soils. The Project Size factor accounts for $15 \%$ of the overall weighted score. No data attributes fields were added during preprocessing. Three additional fields added to the soil layer are: Bin, Project Size Factor and Weighted Project Size.

The GIS workflow for the Project Size factor begins at the end of the Land Evaluation section model. The three attribute fields listed above are first added to the soil layer. The soil units within the study area are then grouped into one of three bins according to their LCC rating values. This is the equivalent of sorting the soils in to high, medium, and low categories. Table 7 summarizes how the soil units are grouped into bins. The bins were named I, J, and K to be consistent with the corresponding columns in the worksheet for Project Size in the 1997 manual. 
Table 6: Summary of LCC rating associated with Bins I, J, and K

\begin{tabular}{|c|l|l|}
\hline Bin & LCC Rating & Equivalent to: \\
\hline I & 80,90 and 100 & High \\
\hline J & 60 and 70 & Medium \\
\hline K & $10,20,30,40$ and 50 & Low \\
\hline
\end{tabular}

A value of $\mathrm{I}, \mathrm{J}$ or $\mathrm{K}$ is added to the Bin field and then the sum of the acres for each category is calculated. The three resulting values of total acreage for each group of soils ratings are further scored based on a range of values provided in the 1997 instruction manual for each bin (Table 8). Finally, the three candidate scores are compared to each other and the single highest value is recorded as the Project Size factor score. The three bins are scored based on different ranges to ensure that small projects with high value soils receive a score appropriate to their value, with the intention of preserving high value soils that may get whittled away from the state's agricultural lands inventory in small pieces.

\section{Table 7: Scoring criteria for Bins I, J, and K}

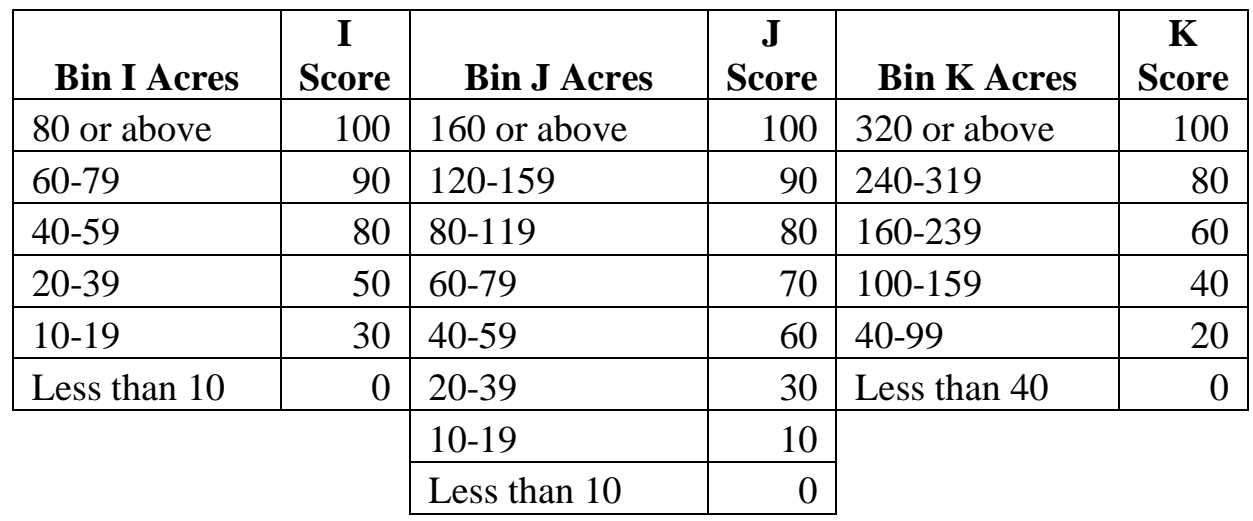

Python scripting was used as an expression within the Field Calculation system tool first to determine the candidate scores, and again to select the single highest score from the three candidate scores. This approach was chosen to reduce the number of custom tools used in the model; however, the same script used as an expression inside the Field Calculation could have been added as a separate custom script tool, and then added to the ModelBuilder interface with the same results. The Python script used as an expression in the Field Calculation tool for computing the project size is provided in Appendix H. This model is consistent with the 1997 instruction manual.

\subsubsection{Water Availability Factor}

The Water Availability factor measures what extent of the property has water delivery infrastructure available. The data inputs used in the model are the study area and water resources, which are derived from federal and private irrigation data layers. The use of irrigation district data as a surrogate for water infrastructure resources was suggested by the client when it was discovered that the California Department of Land and Water Use data, which are suggested for use in the model in the 1997 instruction manual, were not 
available consistently for the entire state. Additionally, the instruction manual requires information that would require first-hand knowledge of the property, and is not available in a statewide dataset. As a result, the GIS workflow doesn't provide the detailed evaluation called for in the original model. However, the presence or absence of water delivery infrastructure at a study area is a reasonable indicator of water availability. The Water Availability factor represents $15 \%$ of the weighted score, as indicated by the instruction manual.

This model measures the extent and proportion of irrigation districts within the study area and did not require the addition of any attribute fields for preprocessing. Fields added during modeling include proportion, water factor, and water weighted score. The process begins by clipping the water layer to the study area. The study area and water areas are compared to calculate the proportion of the water layer within the study area. The factor field is populated with the percent of overlap. The factor is weighted by $15 \%$, and then recorded as the weighed water score.

\subsubsection{Surrounding Agricultural Lands Factor}

The Surrounding Agricultural Lands factor measures how much of the property adjacent and near to the study area remain in agricultural uses or have already been developed. This factor has a $15 \%$ weight in the final score and is an indicator of land use fragmentation. Land use fragmentation occurs at the urban-rural interface where development is spreading into rural areas. A study area situated in a mixed-use region will score lower than a property that is more consistently devoted to agricultural land uses. The data inputs for this model are the study area and FMMP land use layer. No preprocessing was required to prepare the FMMP data for use in the model. Instead, the layer is queried to select the agricultural land uses during the modeling process.

This model deviates slightly from the 1997 instruction because the original model suggests the use of parcel data. The client requested parcel data not be included in the model because of the maintenance overhead associated with county assessor data. County assessor parcel data is available statewide, but must be acquired from each county individually or purchased through a database vendor such as CD-Data ParcelQuest.

Consistent with the 1997 instruction manual, the process begins by drawing a bounding box around the study area, then creating a 0.25 mile buffer around the bounding box. Bounding boxes are referred to as envelopes in ModelBuilder and are a rectangular polygon that represents the minimum and maximum $\mathrm{X}$ and $\mathrm{Y}$ coordinates of a shape. Figure 5-2 illustrates a bounding box draw for an irregular polygon.

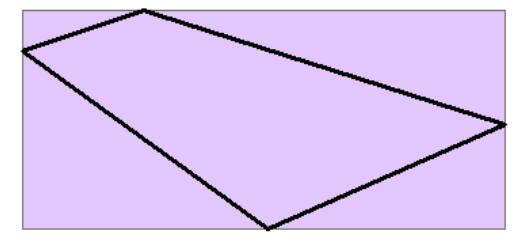

Figure 5-4: Bounding box for an irregular polygon

Next the bounding box is buffered by 0.25 miles, the bounding box and buffer are merged, and then study area is erased from the feature. Figure 5-3 provides an example 
of the resulting polygon used for selecting the nearby features for further processing. This feature is used to select the features adjacent and near to the study area. It is at this point the GIS model deviates from the 1997 instruction manual.

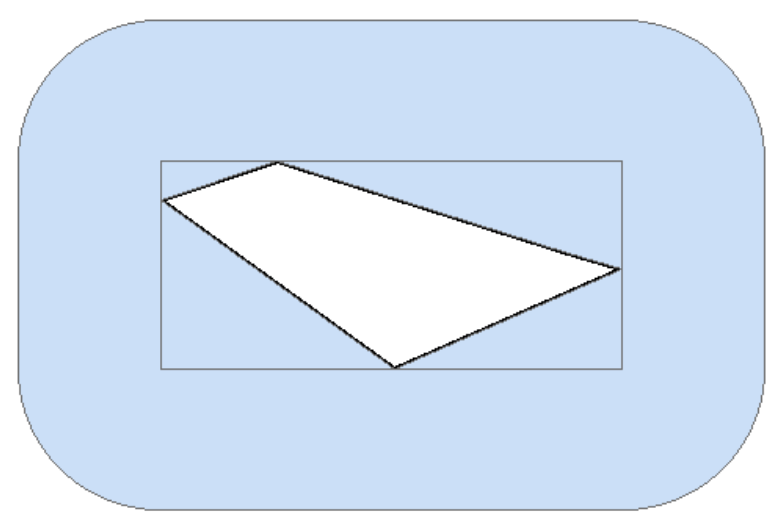

\section{Figure 5-5: Buffered bounding box with study area removed}

If parcel data were used in the GIS model, the selection set extents would be limited to the parcels either touching the study area or within a very short distance, even if there were intervening parcels. However, by using the FMMP data, which is made up of polygons of varying sizes, some quite large, it became necessary to reduce the selection set to a reasonable extent to be consistent with the intent of the original model. To accomplish this, the FMMP agricultural land use selection was clipped to the buffered bounding box. The amount of agricultural lands within was calculated and a score determined using the evaluation criteria from the instruction manual. The score for this factor is determined by calculating the proportion of agricultural lands in the zone of influence, and selecting the corresponding score from the table provided in the instruction manual. Table 9 is reproduced from the instruction manual and provides the criteria for determining the factor score. A study area must have at least forty percent of its surrounding lands in agricultural uses to receive a score for this factor. 
Table 8: Scoring criteria for the Surrounding Agricultural Lands factor

\begin{tabular}{|c|c|}
\hline $\begin{array}{c}\text { Percent of Project's } \\
\text { Zone of Influence } \\
\text { in Agricultural Use }\end{array}$ & $\begin{array}{c}\text { Surrounding } \\
\text { Agricultural Land } \\
\text { Score }\end{array}$ \\
\hline $90-100 \%$ & 100 Points \\
$80-89$ & 90 \\
$75-79$ & 80 \\
$70-74$ & 70 \\
$65-69$ & 60 \\
$60-64$ & 50 \\
$55-59$ & 40 \\
$50-54$ & 30 \\
$45-49$ & 20 \\
$40-44$ & 10 \\
$40<$ & 0 \\
\hline
\end{tabular}

\subsubsection{Surrounding Protected Lands Factor}

The Surrounding Protected Lands factor is the final assessment in the LESA model and has a weight of only 5\% in the final weighted score. Like the Surrounding Agricultural Lands factor, this factor is a measure of how much land adjacent to and near the study area is protected from development. The data inputs for this model are the study area and protected lands derived from the state Williamson Act contract database. This single layer input was used for the model because it is adequate to demonstrate the functionality of the model. However, following delivery to the client additional protected lands layers may be merged with the Williamson Act layer to better represent the extent of protected land. This model followed the same procedure and used the same approach as the Surrounding Agricultural Lands factor. Table 10 provides the criteria for determining the factor score. Forty percent or more of the surrounding lands must have a protected use to score in the model. Like the Surrounding Agricultural Lands factor, the model deviates from the instruction manual due the absence of parcel data within the model. 
Table 9: Scoring criteria for the Surrounding Protected Lands factor

\begin{tabular}{|c|c|}
\hline $\begin{array}{c}\text { Percent of Project's } \\
\text { Zone of Influence } \\
\text { Defined as Protected }\end{array}$ & $\begin{array}{c}\text { Surrounding } \\
\text { Protected Resource } \\
\text { Land Score }\end{array}$ \\
\hline $90-100 \%$ & 100 Points \\
$80-89$ & 90 \\
$75-79$ & 80 \\
$70-74$ & 70 \\
$65-69$ & 60 \\
$60-64$ & 50 \\
$55-59$ & 40 \\
$50-54$ & 30 \\
$45-49$ & 20 \\
$40-44$ & 10 \\
$40<$ & 0 \\
& \\
\hline
\end{tabular}

\subsection{Reporting the LESA Model Results}

As a result of the modeling process of each factor, there is a factor score and a weighted score available in tabular form. The final output of the LESA model is a tabular report which provides the score of each factor, the associated weight, a calculation of the factor multiplied by the weight, and a summation of all the weighted scores which is the final overall score for the study area. The relevant fields must first be compiled into a single table for CEQA reporting. The sample table provided in the 1997 instruction manual was used as the standard for presenting the results so that they would have a familiar appearance. An Excel table template was included in the project workspace for CEQA reporting.

\subsection{Model Documentation}

Custom tools developed in ModelBuilder supply tool help. Metadata was prepared for the data layers compiled in the file geodatabase.

\subsubsection{Tool Help}

ModelBuilder provides developer tools to help add documentation to the custom tools. This documentation is exposed when a tool's help button is clicked. Depending on the system settings, ModelBuilder help will be launched online as an HTML document, or from the desktop. For each of the custom tools, a paragraph was added using the tool's Edit Documentation dialog box, as shown in Figure 5-5.1 


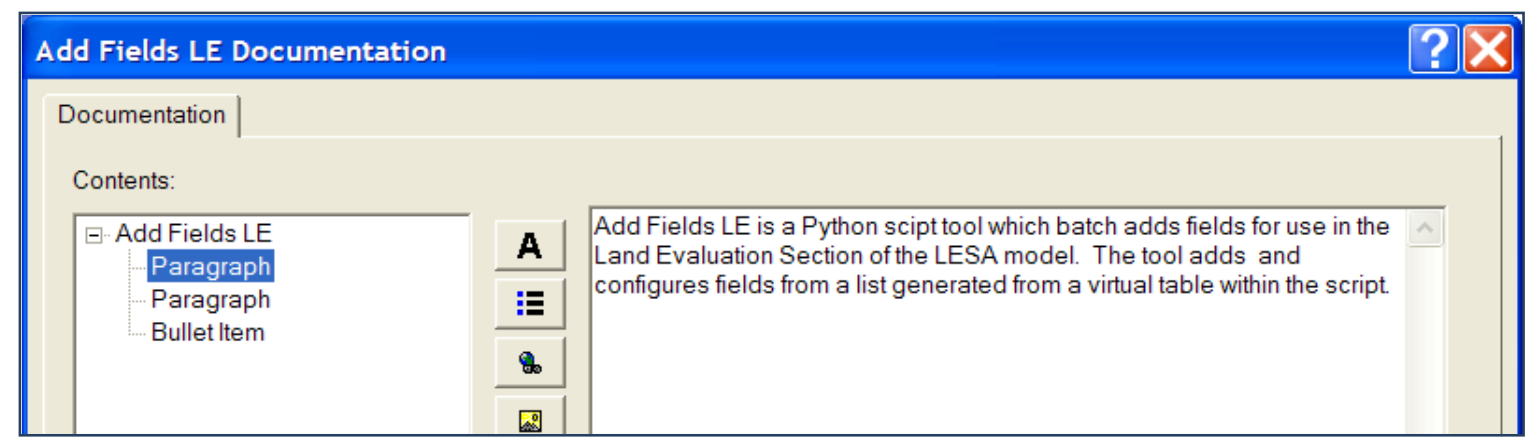

Figure 5-6: Custom tool Edit Documentation dialog box

An Edit Documentation dialog box is also available for the custom toolbox and models and is exposed by right clicking on the toolbox or the model. The help files for a system tool may be viewed, but not edited because they are read only files.

\subsubsection{Metadata}

Metadata for this project was developed using ArcCatalog's metadata editor tool. Metadata was developed or revised to reflect its use in the LESA model. The Department of Conservation metadata is developed using the FGDC ESRI template, and is the standard for this project. FMMP provided metadata documentation for the FMMP dataset, NRCS soils, and protected lands in the form of $\mathrm{xml}$ files. The remaining data layers required metadata to be developed. This included the study area, and the water availability layers.

\subsection{Summary}

This chapter describes how the project was developed and implemented using GIS. Project implementation began with the development of a project workspace that would facilitate porting the project to the client. The workspace contains the data, models and map document that make up the project. The map document provides the user a place to interact with the models and view the results. The LESA toolbox, including the models and script tools, are available within the map document or may be shared by copying the Toolshare folder from the project workspace. The models were developed to provide flexibility to the user. The user may run the model in its entirety, or select a subdivision of the model to evaluate a specific section or factor. Project documentation was developed for the custom tools in the model and for the layers. The following chapter will discuss the results of the modeling process and how the results are interpreted during the CEQA review process. 


\section{Chapter 6 - Results and Analysis}

The results and analysis of the GIS-enabled LESA model begins with a summary of the tools contained in the LESA toolbox, followed by an examination of how the model results are weighed, and interpreted in the CEQA review process. The CEQA interpretation is based on a standard set of scoring thresholds. A ModelBuilder model report was generated at the conclusion of the project that documents the data inputs, outputs and geoprocesses performed on them. The GIS-enabled model was compared to the original instruction manual to document changes to the model and why the deviations were necessary. The efficiency of the new model was analyzed as well. The chapter concludes with an analysis of how the GIS-enable workflow compares to the manual workflow.

\subsection{The LESA Tools Toolbox}

The LESA Tools toolbox and its associated models, tools and scripts are located in the project workspace Toolshare folder (Figure 6-1). As a reminder, there are six factors evaluated in LESA modeling which are grouped into two sections, Land Evaluation and Site Assessment. Therefore, nine individual models were developed for the LESA Tools toolbox. They are organized by the complete model, by section, and by individual factors. The complete LESA model consists of 69 geoprocessing tasks. In addition to the system geoprocessing tools, there are a total of nine Python scripts that were developed. This included six custom script tools and three Python scripts which were embedded in existing system tools. The custom script tools were used developed to add multiple fields to each factor, and to compute the project size score (Figure 6-1). Python scripts were embedded inside the Field Calculation tool for computing the surrounding land use factors.

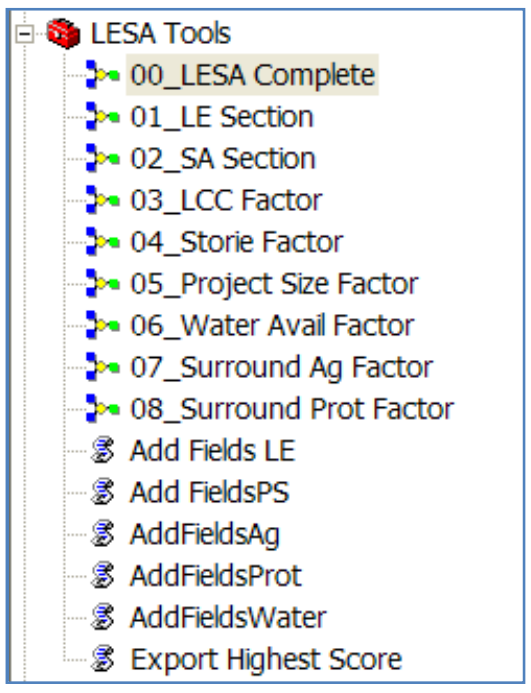

Figure 6-1: LESA Tools toolbox contents 
The GIS-enabled LESA models were analyzed for functional errors and functional efficiency. Functional errors are problems that cause the model to fail due to unplanned behavior. Functional efficiency is achieved when the model has no redundant steps. To identify functional errors, the model was run at a variety of locations within the study area, as well as from both the open model dialog box and the edit model window. It was learned the complete model would not run from the open model dialog box, but would run from the edit model window. It was also learned that the model would produce an error if the study area overlapped an empty space within a data layer. All of the layers used in the model have empty spaces. For example, the white space inside the Fresno County protected lands layer in Figure 6-2 shows there are empty spaces in the layer.

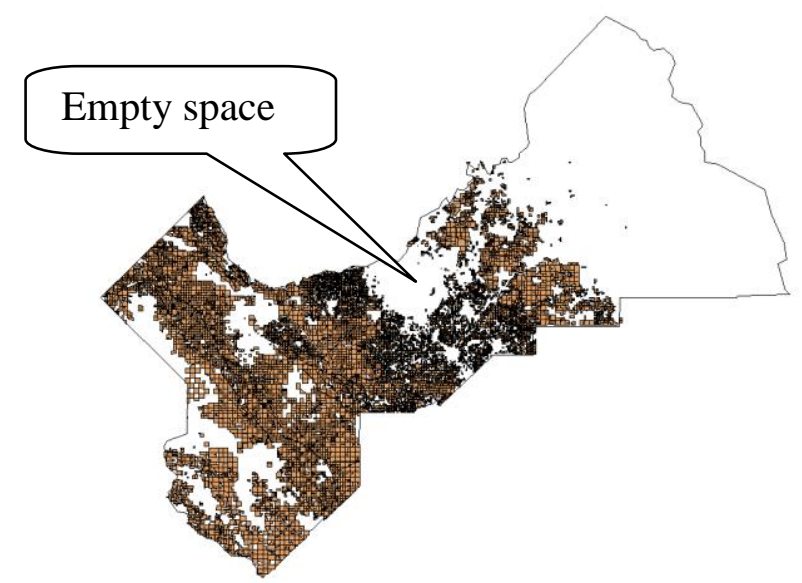

Figure 6-2: Example of empty space in a data layer

Both of these problems were traced back to a custom tool acquired from ESRI ArcScripts website that used Visual Basic (VB) code as an expression embedded in the Calculate Field tool to calculate the amount of overlap between two discreet layers. This geoprocessing task was necessary for calculating the amount of overlap between the study area and the site assessment data inputs including water, agricultural lands and protected lands. It was found the tool would run from the edit model window but not from the open model dialog box. This was problematic because a user is not normally expected to open a modeling edit session in order to run a model. The tool was removed from the model and an alternative method was implemented. The new method calculates the proportions based a single layer, which is a result of unioning the study area and the layer for the factor being evaluated. This approach also led to a solution to the problem of empty selection sets interrupting the model run.

Initially, to determine a proportion value, the study area and the layer of interest would be unioned. This union would then be converted to a feature layer so it could be used as an input to a Select by Attribute tool. It was found that the model would fail if the Select by Attribute tool returned an empty selection. To resolve this, the feature selection was moved into the Make Feature Layer tool as an expression. The reason this approach works is because a feature layer can exist even if it is empty, but a selection cannot be empty. This means that even if the Make Feature Layer tool returns an empty feature layer, the model will continue to run. 
The complete model and the sub models were evaluated for efficiency as well, and a number of tasks were found to be redundant and removed. As the complete model was compiled, tasks that were common to multiple processes were eliminated. For example, both Surrounding Agricultural Lands and Surrounding Protected Lands begin with a common bounding box and buffer that results in a study area Zone of Influence (ZOI) feature. Although the tools used to create this ZOI are required in each of the factor models, it is only needed once in the complete model because it can be reused. As a result the total number of tools that make up the individual factor models is greater than the number of tools in the complete model. The technique of including a selection inside the Make Feature Layer tool also helped to reduce the number of tools in the models.

\subsection{Weighing and Interpreting the Model Results}

A run of the complete LESA model workflow results in a single weighted score, ranging from 1-100. It is a measure of how viable a property is for agriculture, which is used during the initial study phase of the CEQA review process. The modeling process concludes by compiling the result tables of the six individual factors into a single table. The table includes the factor score and the weighted factor score which is used by the client to prepare the LESA model report for CEQA reviews. Table 11 presents the weighing criteria for each of the factors. Table 12 provides an example of how the results should be prepared for use in an environmental review so they may be evaluated for significance based CEQA scoring thresholds.

\section{Table 10: Factor weights}

\begin{tabular}{|l|l|}
\hline Section/Factor: & Weight: \\
\hline Land Evaluation Section: & \\
\hline Land Capability Classification (LCC) & $25 \%$ \\
\hline Storie Index & $25 \%$ \\
\hline Site Assessment Section: & \\
\hline Project Size & $15 \%$ \\
\hline Water Availability & $15 \%$ \\
\hline Surrounding Agricultural Lands & $15 \%$ \\
\hline Surrounding Protected Lands & $5 \%$ \\
\hline
\end{tabular}

Table 11: Sample LESA model results

\begin{tabular}{|c|c|c|c|c|}
\hline Factor: & Subscore: & Weight: & $\begin{array}{l}\text { Weighted } \\
\text { Score: }\end{array}$ & $\begin{array}{l}\text { Section } \\
\text { Subscore: }\end{array}$ \\
\hline LCC & 60 & 0.25 & 15 & \multirow[b]{2}{*}{25} \\
\hline Storie Index & 40 & 0.25 & 10 & \\
\hline Project Size & 100 & 0.15 & 15 & \multirow{4}{*}{32.25} \\
\hline Water Availability & 20 & 0.15 & 3 & \\
\hline Surrounding Ag & 85 & 0.15 & 12.75 & \\
\hline Surrounding Protected & 30 & 0.05 & 1.5 & \\
\hline \multicolumn{3}{|c|}{ Overall Score: } & 57.25 & \\
\hline
\end{tabular}


When used in the CEQA review process, the results are evaluated against a set of scoring thresholds. These threshold ranges also have minimum scoring criteria for the sections to provide balance so that an extremely high score in a single factor does not skew the results. A significant score must demonstrate strengths in both sections to be viable. Table 13 provides the California LESA model scoring thresholds used to interpret the results of LESA modeling. Using the sample results from Table 12, which has an overall score of 57.25 and weighted section scores of 25 and 32.25 for the Land Evaluation and Site Assessment sections respectively, the property would be considered significant for agriculture in the CEQA review process. The sample results also indicate the property would be a good candidate for a long term agricultural conservation contract.

Table 12: California LESA model scoring thresholds

\begin{tabular}{|l|l|}
\hline Total LESA Score: & Scoring Decision: \\
\hline 0-39 Points & Not considered significant \\
\hline 40-59 Points & $\begin{array}{l}\text { Considered significant only if Land Evaluation and Site } \\
\text { Assessment subscores are each greater than or equal to } \\
\text { 20 points }\end{array}$ \\
\hline 60-79 Points & $\begin{array}{l}\text { Considered significant unless either the Land Evaluation } \\
\text { or Site Assessment subscore is less than 20 points }\end{array}$ \\
\hline $80-100$ & Considered significant \\
\hline
\end{tabular}

\subsection{ModelBuilder Model Report}

ModelBuilder provides a model report which is accessed in the ModelBuilder window by right clicking the Model menu item and selecting Report. This exposes a dialog box which allows the user to view a model report in a desktop window, or to save a copy of the report to file for printing (Figure 6-3). A sample Model Report for the Project Size model is provided in Appendix $\mathbf{J}$.

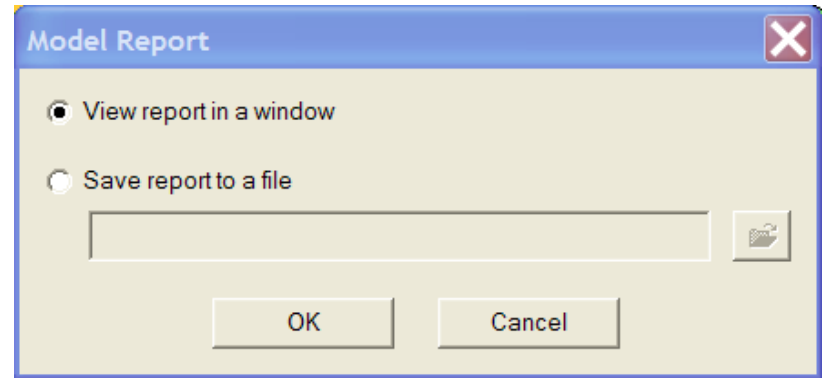

Figure 6-3: Model Report dialog box

The model report provides a summary of the model results which is divided into two sections: variables and processes (Figures 6-4 and 6-5). The variable section identifies each of the model inputs and outputs, such as the input or output layer name. A data type and value are listed for each variable allowing the user to determine what type of data was used in a process without opening the tool. For example, Figure 6-4, which represents the variable section of a Model Report, informs the user that the Project Size input is a feature layer. The process section provides a summary of each tool used in the model, including the tool name, the source of the tool, the tool parameters, and a list of 
messages. Included in the tool parameters are any expressions or code used in the tool. System messages, such as errors are available from the message section, as well as messages that are embedded in any script tools. This allows the user to view these items without opening the tool itself. Figure 6-5 represents the parameter section, which shows that the Add Fields Project Size tool source is inside the Toolshare folder, the results of the processes is a table view, and no error or script messages were generated when the model was run.

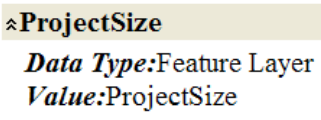

Figure 6-4: Model Report variable excerpt

\begin{tabular}{|c|c|c|c|c|}
\hline \multicolumn{5}{|c|}{ तAdd Fields Project Size } \\
\hline \multicolumn{5}{|c|}{$\begin{array}{l}\text { Tool Name:Add FieldsPS } \\
\text { Tool Source:C:LMyocs } 100 \mathrm{MIP} \backslash \text { ToolShareLESA Tools.tbx\AddFieldsPrjSz }\end{array}$} \\
\hline \multicolumn{5}{|c|}{ तParameters: } \\
\hline Name & Direction & Type & Data Type & Value \\
\hline Input Layer & Input & Required & Table View & 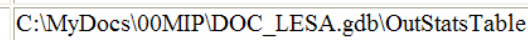 \\
\hline Output Layer & Output & Derived & Table View & C:LMyDocsl00MIP\DOC_LESA.gdb\OutStatsTable \\
\hline
\end{tabular}

\section{Figure 6-5: Model Report processes excerpt}

The report is a valuable tool for understanding the model's design and results. It provides a list of variable and process names in its collapsed form. Viewed in its expanded form, it provides details about every component of the model, and a convenient location for viewing the expressions and scripts used to manipulate data within the model, as well as viewing the names, types and paths for data and tools.

\subsection{Model Consistency}

The model was designed to recreate the workflows from the 1997 instruction manual as closely as possible using statewide datasets in ModelBuilder. The Land Evaluation section of the model, which includes the LCC Storie Index factors, did not deviate from the 1997 instruction manual. However, three of the four factors that make up the Site Assessment section of the model did require deviation from the manual. Specifically, the Project Size factor remained the same while the Water Availability factor required significant changes and the Surrounding Agricultural Lands and Surrounding Protected Lands required minor changes.

The Water Availability factor model provides a measure of how much of the property has water delivery infrastructure present, consistent with the original model. However, all physical and economic feasibility measures were excluded because the measures are subjective, and would require firsthand knowledge of the property which is not practical to collect at a statewide level. The Surrounding Agricultural Lands and Surrounding Protected Lands factor models have small deviations that are a result of excluding county assessor parcel data in the design. By doing so, the determination of the surrounding lands in the model differs slightly from the original way outlined in the manual. 
Originally, the surrounding lands were determined by the extent of the selected surrounding parcels that intersect with the bounding box buffer. However, since the parcel data is not used, a fixed distance buffer is used to clip the surrounding lands, and the proportions are calculated from this abbreviated extent. In both cases, adjacent land uses are captured. In ModelBuilder the influence of nearby properties is changed due to the reduced extent. Whether this change is positive or negative will vary from location to location, depending on the configuration of the surrounding parcels. Figure 6-6 is reproduced from the instruction manual and colored arrows have been added to indicate the differences in extent that are used in the two methods for determining surrounding lands. The green arrow shows the bounding box that was drawn around an irregular shaped parcel that is the study area. The blue arrow shows the extent of the quarter mile bounding box buffer. Finally the red arrow shows the extent of all the parcels selected using the buffer. In the original method, the selected parcels would be used in the proportion calculations. In the automated method the area inside the bounding box buffer is used.
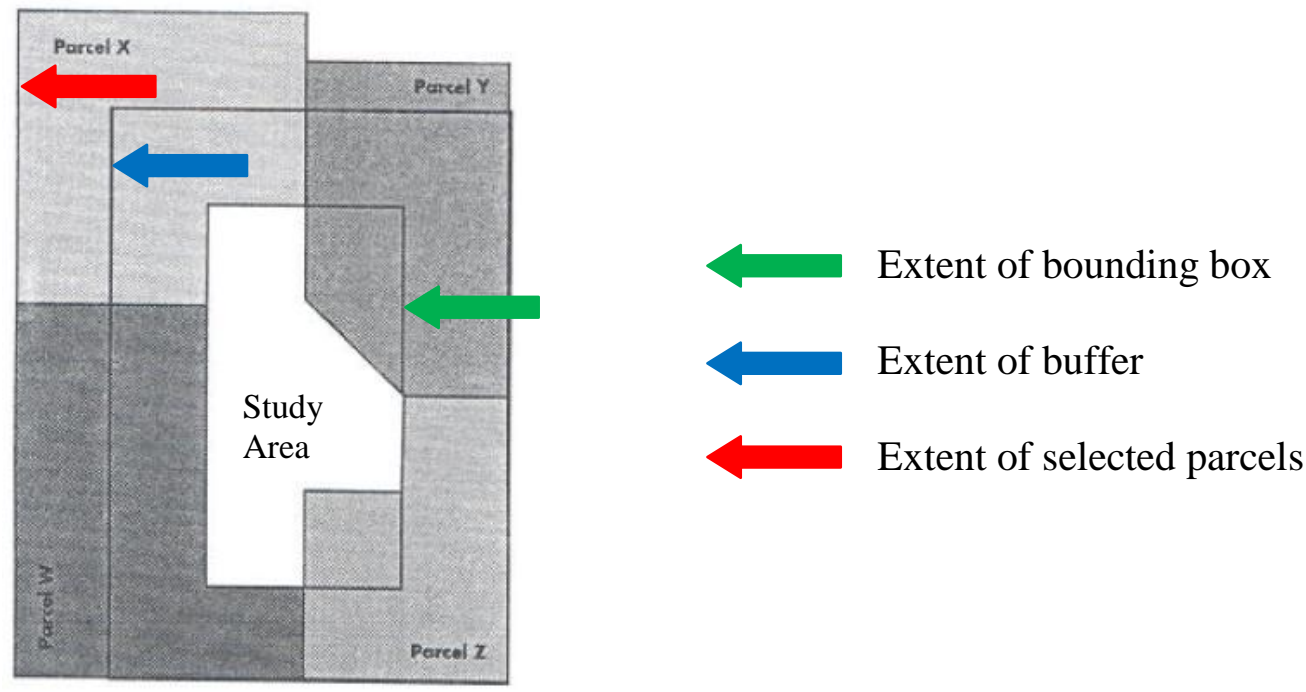

Figure 6-6: Comparison of extents used to model surrounding land factors

Table 14 summarizes the deviations from the 1997 instruction manual. Three of the six factors have no deviations from the manual. The factors with no deviation are LCC, Storie Index, and Project Size. Two of the six factors have minor changes that are deemed acceptable to the client and are the result of the decision to exclude assessor parcel data from the model due to the associated maintenance burden. The factors with minor changes are Surrounding Agricultural Lands and Surrounding Protected Lands. Only one factor significantly deviates from the original model. This factor was the Water Availability factor. Although the presence and extent of water delivery infrastructure is only one aspect of this factor in the original model, it was modeled satisfactorily. The acquisition of current and complete DWR Land and Water Use study datasets in the future would greatly reduce the amount of deviation, but would not eliminate the need for firsthand knowledge the original model calls for. 
Table 13: Summary of the amount of deviation from 1997 manual

\begin{tabular}{|l|l|l|}
\hline Section: & Factor: & $\begin{array}{l}\text { Amount of } \\
\text { Deviation: }\end{array}$ \\
\hline \multirow{3}{*}{ Land Evaluation } & LCC & None \\
\cline { 2 - 3 } & Storie Index & None \\
\hline \multirow{3}{*}{ Site Assessment } & Project Size & None \\
\cline { 2 - 3 } & Water Availability & Significant \\
\cline { 2 - 3 } & Surrounding Ag Lands & Minor \\
\cline { 2 - 3 } & $\begin{array}{l}\text { Surrounding Protected } \\
\text { Lands }\end{array}$ & Minor \\
\hline
\end{tabular}

\subsection{Model Efficiency}

Model efficiency is a measure of how much time it takes to conduct the modeling process. The manual workflow was conducted using the same data inputs and study area extents as the automated workflow in order to measure efficiency. The manual workflow and the automated workflow produced the same scoring results because they used the same inputs. The manual workflow incorporated GIS to measure areas, but the results were recorded and calculated by hand. GIS is suggested as one method for acquiring the acreage measurements in the instruction manual. The NRCS Web Soil Survey online GIS application was used to identify soils units, and the LCC and Storie Indexes for each soil unit, as well as the acreage. The NRCS web soil survey is a web GIS application that allows the user to delineate a study area on a map and returns the soil survey data for that area. The URL for the NRCS Web Soil Survey is provided in Appendix A. Likewise, GIS was used to measure the remaining factors, but the calculations and recording was performed manually. This approach was selected because it is expected a consultant or agency developing the LESA model manually would take advantage of GIS to the extent possible.

The manual method, which is partially automated using web GIS and desktop GIS to measure area, can be completed in 45-60 minutes for a single study area. The length of time to complete the model is affected by the number of soil units present at the study area. If the study area has little soil variation it will result in less calculations. If the study area has a great deal of soil variation, it will require more calculations. A description of the manual methods is provided in Appendix K. The complete GISenabled LESA model runs in less than two minutes. Recording the results in a summary table for CEQA reporting, requires a few additional minutes, for an average of five minutes to complete. Therefore the automated process is 9-12 times more efficient to use than a manual version with the same data inputs and methods. However, in order to fully measure the success of the automated model, it was necessary to test the results of the automated model against the results of the original model, which is discussed in the following section. 


\subsection{Summary}

This project resulted in the implementation of nine models with three levels of complexity. This included a complete model, a model for both sections, and a model for each of the six factors that make up the complete model. This hierarchy allows the user the flexibility to analyze the study area as a whole, or to examine aspects of the property individually. Study areas that have been modeled result in a single score that is evaluated using CEQA score thresholds to determine if the LESA score is significant.

Each of the models was evaluated for redundancy, reliability, and flexibility. Redundancy was reduced by leveraging sections of the model that could be reused in more than one process and by making use of feature layer selection sets. Reliability and flexibility were achieved by testing and troubleshooting the models performance, and by developing a set of models that allow the user to run all or part of the LESA model. The automated model was compared to the manual process and found to be more efficient to use. The conclusions and recommendations for future work resulting from the workflow development, implementation, and analysis are provided in Chapter 7. 


\section{Chapter 7 - Conclusions and Future Work}

This project was undertaken to automate the workflows that make up the California Agricultural LESA Model adopted by the California Department of Conservation in 1997. FMMP uses LESA modeling as part of state mandated CEQA reviews that involve agricultural properties. As a result of this project FMMP is able to more efficiently and effectively conduct environmental evaluations. A review of the project requirements and scope of work verify the successful conclusion of this project. Challenges encountered in the project and future work are discusses as well.

\subsection{Review of Requirements}

This project was designed to meet the need of the client to automate the LESA model so they would not be reliant on LESA model results submitted to them by outside sources. In order for the project to be useful to them, the project had to conform to a set of nonfunctional requirements. Nonfunctional requirements can be described as what the client wants to be achieved. Functional requirements can be described as how the nonfunctional requirements are accomplished. The following sections are a brief review of the project requirements and how well they were each met.

\subsubsection{Ease of Use}

It was important this automated workflow be easy to use so that non-GIS staff would be able to run the model and interpret the results. By developing a set of models in ModelBuilder the client has been provided a simple to use interface that allows the user to select and run a model with a minimum amount of GIS skill. This GIS application only requires the user to open the map document, draw a polygon to represent the study area, then select and run the desired model from the LESA Tools toolbox.

\subsubsection{Light Data Storage}

The file geodatabase was designed to house the minimal data layers required for the models. This is because the client produces or routinely updates all of the datasets used in the model. A lightweight database enhances the projects portability, and reduces complexity. This will be beneficial if the client wished to distribute the project to other agencies, thereby allowing future users to quickly evaluate the database contents. The use of intermediate data during the modeling processes reduces data preprocessing and results in the data layers being returned to their original state after the model has been run. The complete GIS-enabled LESA model project workspace with a single county database is less than $1 \mathrm{~GB}$ in size, and can be stored on a DVD or portable USB storage device.

\subsubsection{Scalability}

Scalability was one of the essential measures of this project because the project database must be expanded to include all agricultural counties within the state to be useful for 
CEQA reviews. The use of standardized datasets that are available statewide allows the data layers in the database to be easily expanded. Each of the data layers in the prototype database can be expanded to include additional counties without making changes to the schema structure. Simple data loading will accomplish the task. It is estimated that the database could be scaled to a statewide extent in a single day, provided the datasets were available for loading.

\subsubsection{User Documentation}

User documentation was prepared at a variety of levels for this project to aid the user and improve efficiency during future work. Metadata was prepared or updated for each of the layers in the file geodatabase. Model help files were added to the custom tools used in the models. A model report was generated to list the variables and processes in the complete model. A bibliography is provided at the end of the project report allowing users to investigate the project resources on their own. Finally, a user manual was developed to instruct how to use the models, and generate model reports.

\subsubsection{CEQA Compliant}

In order for the model results to be useful, it is necessary to compile the results from the model into a single table so the client can prepare a summary report of the factor scores, weighted scores, and scores for each section for use in CEQA reviews. When the complete model is run, the final output table contains the raw and weighted scores for each factor. These scores are evaluated against the CEQA scoring thresholds to determine if the study area is a significant agricultural property.

\subsection{Review of Scope}

This was a prototype GIS application designed to automate the LESA model using available statewide datasets as required by the original LESA model instruction manual adopted by the Department of Conservation. In doing so, CEQA environmental reviews could be conducted efficiently and effectively. The project scope was limited to a single county study area for developing ModelBuilder applications automating the LESA model. The timeframe for the project was November 2008 through August 2009. The project had a budget of 500 hours of labor. No changes were made to the scope of work. This project was successfully delivered on time and within budget.

Project deliverables to the client include:

- DVD containing the project workspace including: file geodatabase that includes study area data, complete set of ModelBuilder applications, and metadata

- ModelBuilder diagrams for the applications

- Instruction manual for the applications

\subsection{Challenges}

This project benefited from the client's expertise in GIS, access to up to date GIS datasets, and a well defined modeling process. Challenges were experienced in selecting 
the most appropriate datasets available statewide, and in retaining consistency with the original modeling process.

\subsubsection{Data}

There were no problems identifying GIS datasets that were equivalent to those suggested in the 1997 instruction manual and the client provided all the data selected for use in the project in a timely manner. The data gathering challenges were selecting alternative datasets and methods as a result of the shortcomings of one available dataset, and making a decision to exclude county assessor parcel data in the model. In the first case it was found that although DWR Land and Water Use data is available statewide in GIS format, the completeness of the attributes and currency of the data varied to the extreme, making it unsuitable at this time. In the case of the parcel data, it was not chosen due to the maintenance burden; correspondingly, the methods for calculating the surrounding land factors were altered slightly to accommodate the use of non-parcel based features in the model.

\subsubsection{Consistency with 1997 Instruction Manual}

Working with preexisting methods had both advantages and challenges. The 1997 manual provided clear instructions, data inputs, calculations, and forms to guide the modeler in an evaluation. However, the challenge was to identify geoprocesses in ModelBuilder that would produce the same result as the hand calculations and evaluations. This typically required a single manual step to be broken down into a series of geoprocesses in ModelBuilder. Particularly, performing evaluations required the most effort, though it is rather straightforward if done by hand. For example, evaluations are performed repeatedly during the Project Size factor scoring to compare three different candidate values to each other, based on scoring criteria. ModelBuilder tools do not have preexisting functionality for this type of computation, so it was necessary to use Python scripting to overcome the challenge.

\subsection{Future Work}

The project scope of work and functional requirements have been successfully met. However, during project design and implementation, a number of topics arose that would benefit from further investigation. Aside from tasks to install and scale the project to a statewide extent, the following topics are recommended for future work: converting the project to a web GIS application, developing batch processing capabilities, adopting to DWR Land and Water Use datasets, and investigating the use of LESA as an input to UPlan, or other regional planning tools.

\subsubsection{Web GIS}

Web GIS improvements that were identified during project planning and development included shifting the project to an ArcGIS Server platform for distribution and use. In addition to the increased accessibility this would provide, it might also allow the use of NRCS soils data on the fly, through a "mash up" because NRCS makes use of web GIS 
to disseminate soil data. If this could be implemented, it would reduce the amount of data the client would be required to store and maintain. It would also ensure the data was the most current, since it would be acquired directly from the source agency. This possibility was discussed with the client and received favorably, however their agency is only just beginning to incorporate ArcGIS Server technology into their work, and they need more time to become proficient and confident in the software.

\subsubsection{Batch Processing}

LESA modeling is not currently a high volume activity for FMMP. As such, batch processing for multiple properties was not included in the project scope. However, it is conceivable that as a result of automation, it will be used more frequently in the future. For example, FMMP has indicated it would like to use the model for exploratory purposes to identify good candidates for conservation, not just in reaction to development proposals. In that case, batch processing capabilities could be developed to allow multiple properties to be evaluated in a session, and to run the session during non peak times.

\subsubsection{Replace Agricultural and Water Layers with DWR Land and Water Use Study Layers}

The DWR Land and Water Use datasets should continue to be monitored for future studies. Should these datasets become more current statewide and more completely attributed, the model should be revised to incorporate this data for both the Surrounding Agricultural Lands factor and the Water Availability factor. This is recommended for three reasons. First, the data features are parcel based and would allow the original methods for calculating the proportion of surrounding agricultural lands to be modeled, increasing the overall consistency of the model. Second, the datasets include attributes about what type of crops are planted at each parcel, and if combined with future or past studies at the same location it may provide insight into the behavior of the property owner during drought conditions. This too would increase the consistency of the model. Third, fully attributed datasets include the different types of water resources available at each parcel, such as groundwater wells, surface water or both. In the current model, only surface water data is evaluated.

\subsubsection{Incorporate LESA Model Results in UPlan Model}

UPlan was discussed in the literature review. It is an ArcView software extension, developed to predict where development is likely to occur. It has been used in urban regional blueprint planning and is beginning to be used for rural blueprint planning. Blueprint planning is integrated land use and transportation planning. The value of the UPlan model is that it allows decision makers to prepare what-if scenarios. LESA model results could be used to identify high value and low value lands for use as parameters within the UPlan model. This would allow the UPlan modelers to analyze what how excluding high value agricultural lands from the inventory of land available for development would impact growth in other locations in the study area. 


\subsection{Summary}

The development of a GIS-enabled LESA model will help FMMP improve the efficiency and effectiveness when conducting state mandated CEQA reviews, or assessing applications for long term agricultural conservation. In the past, FMMP relied on LESA model results prepared by consultants or other agencies and did not have an efficient method of evaluating these submittals, or conducting investigations of their own. As a result of this effort, FMMP improved the tools available to them for evaluating rural land uses in California. This will greatly enhance their work capability and improve decisions made regarding agricultural land use. The functional and nonfunctional requirements of the project have been met and the milestones and deliverables of the project have been completed and delivered. Furthermore, this project was completed on time and within budget, to the satisfaction of the client. Based on this application, future studies can be conducted to facilitate results dissemination through web GIS technology, improve the overall model accuracy by integrating more data, or enhance the performance of the models by implementing batch processing. 



\section{Works Cited}

Arendt, R. (1994). Rural by Design. Chicago: Planners Press, American Planning Association.

Boyd, B. (2008). GIS Solutions: Implementation of the Land Evaluation and Site Assessment (LESA) Model. ESRI California, Hawaii, Nevada Regional Users Group Conference. ESRI.

Bradshaw, T. K., \& Muller, B. (1998). Impacts of Rapid Urban Growth on Farmland Conversion: Application of New Regional Land Use Policy Models and Geographical Information Systems. Rural Sociology Society, 63 (1), 1-25.

California Department of Conservation. (2008a). California Department of Conservation, Farmland Mapping and Monitoring Program. Retrieved October 1, 2008, from Farmland Mapping and Monitoring Program: http://www.consrv.ca.gov/dlrp/fmmp/Pages/Index.aspx

California Department of Conservation. (2008b). Williamson Act Fact Sheet. Division of Land Resource Protection. Sacramento: California Department of Conservation.

California Department of Conservation. (2009). Using Soil Surveys in DLRP. Sacramento: California Department of Conservation.

California Department of Food and Agriculture. (2006). Agricultural Statistical Review. California Department of Food and Agriculture, Sacramento.

County of Fresno, California. (2009). Retrieved May 22, 2009, from Fresno County General Information: http://www.co.fresno.ca.us/CountyPage.aspx?id=19947

ESRI. (2001). GIS Solutions for Agriculture. Redlands, California, United States.

ESRI. (2002). ESRI GIS Solutions for Agricultural Government. Redlands, California, United States.

ESRI. (2008). GIS for Agriculture. Retrieved October 1, 2008, from ESRI Industry Solutions: http://www.esri.com/industries/agriculture/index.html

Inland Orange Conservancy home page. (2009). Retrieved May 12, 2009, from Inland Orange Conservancy: http://www.inlandorange.org/

Landis, J., \& Zhang, M. (1998). The Second Generation of the California Urban Futures Model. Environment and Planning , 30, 657-666.

Lindhult, M. S., Fabos, J., Brown, P., \& Price, N. (1988). Using Geographic Information Systems to Assess Conflicts Between Agriculture and Development. Landscape and Urban Planning , 16 (4), 333-343.

Natural Resources Conservation Service. (2009). Natural Resources Conservation Service Computer-Aided Land Evaluation System. Retrieved June 4, 2009, from Natural Resources Conservation Service: http://nasis.usda.gov/cales/

Organization for Economic Co-Operation and Development. (2001). Environmental Indicators for Agriculture: Methods and Results. 3, 389-391.

Pease, J. R., \& Coughlin, R. E. (1994). Land Evaluatin and Site Assessment: a Guidebook for Rating Agricultural Lands, Second Edition. United States Department of Agriculture, Natural Resources Cosnervation Service. Ankeny: Soil and Water Conservation Society.

Pennsylvania State University. (2008). LESA Farmland Evaluation and Site Assessment. Retrieved October 13, 2008, from Pennsylvania State University Geospatial Technology Program: http://lal.cas.psu.edu/Research/localGovt/lesa.asp 
Pierce, F. J., \& Clay, D. (2007). GIS Applications in Agriculture. Boca Raton, Florida: Taylor and Francis Group, LLC.

Rash, W. (2008). October 16. NRCS Soil Conservationist. (D. Watkins, Interviewer)

Roth, N. (2007). UPlan Training for Rural Blueprint Planning, University of California Davis. Davis, California.

Tomlinson, R. (2003). Thinking About GIS: Geographic Information Systems Planning for Managers. Redlands, CA: ESRI Press.

United States Census Bureau. (2009). State and County Quickfacts. Retrieved August 13, 2009, from United States Census Bureau:

http://quickfacts.census.gov/qfd/states/06000.html 


\section{Appendix A - List of URLs}

\section{California Agricultural LESA model instruction manual:}

http://www.conservation.ca.gov/dlrp/Pages/qh_lesa.aspx

\section{Data Acquisition Sites:}

1. Farmland Mapping and Monitoring Program (FMMP) ftp site:

http://www.consrv.ca.gov/dlrp/fmmp/products/Pages/DownloadGISdata.aspx

2. California Spatial Information Library (CaSIL)

http://www.atlas.ca.gov/

3. Natural Resources Conservation Service (NRCS) Soil Surveys

http://websoilsurvey.nrcs.usda.gov/app/HomePage.htm

\section{ESRI ArcScripts:}

1. ArcGIS Diagrammer

http://arcscripts.esri.com/details.asp?dbid=15166

2. Ruth Bowers Add Fields Script

http://arcscripts.esri.com/details.asp?dbid=14154 


\section{Appendix B - ESRI System Specifications}

\section{ESRI software operating system requirements}

\begin{tabular}{|c|c|c|c|}
\hline Supported Operating System & $\underset{\text { Version }}{\text { Minimum }}$ & $\begin{array}{l}\text { Maximum } \\
\text { Version }\end{array}$ & Limitations \\
\hline Windows 2000 Professional & SP3 & SP4 & \\
\hline $\begin{array}{c}\text { Windows } 2003 \text { (32-bit) Server Standard, Enterprise } \\
\text { \& Datacenter }\end{array}$ & SP1 & SP2 & \\
\hline $\begin{array}{c}\text { Windows } 2003 \text { (64-bit (EM64T)) Server Standard, } \\
\text { Enterprise \& Datacenter }\end{array}$ & SP1 & SP2 & 64-bit processors support 旬 \\
\hline Windows 2003 Server Terminal Services & SP1 & SP2 & $\frac{\text { Support for Windows Terminal Server (WTS) and }}{\text { Citrix MetaFrame }}$ \\
\hline \multicolumn{4}{|l|}{$\begin{array}{c}\text { Windows } 2008 \text { (32-bit) Server Standard, Enterprise } \\
\text { \& Datacenter }\end{array}$} \\
\hline $\begin{array}{c}\text { Windows } 2008 \text { (64-bit (EM64T)) Server Standard, } \\
\text { Enterprise \& Datacenter }\end{array}$ & & & 64-bit processors support 旬 \\
\hline $\begin{array}{c}\text { Windows Vista (32-bit) Ultimate, Enterprise, } \\
\text { Business, Home Premium }\end{array}$ & SP1 & SP1 & \\
\hline $\begin{array}{l}\text { Windows Vista (64-bit (EM64T)) Ultimate, } \\
\text { Enterprise, Business, Home Premium }\end{array}$ & SP1 & SP1 & 64-bit processors support 旬 \\
\hline $\begin{array}{l}\text { Windows XP (32-bit) Professional Edition, Home } \\
\text { Edition }\end{array}$ & SP1 & SP3 & Windows XP SP2 \& SP3 Limitations 司 \\
\hline $\begin{array}{c}\text { Windows XP (64-bit (EM64T)) Professional Edition, } \\
\text { Home Edition }\end{array}$ & SP1 & SP3 & $\frac{\text { Windows XP SP2 \& SP3 Limitations }}{\text { 64-bit processors support 易 }}$ \\
\hline
\end{tabular}




\section{ESRI Hardware Requirements}

\begin{tabular}{|c|c|}
\hline & ArcInfo, ArcView, ArcEditor \\
\hline CPU Speed & $1.6 \mathrm{GHz}$ recommended or higher \\
\hline Processor & $\begin{array}{l}\text { Intel Core Duo, Pentium } 4 \text { or Xeon Processors } \\
\text { See Dual or dual-core support policy }\end{array}$ \\
\hline Memory/RAM & $\begin{array}{l}1 \mathrm{~GB} \text { minimum, } 2 \mathrm{~GB} \text { recommended or higher } \\
\text { If using the ArcSDE Personal Edition for Microsoft SQL Server Express software, } 2 \mathrm{~GB} \text { of RAM is required. }\end{array}$ \\
\hline Display Properties & 24 bit color depth \\
\hline Screen Resolution & $1024 \times 768$ recommended or higher at Normal size (96dpi) \\
\hline Swap Space & Determined by the operating system, 500 MB minimum. \\
\hline Disk Space & $\begin{array}{l}2.4 \mathrm{~GB} \\
\text { In addition, up to } 50 \mathrm{MB} \text { of disk space maybe needed in the Windows System directory (typically } \\
\text { C: }(\text { Windows } \backslash \text { System } 32) \text {. You can view the disk space requirement for each of the } 9.3 \text { components in the } \\
\text { Setup program. }\end{array}$ \\
\hline $\begin{array}{l}\text { Video/Graphics } \\
\text { Adapter }\end{array}$ & $\begin{array}{l}\text { 24-bit capable graphics accelerator } \\
\text { An OpenGL } 1.3 \text { or higher compliant video card is required, with at least } 32 \mathrm{MB} \text { of video memory, however } \\
64 \mathrm{MB} \text { of video memory or higher is recommended. }\end{array}$ \\
\hline $\begin{array}{l}\text { Networking } \\
\text { Hardware }\end{array}$ & Simple TCP/IP, Network Card or Microsoft Loopback Adapter is required for the License Manager. \\
\hline Media Player & DVD-ROM drive is required to install the application. \\
\hline
\end{tabular}

\section{Software Requirements including Python Scripting ?}

- .NET Framework 2.0 Requirement

- Internet Explorer Requirement:

O Some features of ArcGIS Desktop require a minimum installation of Microsoft Internet Explorer Version 6.0 or 7.0. If you do not have an installation of Microsoft Internet Explorer Version 6.0/7.0, you must obtain and install it prior to installing ArcGIS Desktop.

O IE 7 Limitations: You cannot see inset maps in the directions window until you right-click on the box with the red $\mathrm{X}$ to bring up the context menu and then click on "Show Picture."

- Python Requirement for Geoprocessing:

Several ArcGIS geoprocessing tools, such as Multiple Ring Buffer, use the Python scripting language and require that Python is installed. If the ArcGIS Desktop, Engine or Server setups do not find Python 2.5.1 on the target computer, it will install Python 2.5.1 plus Numerical Python 1.0.3 during a typical or complete installation. You may choose a Custom installation to unselect the Python feature to avoid installing this feature. See the install guide for additional information concerning Python. 


\section{Appendix C - Information Product Description}

Name:

Required by Dept:

Required by Person:

Last Revised:
CA Agricultural Land Evaluation and Site Assessment (LESA) Model

Score

Farmland Mapping and Monitoring (FMMP) Program

Molly Penberth, FMMP Manager

1997

Frequency: Bi-Monthly

Synopsis: A process to automate the evaluation and scoring of the agriculture viability of lands proposing development or long term conservation, as mandated by the California Environmental Quality Act (CEQA) environmental review process

Map Requirements: (optional) 8.5x11 map of project study area to supplement model report. List Requirements: Report providing the scores for each section of the model, as well as the overall score for the study area.

Document Requirements: CEQA environmental review packet

Image Requirements: N/A

Schematic Requirements: N/A

Steps required to make the product using GIS:

Step: Delineate study area and soil mapping units

Description: $\quad$ Create a polygon of the study area to identify the extents, what soil mapping units (soil types) are present at that location, and the acreage of each unit.

Data needed: $\quad$ Study area extents, SSURGO soils

Function Needed: $\quad$ Edit feature, clip, field calculator

Step: $\quad$ Land Capability Classification (LCC) score

Description: $\quad$ The LCC is an indication of how productive a location would be for agricultural purposes, based on the soils present. Values range from I to VIII.

Data needed: $\quad$ Soil mapping units, LCC look up table, area/proportions

Function Needed: Database relation, field calculator

Step: $\quad$ Storie Index score

Description: The Storie Index is a general assessment of a location by a soil scientist that considers a variety of factors. Values range from 1-100. If the index is not available for a location, the LCC weight is increased in the final calculations.

Data needed: $\quad$ Study area extents, SSURGO soils, area/proportions

Function Needed: Field calculator

Note: This completes the land evaluation part of the model. The following steps are site assessment processes.

Step:

Description:

Data needed:

Function Needed:

Step:

\section{Project Size}

An evaluation of the project size, determined by multiplying each soil units LLC by its acres to identify the single highest scoring proportion of the study area.

Acreage, LCC

Field calculator, summary table

Water Availability 
Description: $\quad$ An assessment of what types of water resources are available at a location and how reliable they are during drought conditions. The model requires and evaluation of both physical and economic feasibility.

Data needed: $\quad$ Study area, water sources, irrigation district boundaries, groundwater performance (hydrographs), crop history

Function Needed: Custom-possibly a form/interface to check and evaluate each of the variables in the manual.

Step:

Surround Agricultural Lands

Description:

Quantification of what percentage of surrounding land is in agricultural uses

Data needed: $\quad$ Study area, bounding box, FMMP

Function Needed: Create envelope polygon, buffer, summary table, field calculator

Step: $\quad$ Surrounding Protected Lands

Description: Quantification of what percentage of surrounding land is protected, or in conservation

Data needed: $\quad$ Study area, bounding box, FMMP, Williamson Act lands, conservation easements, BLM

Function Needed: Create envelope polygon, buffer, summary table, field calculator

Note: This completes the site assessment part of the model. The following steps are to complete the model.
Step:
Compile Results
Description:
The scores for each factor is compiled and weighed to determine the overall score for the study area.
Data needed: $\quad$ Scores from each of the 6 factors, weight criteria
Function Needed: Compile, weight, summary table

Function utilization table:

Function:

Number:

Edit

Clip

Field calculator

1

Database relation

1

Summary table

6

Custom interface/form 1

Bounding box 2

Buffer 2

Compile 2

Weight 1

$\begin{array}{ll}\text { Estimate } 2 \text { CEQA reviews per month } & 24\end{array}$

Function frequency table:

Function:

Frequency:

Edit

Clip 
$\begin{array}{ll}\text { Field calculator } & 144\end{array}$

Database relation $\quad 24$

$\begin{array}{ll}\text { Summary table } & 96\end{array}$

$\begin{array}{lr}\text { Custom interface/form } & 24\end{array}$

Bounding box $\quad 48$

$\begin{array}{lr}\text { Buffer } & 48\end{array}$

Compile $\quad 48$

Weight 24

TOTAL PER YEAR: $\quad 504$

Logical Linkages:

List to Graphic: $\quad$ Soil units to study area

Map to Map Study area to: soils, water sources/water availability, surrounding ag land, surrounding protected land,

Attribute to Attribute: Soil units to: acres, proportion, LCC, Storie index,

Error tolerance table:

Types of Error: Referential, Topological, Relative, And Absolute.

Type of Error:

Possible occurrences:

Result of error:

Impact on benefits:

Error tolerance

Mitigation measures

Type of Error:

Possible occurrences:

Result of error:

Impact on benefits:

Error tolerance

Mitigation measures
Topological-FMMP MMU is 10 acres

Small projects

Land use variation across surface may be aggregated in areas less than 10 acres

Land use may be inaccurate

$0 \%$

For study areas less than 10 acres, confirm land use using other resources such as aerial photography, and local planning departments.

Referential-FMMP fallow lands

Lands not irrigated due to fallowing

Water source and surrounding land use scores lowered

High value lands score lower due to temporary fallowing $0 \%$

Study areas which include fallowed lands will require review of previous land uses, using previous FMMP studies to determine if the fallowed lands are of high value agriculturally.

Wait tolerance and response tolerance: The wait tolerance is not a concern because once the study area is provided; the model may run without human supervision and will not be used frequently by the FMMP staff (1-2 times per month).

The response tolerance may vary depending on CEQA, Williamson Act contract and Conservation Easement application deadlines, and FMMP staff workloads. It is anticipated FMMP staff will have at least one week to run the model and evaluate the results. 


\section{Appendix D - Project Tasks and Schedule}

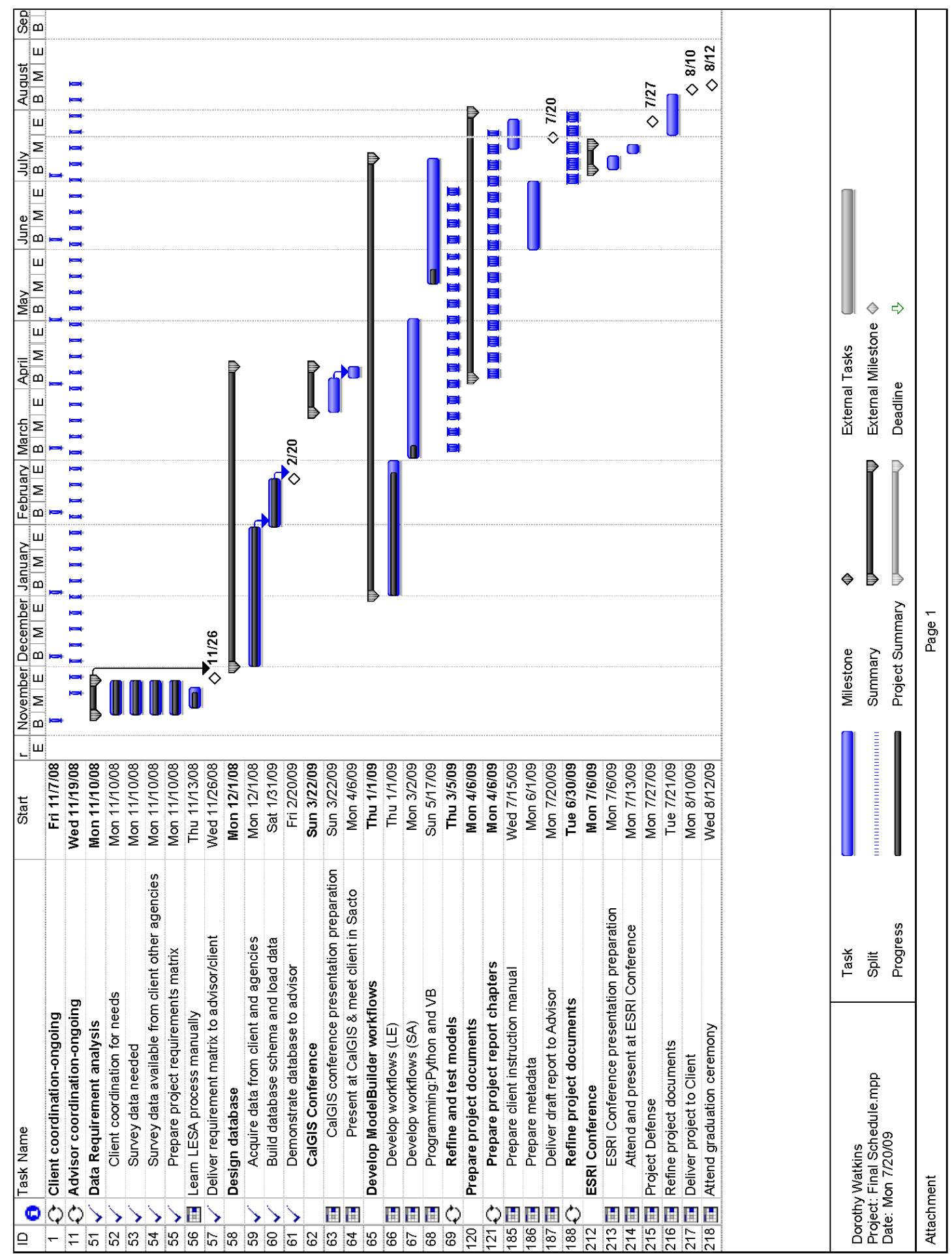




\section{Appendix E - ArcGIS Diagrammer Database Schema}

\section{ArcGIS Diagrammer}

\section{Report Creation}

Date

Author

\section{System Information}

Operating System

.Net Framework

Diagrammer

Geodatabase

Workspace Type

File

\section{ObjectClasses \\ Spatial Reference}

Table Of Contents

Listing of Tables and FeatureClasses.

Listing of Spatial References used by FeatureClasses and FeatureDatasets.

\begin{tabular}{|c|c|c|c|c|}
\hline ObjectClass Name & Type & Geometry & Subtype & \\
\hline \multicolumn{5}{|c|}{ Stand Alone ObjectClass(s) } \\
\hline FMMP2006 & \begin{tabular}{|l|} 
Simple \\
FeatureClass
\end{tabular} & Polygon & - & $S R$ \\
\hline Protected & \begin{tabular}{|l|} 
Simple \\
FeatureClass
\end{tabular} & Polygon & - & $S R$ \\
\hline Soils & \begin{tabular}{|l|} 
Simple \\
FeatureClass
\end{tabular} & Polygon & - & $S R$ \\
\hline StudyArea & \begin{tabular}{|l} 
Simple \\
FeatureClass
\end{tabular} & Polygon & - & $S R$ \\
\hline Water & \begin{tabular}{|l} 
Simple \\
FeatureClass
\end{tabular} & Polygon & - & $S R$ \\
\hline
\end{tabular}

Saturday, July 18, 2009

dorothy_watkins/SPATIAL on DOTI_WATKINS

Microsoft Windows NT

5.1.2600 Service Pack 3

2.0.50727.3082

1.0.3422.27552

Personal Geodatabase

C:|MyDocs|O0MIP|LESA

FINAL XML.Xml

\section{ObjectClasses}


FMMP2006

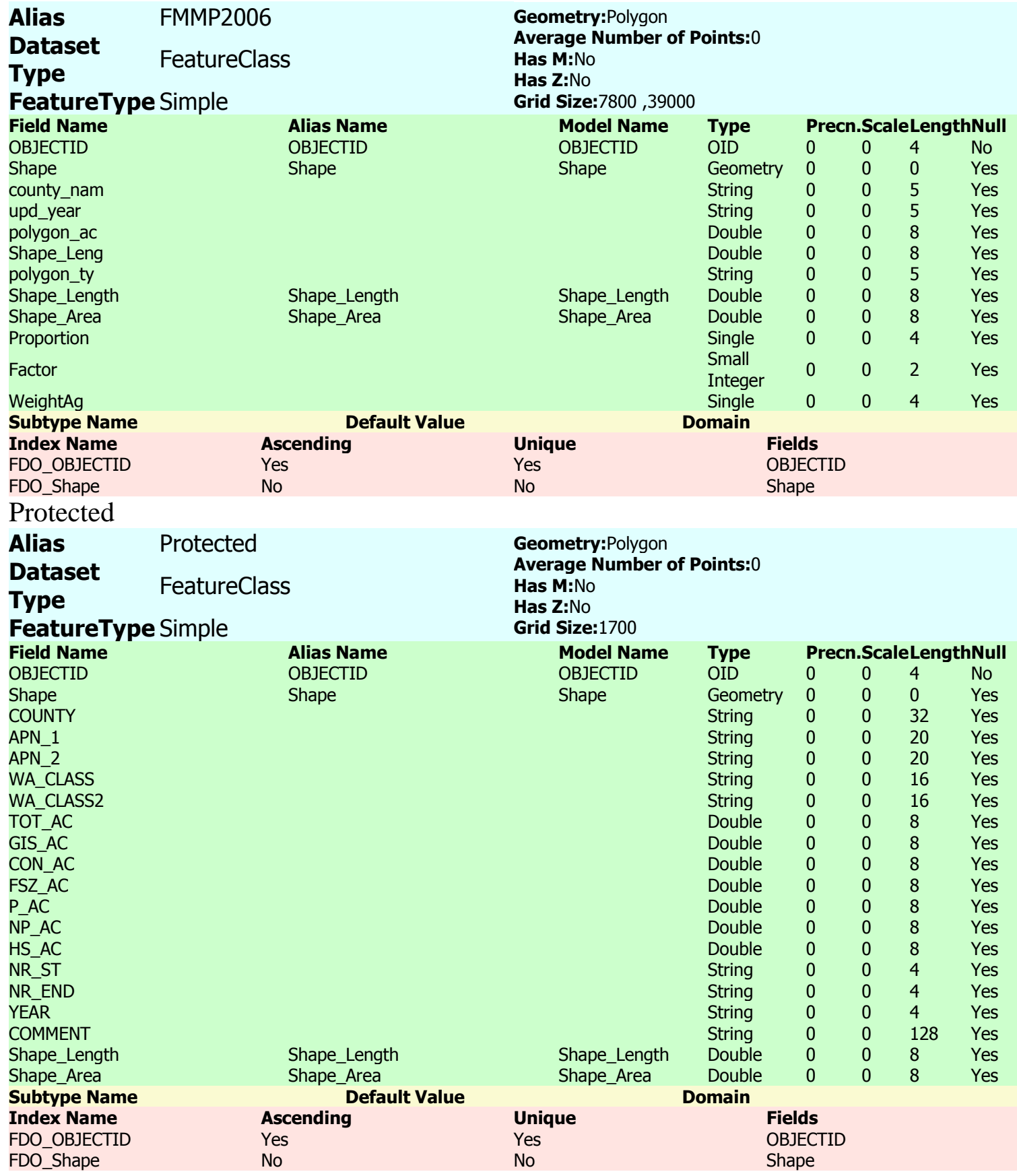


Soils

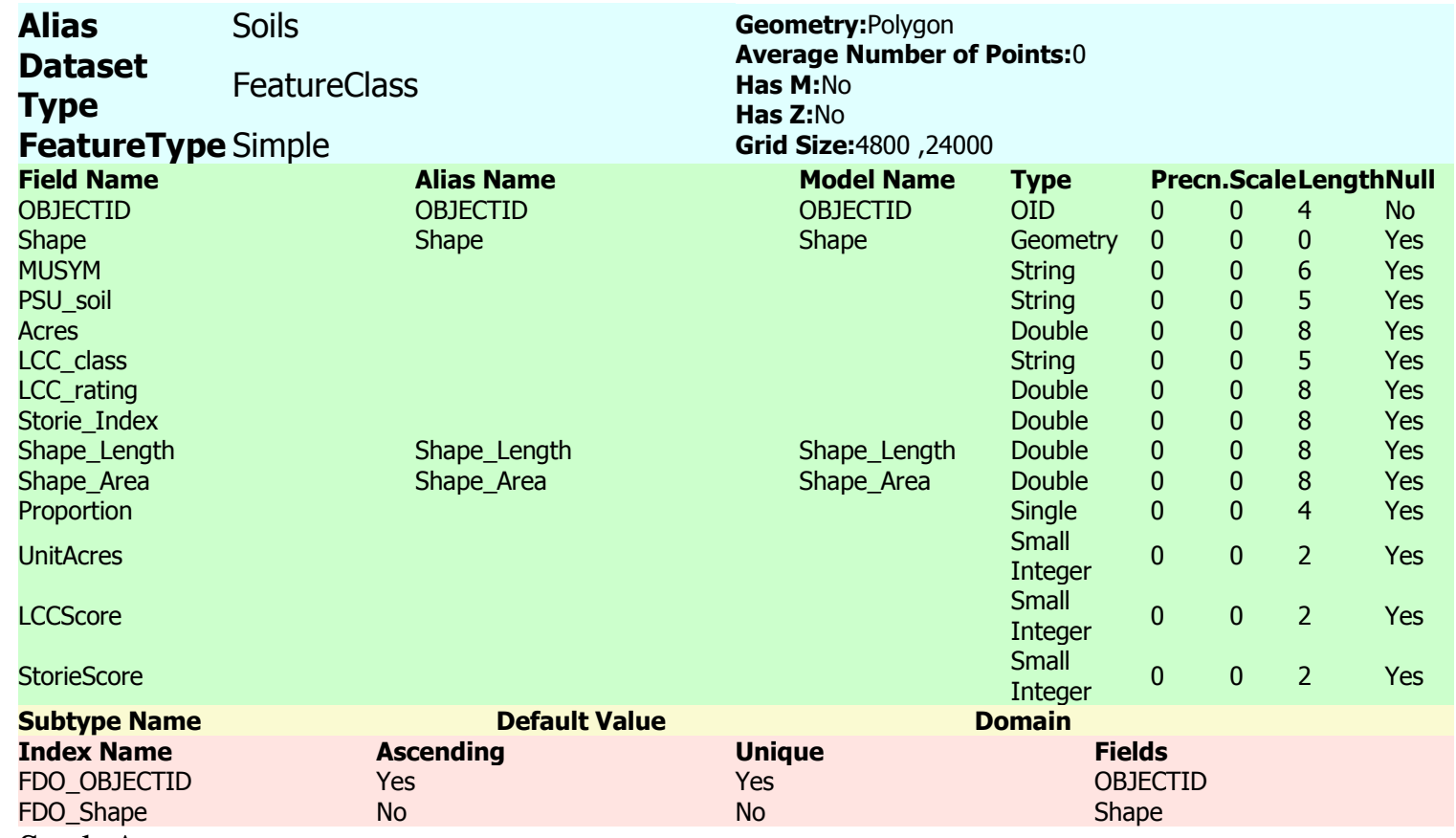

StudyArea

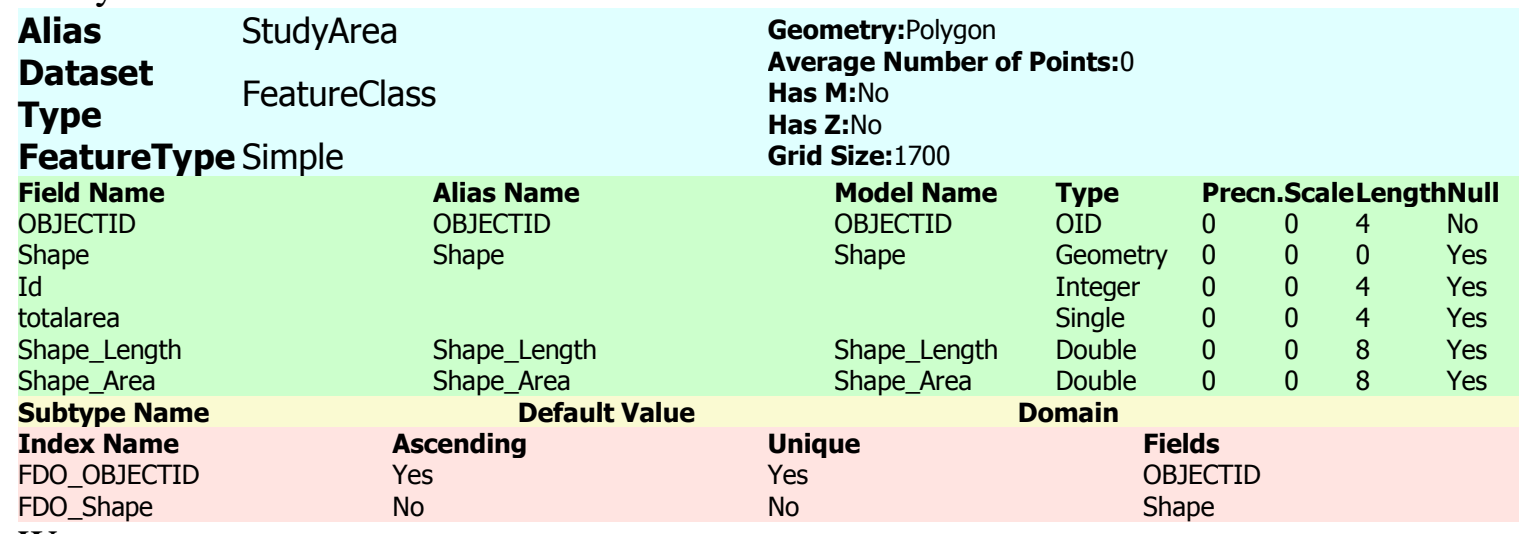

Water

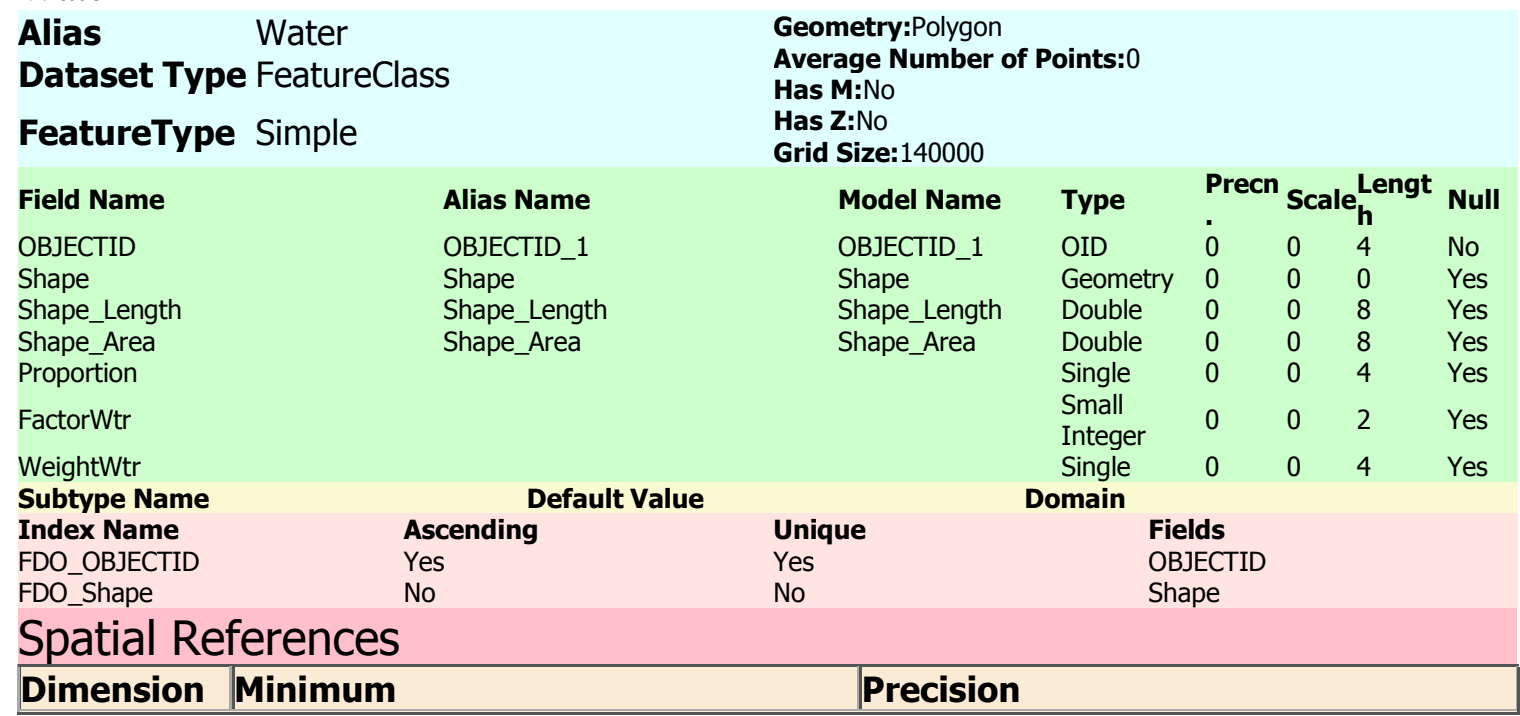




\begin{tabular}{|c|c|c|}
\hline \multicolumn{3}{|c|}{ FMMP2006 } \\
\hline $\mathbf{x}$ & $\mid-16909700$ & \multirow{2}{*}{9999.99952502551} \\
\hline \multirow{2}{*}{\begin{tabular}{|l}
$\mathbf{Y}$ \\
$\mathbf{M}$
\end{tabular}} & -8597000 & \\
\hline & - & - \\
\hline $\mathbf{Z}$ & - & - \\
\hline & $\begin{array}{l}\text { System Descriptio } \\
\text { ifornia } \\
\text { SCS["GCS_North_Am } \\
\text { EM["Greenwich",0.0] } \\
\text { ER["False_Northing", } \\
\text { METER["Standard_Pa } \\
\text { ",1.0]] }\end{array}$ & $\begin{array}{l}\text { can_1927",SPHEROID["Clarke_1866",6378206.4,294.978 } \\
\text { ],PROJECTION["Albers"],PARAMETER["False_Easting",0. } \\
\text { ridian",-- } \\
\text { Parallel_2",40.5],PARAMETER["Latitude_Of_Origin",0.0], }\end{array}$ \\
\hline \multicolumn{3}{|c|}{ Protected } \\
\hline $\mathbf{X}$ & -16909700 & \multirow{2}{*}{9999.99952502551} \\
\hline $\mathbf{Y}$ & -8597000 & \\
\hline M & - & - \\
\hline $\mathbf{Z}$ & - & - \\
\hline \multicolumn{3}{|c|}{$\begin{array}{l}\text { PROJCS["California } \\
\text { Albers",GEOGCS["GCS_North_American_1927",DATUM["D_North_American_1927",SPHEROID["Clarke_1866",6378206.4,294.978 } \\
\text { 6982],PRIMEM["Greenwich",0.0],UNIT["Degree",0.0174532925199433]],PROJECTION["Albers"],PARAMETER["False_Easting",0. } \\
\text { O],PARAMETER["False_Northing",-4000000.0],PARAMETER["Central_Meridian",-- } \\
\text { 120.0],PARAMETER["Standard_Parallel_1",34.0],PARAMETER["Standard_Parallel_2",40.5],PARAMETER["Latitude_Of_Origin",0.0], } \\
\text { UNIT["Meter",1.0]] }\end{array}$} \\
\hline \multicolumn{3}{|c|}{ Soils } \\
\hline $\mathbf{X}$ & -16909700 & \multirow{2}{*}{9999.99952502551} \\
\hline $\mathbf{Y}$ & -8597000 & \\
\hline M & - & - \\
\hline $\mathbf{Z}$ & - & - \\
\hline \multicolumn{3}{|c|}{ 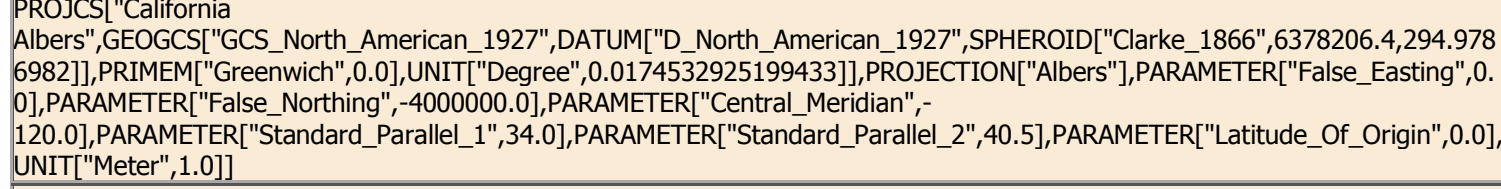 } \\
\hline \multicolumn{3}{|c|}{ StudyArea } \\
\hline $\mathbf{X}$ & -16909700 & \multirow{2}{*}{9999.99952502551} \\
\hline $\mathbf{Y}$ & -8597000 & \\
\hline M & - & - \\
\hline $\mathbf{Z}$ & - & - \\
\hline \multicolumn{3}{|c|}{$\begin{array}{l}\text { PROJCS["California } \\
\text { Albers",GEOGCS["GCS_North_American_1927",DATUM["D_North_American_1927",SPHEROID["Clarke_1866",6378206.4,294.978 } \\
\text { 6982],PRIMEM["Greenwich",0.0],UNIT["Degree",0.0174532925199433]],PROJECTION["Albers"],PARAMETER["False_Easting",0. } \\
\text { O],PARAMETER["False_Northing",-4000000.0],PARAMETER["Central_Meridian",-- } \\
\text { 120.0],PARAMETER["Standard_Parallel_1",34.0],PARAMETER["Standard_Parallel_2",40.5],PARAMETER["Latitude_Of_OOrigin",,0.0], } \\
\text { UNIT["Meter",1.0]] }\end{array}$} \\
\hline \multicolumn{3}{|c|}{ Water } \\
\hline $\mathbf{x}$ & -16909700 & \multirow{2}{*}{10000} \\
\hline $\mathbf{Y}$ & -8597000 & \\
\hline $\mathbf{M}$ & - & F \\
\hline $\mathbf{Z}$ & - & - \\
\hline \multicolumn{3}{|c|}{$\begin{array}{l}\text { Coordinate System Description } \\
\text { PROJCS["California }\end{array}$} \\
\hline
\end{tabular}


0],PARAMETER["False_Northing",-4000000.0],PARAMETER["Central_Meridian",-

120.0],PARAMETER["Standard_Parallel_1",34.0],PARAMETER["Standard_Parallel_2",40.5],PARAMETER["Latitude_Of_Origin",0.0], UNIT["Meter",1.0]]

ArcGIS Diagrammer is prototype application and is not supported by ESRI. The commands associated with this application and the output generated by those commands is not to be used in a production environment. ESRI is not responsible for errors, omissions or any damages resulting from the use of application and associated output. Use of this application is conditional on the acceptance of this statement. 


\section{Appendix F - ArcGIS Diagrammer Data Report}

\section{ArcGIS Diagrammer}

\section{Report Creation \\ Date}

Author

\section{System Information}

Operating System

.Net Framework

Diagrammer

Geodatabase

Workspace Type

File
Saturday, July 18, 2009 dorothy_watkins/SPATIAL on DOTI_WATKINS

Microsoft Windows NT 5.1.2600

Service Pack 3

2.0.50727.3082

1.0.3422.27552

File Geodatabase

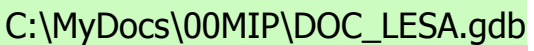

Data Report

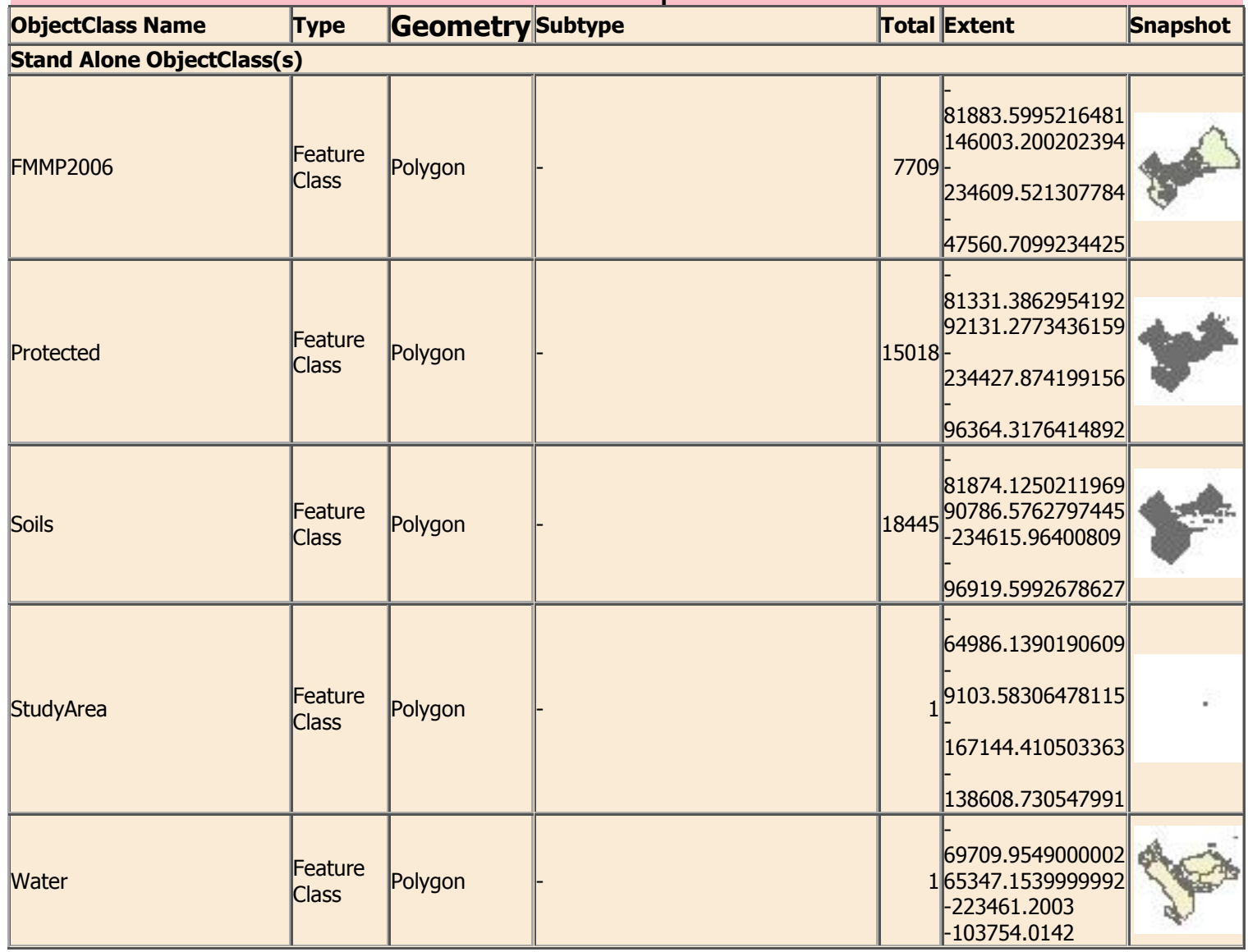




\title{
Appendix G - Fresno County Soil Survey Pre- processing
}

Metadata:

\author{
Ca653: Fresno County, Western Part \\ Spatial version: 12-07-2004 \\ Tabular version: 01-02-2008 \\ Ca654: Eastern Fresno Area \\ Spatial version: 01-20-2005 \\ Tabular version: 01-02-2008
}

Tabular data used (from the NASIS data):

California Revised Storie Index Rating

Irrigated and Nonirrigated Yields by Map Unit (includes Irrigated and

Nonirrigated Land Capability Classification)

Prime and Other Important Farmlands

Storie Index Rating

Fields added to attribute table:

Acres: calculated acreage, [Shape_Area]/4046.856422

LCC_class: The Land Capability Classification

LCC_rating: The Land Capability Classification Point Rating

PSU_soil: Prime Farmland (P), Farmland of Statewide Importance (S), or Unique

Farmland (U)

Storie_Index: The California Revised Storie Index Rating

Note: MUSYM stands for Map Unit Symbol

\section{Determination of Land Capability Classification:}

In cases where both a nonirrigated (N) and an irrigated (I) Land Capability Class (LCC) was given for a map unit, I chose the Irrigated LCC. For example:

101: Armona, loam, partially drained $\mathrm{N}=7 \mathrm{w}, \mathrm{I}=3 \mathrm{w} \quad \mathrm{LCC}=3 \mathrm{w}$

Map units can have one dominant soil type ( $80 \%$ or more) or multiple soil types. For map units with multiple soil types, I chose the LCC of the soil type with the majority. For Example:

462: Ciervo, clay, saline-sodic, wet $\mathrm{N}=7 \mathrm{~s}, \mathrm{I}=3 \mathrm{~s} \quad(50 \%)$

Ciervo, clay, saline-sodic $\quad \mathrm{N}=7 \mathrm{~s}, \mathrm{I}=2 \mathrm{~s} \quad(30 \%) \quad \mathrm{LCC}=3 \mathrm{~s}$

In some cases there were multiple soil types, but the soil types were equal or there was no clear majority. If there were two soil types, I chose the highest LCC. If there were three soil types, I chose the middle LCC. For example:

DsF: Delpiedra N=7e (45\%) 
590: Anela, very gravelly sandy loam $\mathrm{N}=4 \mathrm{w}, \mathrm{I}=4 \mathrm{w} \quad(30 \%)$

Cerini, sandy loam $\mathrm{N}=7 \mathrm{c}, \mathrm{I}=1 \quad(30 \%)$

Fluvaquents, saline-sodic $\quad \mathrm{N}=7 \mathrm{w} \quad(20 \%) \quad \mathrm{LCC}=4 \mathrm{w}$

Note: The percentage of each soil type within a map unit can be found on the California Revised Storie Index Rating report.

Some of the map units do not have a Land Capability Classification. These units are typically non-soil areas, such as a dumps, dams, urban land, sewage disposal ponds, and water.

Determination of Land Capability Classification Point Rating:

Once the Land Capability Classification was determined for each map unit, I used the following table from page 10 of the LESA Model Instruction Manual (http://www.conservation.ca.gov/dlrp/LESA/Documents/lesamodl.pdf) to assign a point value to each map unit:

Table 2: Numeric Conversion of Land Capability Classification Units

Land Capability Classification LCC Point Rating

\begin{tabular}{|c|c|}
\hline & \\
\hline I & $\mathbf{1 0 0}$ \\
\hline IIe & 90 \\
\hline IIs, IIw & $\mathbf{8 0}$ \\
\hline IIIe & $\mathbf{7 0}$ \\
\hline IIIs, IIIw & $\mathbf{6 0}$ \\
\hline IVe & $\mathbf{5 0}$ \\
\hline IVs, IVw & $\mathbf{4 0}$ \\
\hline V & $\mathbf{3 0}$ \\
\hline VI & $\mathbf{2 0}$ \\
\hline VII & $\mathbf{1 0}$ \\
\hline VIII & 0 \\
\hline
\end{tabular}

Determination of PSU_soil:

The Prime and Other Important Farmlands report lists the soil map units that qualify for Prime Farmland and Farmland of Statewide Importance. The soil units that do not qualify as either Prime Farmland or Farmland of Statewide Importance were designated as soils that qualify for Unique Farmland. (Note: these are soils that qualify; FMMP maps land use and then overlays this soil information over currently Irrigated farmlands.) 


\section{Determination of Storie Index Rating:}

The California Revised Storie Index Rating report was the prime source. These ratings are determined by a mathematical model using the NASIS (National Soil Information System) database. Occasionally, there is an error in the NASIS database and a rating could not be determined for a map unit. In these cases, I used the Storie Index Rating report (older, manually determined ratings) to determine a rating.

Map units can have one dominant soil type (80\% or more) or multiple soil types. For map units with multiple soil types, I used a weighted average calculation to determine the rating for the map unit. For example:

285: Tranquility, clay, saline-sodic Tranquility, clay, saline-sodic, wet

Weighted Average Calculation: $(\mathrm{A} \times \mathrm{B} / \mathrm{C})+(\mathrm{A} \times \mathrm{B} / \mathrm{C})$

$$
(28 \times 60 / 85)+(16 \times 25 / 85)=(28 \times .706)+(16 \times .294)=19.76+4.71=24.47
$$

With rounding, the Storie Index Rating is 24 .

(A simple average would be 22)

Some soil map units included "Rock land", "Rock Outcrop", or "Pits, asbestos" as one soil component. These components didn't have a rating in either report, so I rated them as a zero for the weighted average calculation.

If the soil map unit was given a Land Capability Classification, then it was also given a Storie Index Rating. In some cases, neither report had a rating for a particular map unit (i.e. SPILLW: dam spillway), so I rated it as a zero.

Kerri Kisko, Department of Conservation, Farmland Mapping and Monitoring Program, 01-16-09 


\section{Appendix H - Python Script Samples}

Sample 1: Add Fields Custom Tool

\# Description: Adds fields from value table.

\# NOTES: Fields are only added if they don't exist.

\# Requirements: ArcView or ArcInfo license.

\# User must code in input layer.

\# User must code in value table (see comments for format).

\# Should be used as script tool in ArcCatalog toolbox.

\# Assumes active doc is a data frame (uses layers).

\# Modified from Ruth Bowers Add Field Script

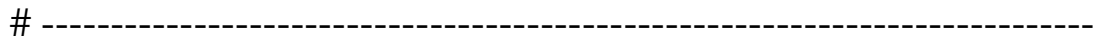

\# IMPORT SYSTEM MODULES

import sys, string, os, win32com.client

\# CREATE THE GEOPROCESSOR OBJECT

gp = win32com.client.Dispatch("esriGeoprocessing.GpDispatch.1")

\# CREATE LOCAL VARIABLES

Layer1 = sys.argv[1]

gp.AddMessage("Input layer: " + Layer1)

\#Output Feature Class

OutFC $=$ sys.argv[2]

\# CREATE VALUE TABLE (FIELDS TO ADD)

try:

vtab = gp.CreateObject("ValueTable",5)

\# ADDROW FORMAT: Name Type Prec Scale Length

vtab.AddRow("Proportion FLOAT \# 2 5")

vtab.AddRow("UnitAcres SHORT \# \# 15")

vtab.AddRow("LCCScore SHORT \# \# 5")

vtab.AddRow("StorieScore SHORT \# \# 5")

except:

\# PRINT ERROR MESSAGES

gp.AddMessage("There is an error(s) in the field parameters: In" + gp.GetMessages(2))

\# ADD FIELDS WITH GEOPROCESSING TOOLS, USING VALUE TABLE

try:

$\mathrm{x}=0$

\# LOOP THROUGH THE VALUE TABLE

while $\mathrm{x}<\mathrm{vtab}$.RowCount:

\# SEE IF THE FIELD EXISTS

if gp.ListFields(Layer1,vtab.GetValue(x,0)).Next(): 
gp.AddMessage(vtab.GetValue(x,0) + " already exists; field not added.")

\# ADD THE FIELD IF IT DOES NOT EXIST

else:

gp.AddField(Layer1,vtab.GetValue(x,0),vtab.GetValue(x,1),vtab.GetValue(x,2), vtab.Get Value(x,3),vtab.GetValue(x,4))

gp.AddMessage("Added field " + vtab.GetValue $(\mathrm{x}, 0)+$ ".")

$\mathrm{x}=\mathrm{x}+1$

except:

\# PRINT ERROR MESSAGES

gp.AddMessage("There was an error creating fields: In" + gp.GetMessages(2))

Sample 2: Use of Python scripting inside a system tool. This tool computes the three possible candidate scores for project size, which are input to the ExportHighest custom tool in sample 3 .

\section{Calculate PS Scores for I, J, K}

Input Table

butStatsTable_View $\quad$ ¿

Field Name

PSscore

Expression

getscore(float(!SUM_UnitAcres!), !Bin!)

Expression Type (optional)

PYTHON_9.3

Code Block (optional)

def getscore(SUM_UnitAcres, Bin):

if $\mathrm{Bin}==$ "I":

if SUM_UnitAcres $>=80$ :

return 100

elif SUM_UnitAcres $>=60$ and SUM_UnitAcres $<=79$ :

return 90

elif SUM_UnitAcres $>=40$ and SUM_UnitAcres $<=59$ :

return 80

elif SUM_UnitAcres $>=20$ and SUM_UnitAcres $<=39$ :

return 50 


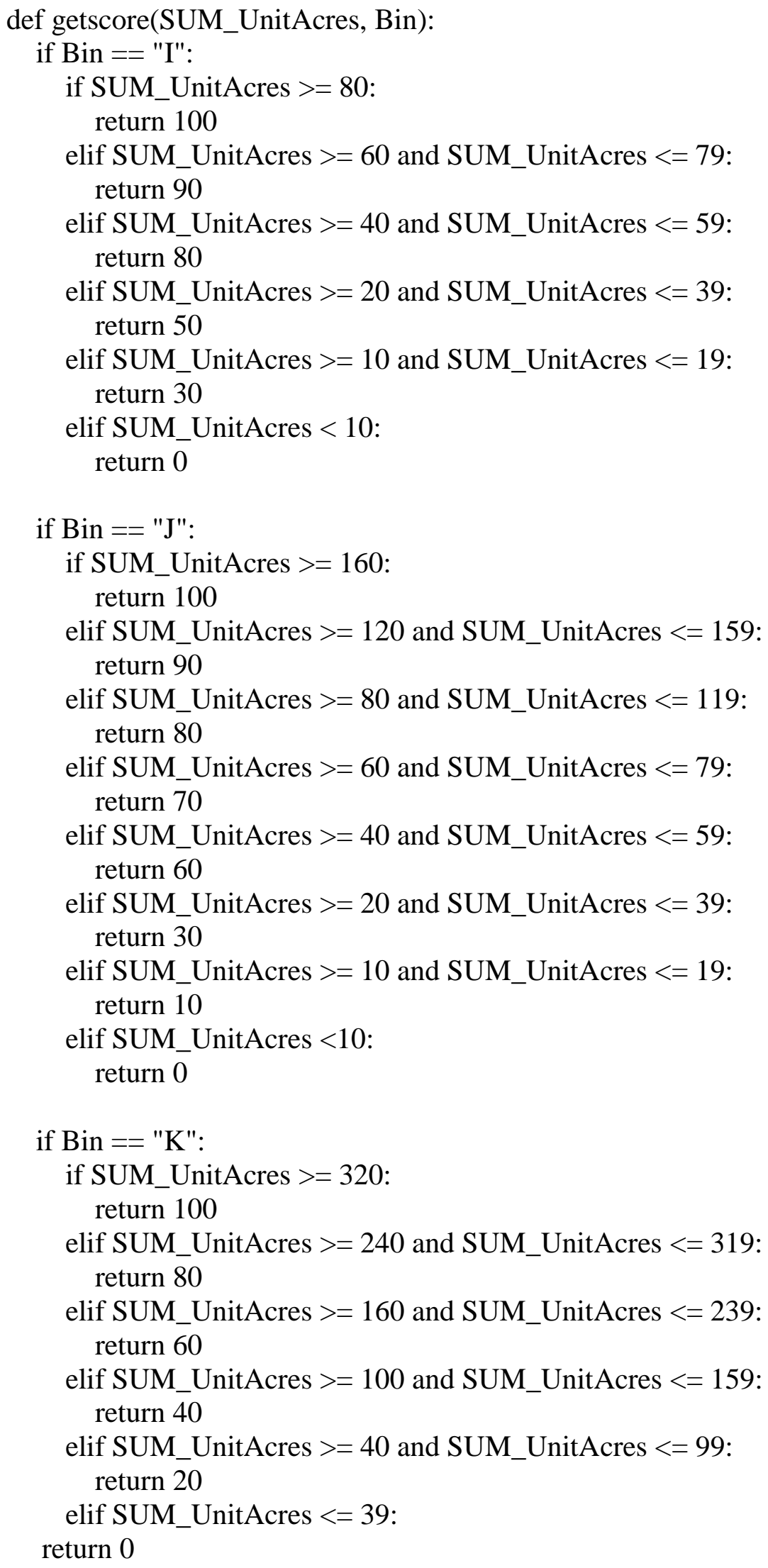


Sample 3: ExportHighest custom tool

\# ExportHighest is used to pick the single highest score for project size \# from the 3 candidate scores calculated in the previous field calculation. \# Developed by Nate Strout and Doti Watkins July 2009 for use in the \# California GIS enabled LESA Model

\# Import system modules

import sys, string, os, arcgisscripting

\# Create the Geoprocessor object

$\mathrm{gp}=$ arcgisscripting.create()

InputTable $=$ sys.argv[1]

CompareField $=$ sys.argv[2]

OutputTable $=$ sys.argv[3]

desc $=$ gp.describe $($ InputTable $)$

idfield $=$ desc. OIDFieldName

TopID = -99999

MaxScore = -99999

rows $=$ gp.SearchCursor(InputTable $)$

row $=$ rows.Next ()

while row:

Score $=$ row.GetValue $($ CompareField $)$

if Score > MaxScore:

Max Score $=$ Score

TopID $=$ row.getvalue $($ idfield $)$

row $=$ rows.Next ()

gp.addmessage("The highest score is " + str(MaxScore))

gp.MakeTableView(InputTable,"HighestScore",idfield + " = " + $\operatorname{str}($ TopID))

gp.CopyRows("HighestScore",OutputTable)

gp.addmessage("Operation complete") 


\section{Appendix I - Model Diagrams}

LCC Factor:
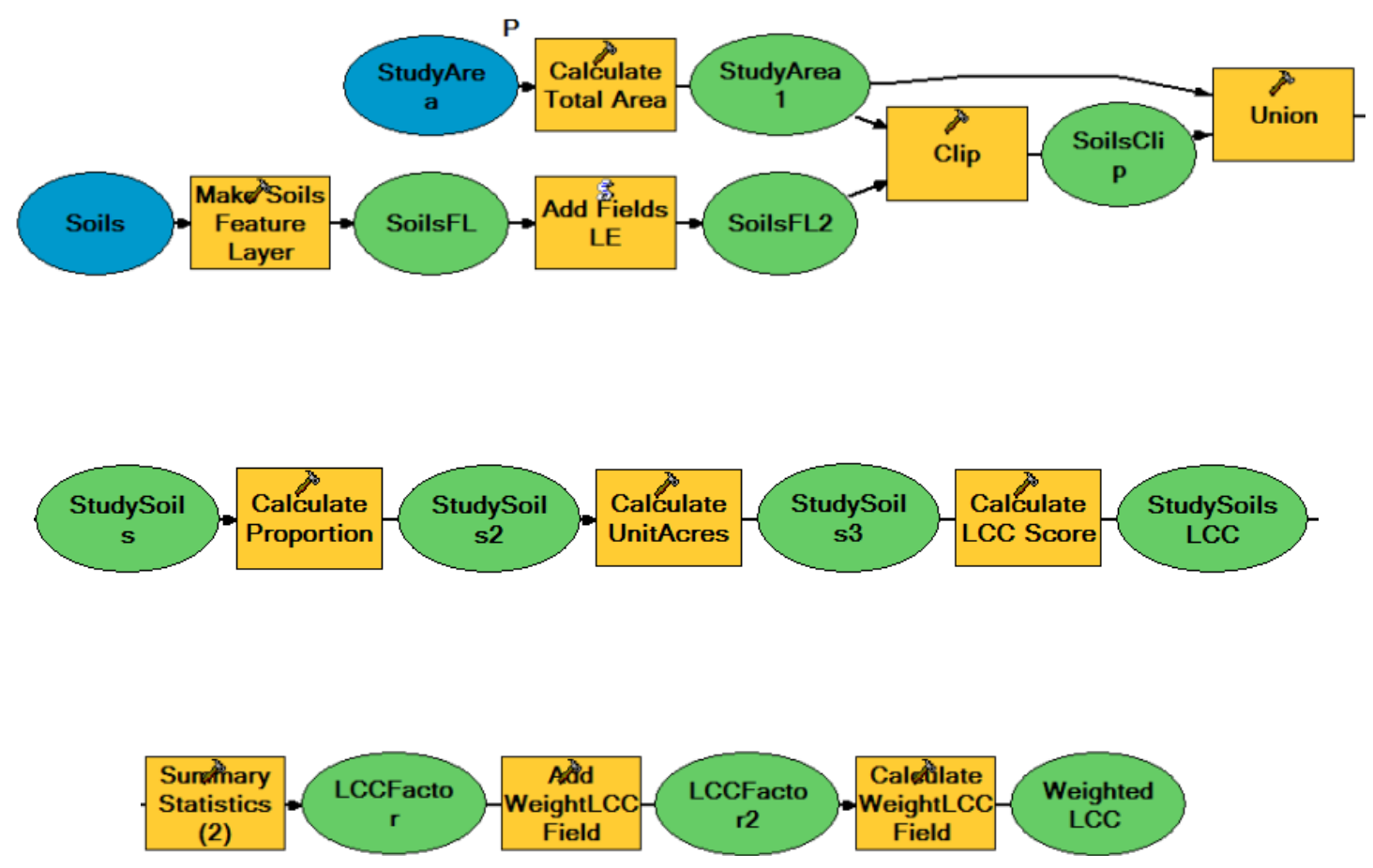
Storie Index Factor:
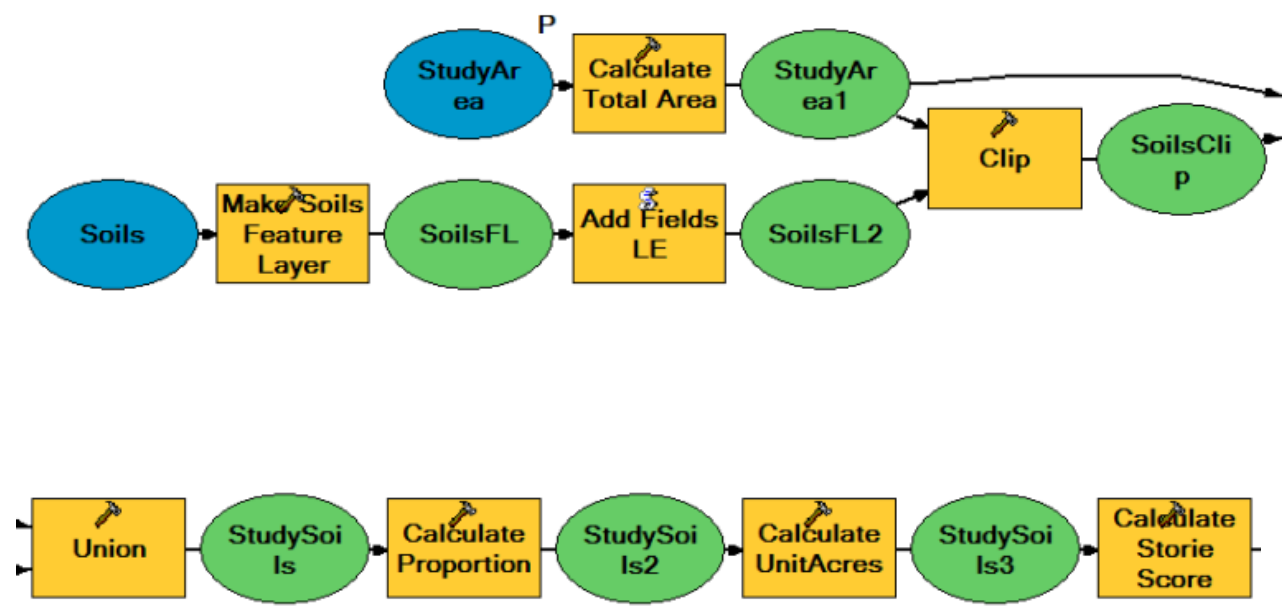

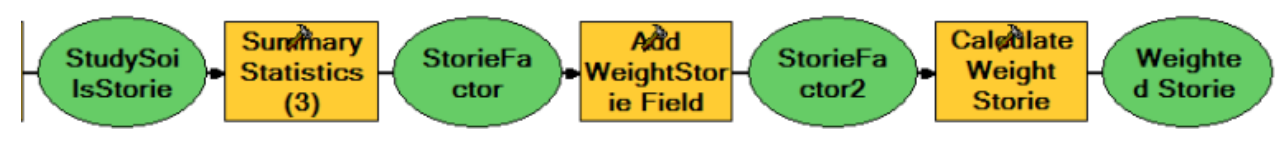


Project Size Factor:
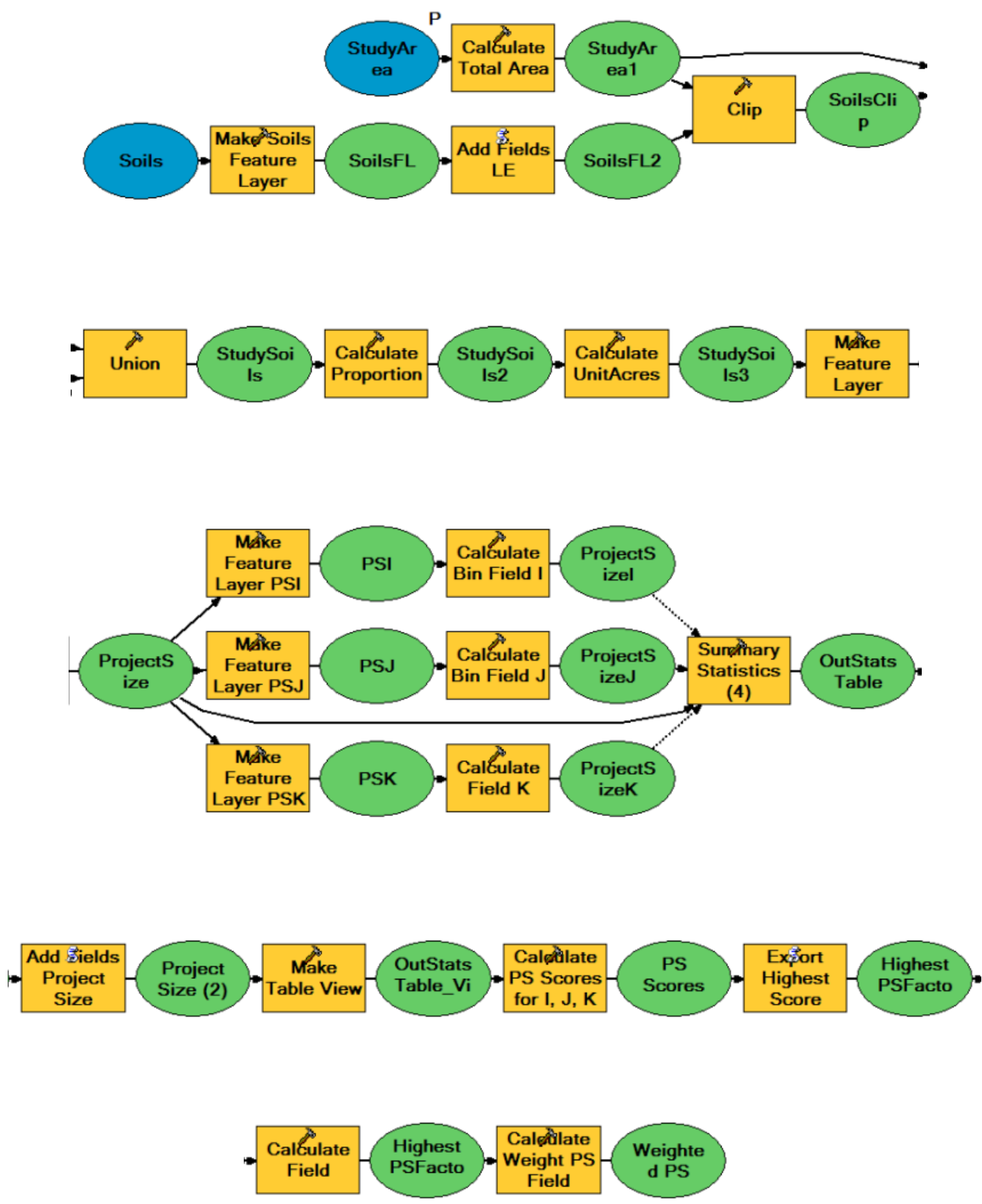
Water Availability Factor:
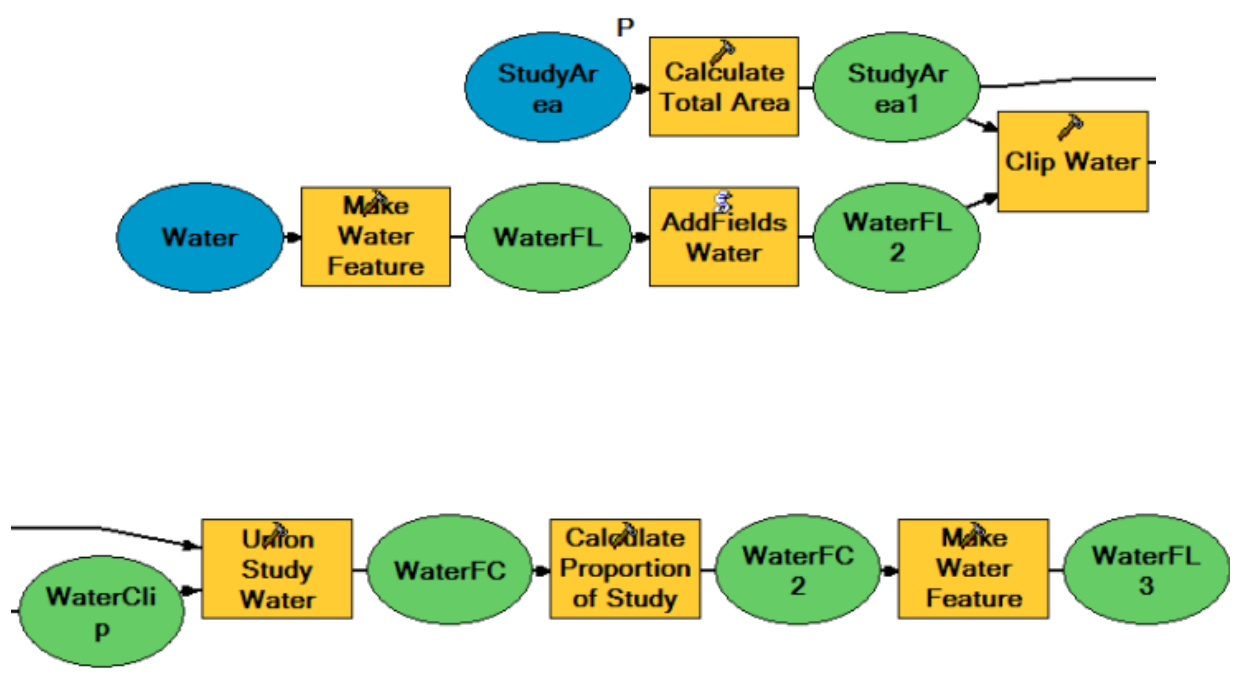

- $\begin{gathered}\text { Calfallate } \\ \text { Water } \\ \text { Factor }\end{gathered}-\begin{aligned} & \text { Water } \\ & \text { Factor }\end{aligned}-\begin{aligned} & \text { Caløälate } \\ & \text { WeightWat } \\ & \text { er Field }\end{aligned}-\begin{aligned} & \text { Weighte } \\ & \text { d Water }\end{aligned}$


Surrounding Agricultural Lands Factor:
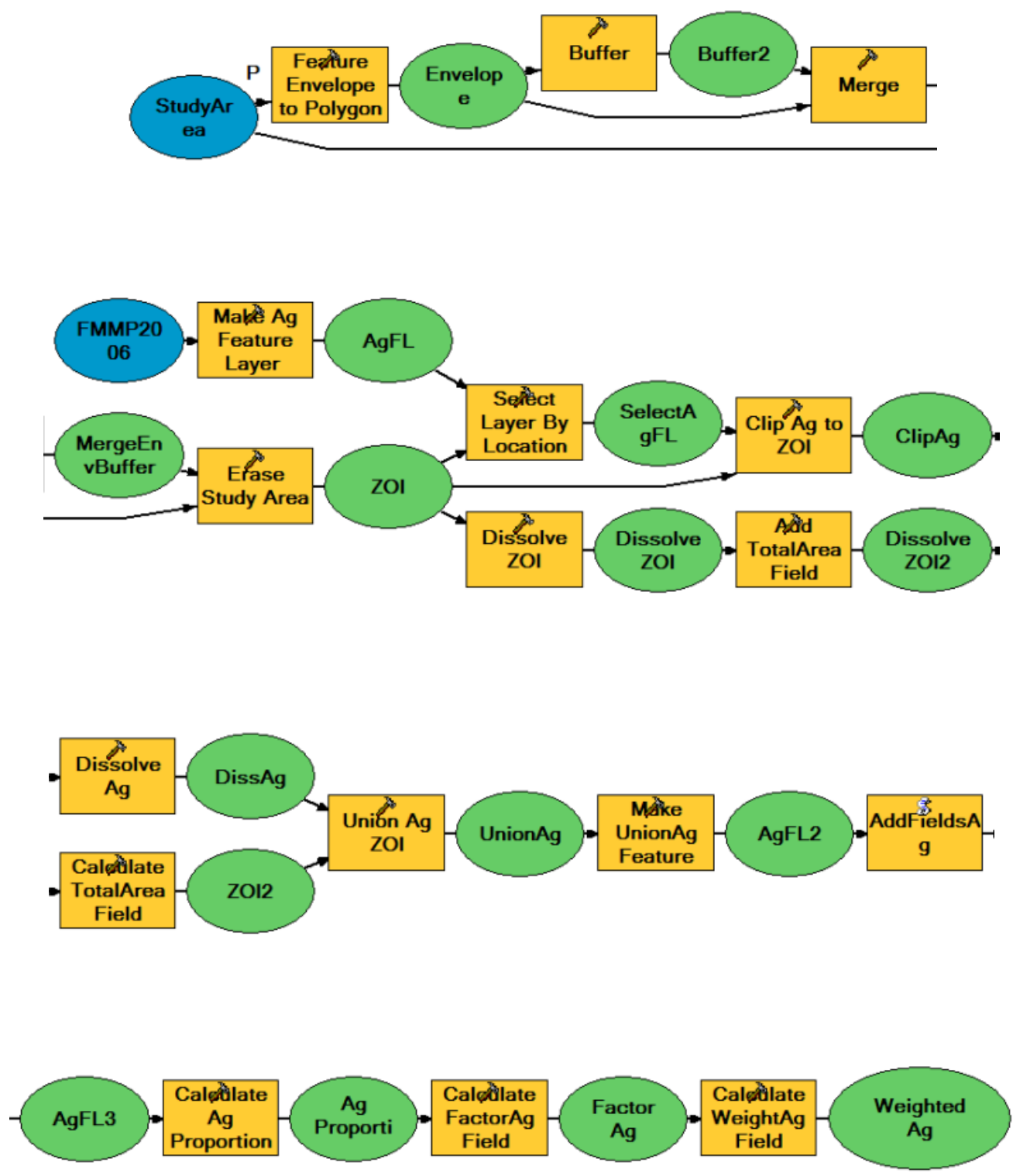
Surrounding Protected Lands Factor:
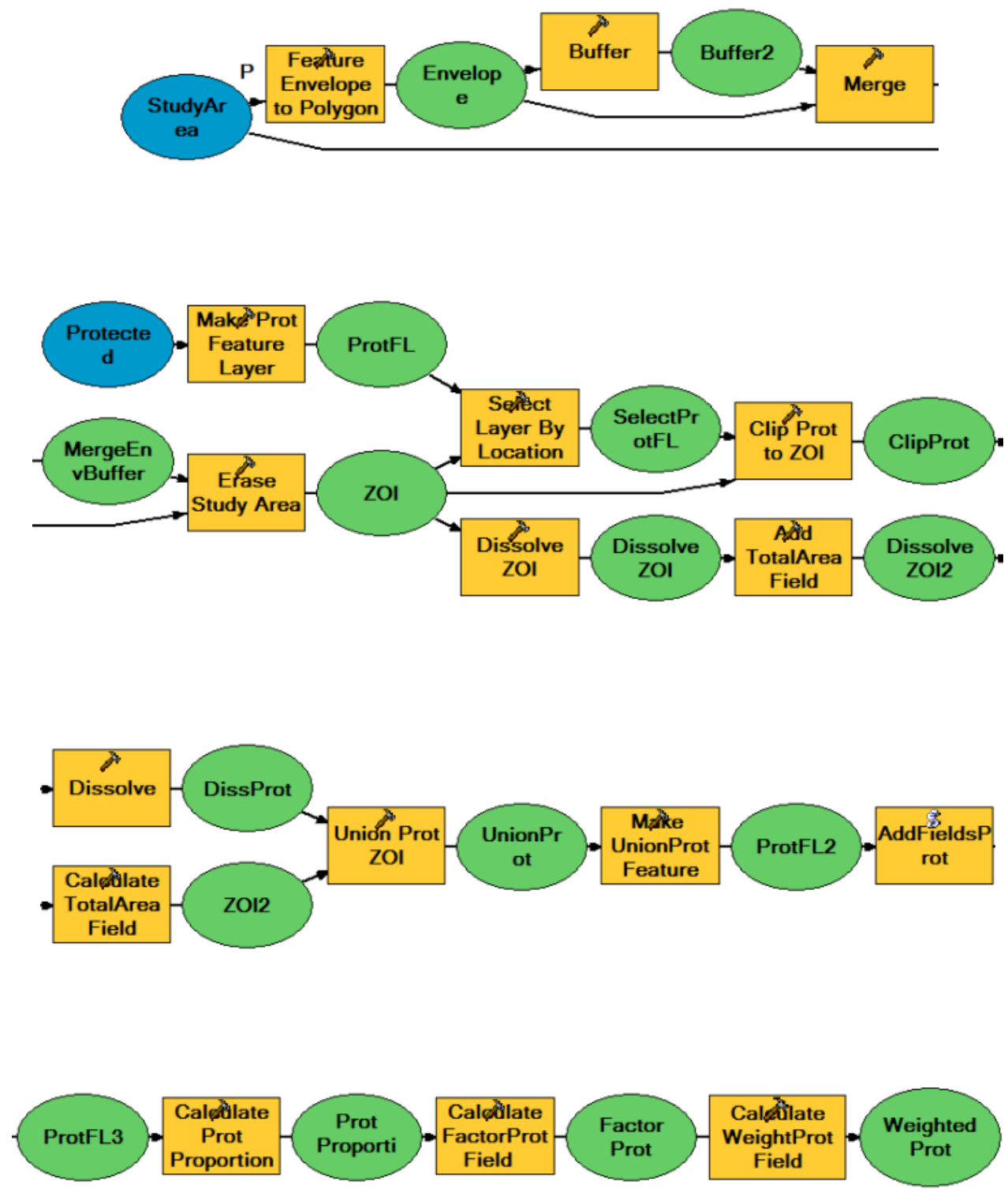


\section{Appendix J - Project Size ModelBuilder Model Report}

Model Report

Expand/Collapse All

Generated on: Sun Jul 19 07:43:38 2009

\section{$\underline{\text { Variables }}$}

\section{StudyArea}

Data Type:Feature Layer

Value:StudyArea

StudyArea1

Data Type:Table View or Raster Layer

Value:StudyArea

\section{Soils}

Data Type:Feature Layer

Value:Soils

SoilsFL

Data Type:Feature Layer

Value:Soils_Layer

\section{SoilsFL2}

Data Type:Feature Layer

Value:Soils_Layer

\section{SoilsClip}

Data Type:Feature Class

Value:C:IMyDocs\00MIPIDOC_LESA.gdb\Soils_Clip

\section{StudySoils}

Data Type:Feature Class

Value:C:IMyDocs 100MIPIDOC_LESA.gdb।StudyArea_Union

\section{StudySoils2}

Data Type:Table View or Raster Layer

Value:C:IMyDocs\00MIP\DOC_LESA.gdb\StudyArea_Union

\section{StudySoils3}

Data Type:Table View or Raster Layer

Value:C:IMyDocs\00MIP\DOC_LESA.gdb\StudyArea_Union

StudyArea_Union

Data Type:Table View or Raster Layer

Value:C:MyDocs100MIPIDOC_LESA.gdb\StudyArea_Union

ProjectSize

Data Type:Feature Layer

Value:ProjectSize 


\section{PSI}

Data Type:Feature Layer

Value:PSI

\section{ProjectSizeI}

Data Type:Table View or Raster Layer Value:PSI

\section{PSJ}

Data Type:Feature Layer Value:PSJ

\section{ProjectSizeJ}

Data Type:Table View or Raster Layer Value:PSJ

\section{PSK}

Data Type:Feature Layer Value:PSK

\section{ProjectSizeK}

Data Type:Table View or Raster Layer Value:PSK

\section{OutStatsTable}

Data Type:Table

Value:C:MyDocs100MIP\DOC_LESA.gdb\OutStatsTable

Project Size (2)

Data Type:Feature Layer

Value:C:IMyDocs100MIP\DOC_LESA.gdb\OutStatsTable

\section{OutStatsTable_View}

Data Type:Table View or Raster Layer Value:OutStatsTable_View

\section{PS Scores Candidates}

Data Type:Table View or Raster Layer Value:OutStatsTable_View

\section{HighestPSFactor}

Data Type:Table

Value:C:LMyDocsI00MIPIDOC_LESA.gdb\HighestPSFactor

\section{HighestPSFactor (2)}

Data Type:Table View or Raster Layer

Value:C:LMyDocsI00MIPIDOC_LESA.gdb\HighestPSFactor

\section{Weighted PS}

Data Type:Table View or Raster Layer

Value:C:LMyDocsI00MIPLDOC_LESA.gdb\HighestPSFactor 


\section{$\underline{\text { Processes }}$}

\section{Calculate Total Area}

Tool Name:Calculate Field

Tool Source:C:\Program Files $\backslash A r c G I S \backslash A r c T o o l b o x \backslash T o o l b o x e s \backslash D a t a$ Management Tools.tbx \Fields\CalculateField

Parameters:

\begin{tabular}{|l|l|l|l|l||}
\hline \multicolumn{1}{|c|}{ Name } & Direction & \multicolumn{1}{|c|}{ Type } & \multicolumn{1}{c|}{ Data Type } & \multicolumn{1}{c|}{ Value } \\
\hline Input Table & Input & Required & $\begin{array}{l}\text { Table View or } \\
\text { Raster Layer }\end{array}$ & StudyArea \\
\hline Field Name & Input & Required & Field & totalarea \\
\hline Expression & Input & Required & SQL Expression & [Shape_Area] \\
\hline Expression Type & Input & Optional & String & VB \\
\hline Code Block & Input & Optional & String & \\
\hline $\begin{array}{l}\text { Output Feature } \\
\text { Class }\end{array}$ & Output & Derived & $\begin{array}{l}\text { Table View or } \\
\text { Raster Layer }\end{array}$ & StudyArea \\
\hline
\end{tabular}

Messages:

Executing (Calculate Total Area): CalculateField StudyArea totalarea [Shape_Area] VB \# StudyArea

Start Time: Sun Jul 19 07:42:09 2009

Executed (Calculate Total Area) successfully.

End Time: Sun Jul 19 07:42:09 2009 (Elapsed

Time: 0.00 seconds)

\section{Make Soils Feature Layer}

Tool Name:Make Feature Layer

Tool Source:C:\Program Files $\backslash A r c G I S \backslash A r c T o o l b o x \backslash T o o l b o x e s \backslash D a t a$ Management Tools.tbx \Layers and Table Views\MakeFeatureLayer

Parameters:

\begin{tabular}{|l|l|l|l|l|}
\hline \multicolumn{1}{|c|}{ Name } & Direction & Type & Data Type & \multicolumn{1}{|c|}{ Value } \\
\hline Input Features & Input & Required & $\begin{array}{l}\text { Feature } \\
\text { Layer }\end{array}$ & Soils \\
\hline Output Layer & Output & Required & $\begin{array}{l}\text { Feature } \\
\text { Layer }\end{array}$ & Soils_Layer \\
\hline Expression & Input & Optional & $\begin{array}{l}\text { SQL } \\
\text { Expression }\end{array}$ & \\
\hline $\begin{array}{l}\text { Workspace or Feature } \\
\text { Dataset }\end{array}$ & Input & Optional & $\begin{array}{l}\text { Workspace } \\
\text { Or Feature }\end{array}$ & \\
\hline
\end{tabular}




\begin{tabular}{|c|c|c|c|c|}
\hline & & & Dataset & \\
\hline Field Info & Input & Optional & Field Info & $\begin{array}{l}\text { MUSYM MUSYM } \\
\text { VISIBLE } \\
\text { NONE;PSU_soil } \\
\text { PSU_soil VISIBLE } \\
\text { NONE;Acres Acres } \\
\text { VISIBLE } \\
\text { NONE;LCC_class } \\
\text { LCC_class VISIBLE } \\
\text { NONE;LCC_rating } \\
\text { LCC_rating } \\
\text { VISIBLE } \\
\text { NONE;Storie_Index } \\
\text { Storie_Index } \\
\text { VISIBLE } \\
\text { NONE;Shape_Lengt } \\
\text { h Shape_Length } \\
\text { VISIBLE } \\
\text { NONE;Shape_Area } \\
\text { Shape_Area } \\
\text { VISIBLE } \\
\text { NONE;Proportion } \\
\text { Proportion VISIBLE } \\
\text { NONE;UnitAcres } \\
\text { UnitAcres VISIBLE } \\
\text { NONE;LCCScore } \\
\text { LCCScore VISIBLE } \\
\text { NONE;StorieScore } \\
\text { StorieScore VISIBLE } \\
\text { NONE }\end{array}$ \\
\hline
\end{tabular}

\section{Messages:}

Executing (Make Soils Feature Layer):

MakeFeatureLayer Soils Soils_Layer \# \#

"MUSYM MUSYM VISIBLE

NONE;PSU_soil PSU_soil VISIBLE

NONE;Acres Acres VISIBLE

NONE;LCC_class LCC_class VISIBLE

NONE;LCC_rating LCC_rating VISIBLE

NONE;Storie_Index Storie_Index

VISIBLE NONE;Shape_Length

Shape_Length VISIBLE

NONE;Shape_Area Shape_Area VISIBLE

NONE;Proportion Proportion VISIBLE

NONE; UnitAcres UnitAcres VISIBLE

NONE;LCCScore LCCScore VISIBLE 
NONE;StorieScore StorieScore VISIBLE

NONE"

Start Time: Sun Jul 19 07:42:09 2009

Executed (Make Soils Feature Layer)

successfully.

End Time: Sun Jul 19 07:42:09 2009

(Elapsed Time: 0.00 seconds)

\section{Add Fields LE}

Tool Name: Add Fields LE

Tool Source:C: \MyDocs\00MIP\ToolSharelLESA Tools.tbx \AddFieldsLE

Parameters:

\begin{tabular}{|l|l|l|l|l|}
\hline \multicolumn{1}{|c|}{ Name } & \multicolumn{1}{|c|}{ Direction } & \multicolumn{1}{|c|}{ Type } & \multicolumn{1}{c|}{ Data Type } & \multicolumn{1}{c|}{ Value } \\
\hline Input Layer & Input & Required & Feature Layer & Soils_Layer \\
\hline $\begin{array}{l}\text { Output } \\
\text { Layer }\end{array}$ & Output & Derived & Feature Layer & Soils_Layer \\
\hline
\end{tabular}

Messages:

Executing (Add Fields LE): AddFieldsLE Soils_Layer

Soils_Layer

Start Time: Sun Jul 19 07:42:09 2009

Running script AddFieldsLE...

Input layer: Soils_Layer

Proportion already exists; field not added.

UnitAcres already exists; field not added.

LCCScore already exists; field not added.

StorieScore already exists; field not added.

Completed script AddFieldsLE...

Executed (Add Fields LE) successfully.

End Time: Sun Jul 19 07:42:09 2009 (Elapsed Time: 0.00 seconds)

\section{Clip}

\section{Tool Name:Clip}

Tool Source:C:\Program Files\ArcGIS\ArcToolbox\Toolboxes\Analysis

Tools.tbxlExtract|Clip

Parameters:

\begin{tabular}{|l|c|c|c|l|l|}
\hline Name & $\begin{array}{c}\text { Directio } \\
n\end{array}$ & Type & $\begin{array}{c}\text { Data } \\
\text { Type }\end{array}$ & Value \\
\hline Input & Input & Require & Featur & Soils Layer \\
\hline
\end{tabular}




\begin{tabular}{|c|c|c|c|c|}
\hline Features & & d & $\begin{array}{l}\text { e } \\
\text { Layer }\end{array}$ & \\
\hline \begin{tabular}{|l} 
Clip \\
Features
\end{tabular} & Input & $\begin{array}{l}\text { Require } \\
\text { d }\end{array}$ & $\begin{array}{l}\text { Featur } \\
\text { e } \\
\text { Layer }\end{array}$ & StudyArea \\
\hline $\begin{array}{l}\text { Output } \\
\text { Feature } \\
\text { Class }\end{array}$ & Output & $\begin{array}{l}\text { Require } \\
\mathrm{d}\end{array}$ & $\begin{array}{l}\text { Featur } \\
\text { e Class }\end{array}$ & $\begin{array}{l}\text { C:IMyDocs100MIPIDOC_LESA.gdbISoils_C } \\
\text { lip }\end{array}$ \\
\hline $\begin{array}{l}\text { XY } \\
\text { Toleranc } \\
\text { e }\end{array}$ & Input & Optional & $\begin{array}{l}\text { Linear } \\
\text { unit }\end{array}$ & \\
\hline
\end{tabular}

\section{Messages:}

Executing (Clip): Clip Soils_Layer StudyArea

C:MyDocs100MIPIDOC_LESA.gdb|Soils_Clip \#

Start Time: Sun Jul 19 07:42:09 2009

Reading Features...

Cracking Features...

Assembling Features...

Executed (Clip) successfully.

End Time: Sun Jul 19 07:42:12 2009 (Elapsed

Time: 3.00 seconds)

\section{Union}

Tool Name:Union

Tool Source:C:|Program Files\ArcGIS\ArcToolbox\Toolboxes\Analysis

Tools.tbxlOverlaylUnion

Parameters:

\begin{tabular}{|l|l|l|l|l|}
\hline \multicolumn{1}{|c|}{ Name } & $\begin{array}{l}\text { Directi } \\
\text { on }\end{array}$ & Type & $\begin{array}{l}\text { Data } \\
\text { Type }\end{array}$ & \multicolumn{1}{|c|}{ Value } \\
\hline \begin{tabular}{l|l|l|l|} 
Input \\
Features
\end{tabular} & Input & $\begin{array}{l}\text { Requir } \\
\text { ed }\end{array}$ & $\begin{array}{l}\text { Value } \\
\text { Table }\end{array}$ & $\begin{array}{l}\text { StudyArea } \\
\text { \#;C:LyDocs100MIPLDOC_LESA.gdbISoils_ } \\
\text { Clip \# }\end{array}$ \\
\hline $\begin{array}{l}\text { Output } \\
\text { Feature } \\
\text { Class }\end{array}$ & Output & $\begin{array}{l}\text { Requir } \\
\text { ed }\end{array}$ & $\begin{array}{l}\text { Featur } \\
\text { e } \\
\text { Class }\end{array}$ & $\begin{array}{l}\text { C:LMDocs100MIPLDOC_LESA.gdbIStudyA } \\
\text { rea_Union }\end{array}$ \\
\hline $\begin{array}{l}\text { JoinAttribu } \\
\text { tes }\end{array}$ & Input & $\begin{array}{l}\text { Option } \\
\text { al }\end{array}$ & String & ALL \\
\hline $\begin{array}{l}\text { XY } \\
\text { Tolerance }\end{array}$ & Input & $\begin{array}{l}\text { Option } \\
\text { al }\end{array}$ & $\begin{array}{l}\text { Linear } \\
\text { unit }\end{array}$ & \\
\hline Gaps & Input & Option & Boole & true \\
\hline
\end{tabular}




\begin{tabular}{|l|l|l|l|}
\hline Allowed & al & an & \\
\hline
\end{tabular}

Messages:

Executing (Union): Union "StudyArea

\#;C:IMyDocs\00MIP\DOC_LESA.gdb\Soils_Cl

ip \#"

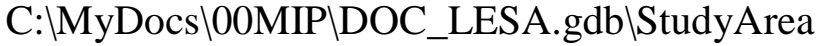

_Union ALL \# GAPS

Start Time: Sun Jul 19 07:42:12 2009

Reading Features...

Cracking Features...

Assembling Features...

Executed (Union) successfully.

End Time: Sun Jul 19 07:42:13 2009 (Elapsed

Time: 1.00 seconds)

\section{Calculate Proportion}

Tool Name:Calculate Field

Tool Source:C:\Program Files\ArcGIS $\backslash A r c T o o l b o x \backslash T o o l b o x e s \backslash D a t a$ Management

Tools.tbx \Fields \CalculateField

Parameters:

\begin{tabular}{|c|c|c|c|c|}
\hline Name & $\begin{array}{c}\text { Directi } \\
\text { on }\end{array}$ & Type & $\begin{array}{l}\text { Data } \\
\text { Type }\end{array}$ & Value \\
\hline $\begin{array}{l}\text { Input } \\
\text { Table }\end{array}$ & Input & $\begin{array}{l}\text { Requir } \\
\text { ed }\end{array}$ & \begin{tabular}{|l|} 
Table \\
View or \\
Raster \\
Layer
\end{tabular} & $\begin{array}{l}\text { C:IMyDocsI00MIPIDOC_LESA.gdbIStudyAr } \\
\text { ea_Union }\end{array}$ \\
\hline $\begin{array}{l}\text { Field } \\
\text { Name }\end{array}$ & Input & $\begin{array}{l}\text { Requir } \\
\text { ed }\end{array}$ & Field & Proportion \\
\hline $\begin{array}{l}\text { Expressi } \\
\text { on }\end{array}$ & Input & $\begin{array}{l}\text { Requir } \\
\text { ed }\end{array}$ & $\begin{array}{l}\text { SQL } \\
\text { Expressi } \\
\text { on }\end{array}$ & [Shape_Area] / [TotalArea] \\
\hline $\begin{array}{l}\text { Expressi } \\
\text { on Type }\end{array}$ & Input & $\begin{array}{l}\text { Option } \\
\text { al }\end{array}$ & String & VB \\
\hline $\begin{array}{l}\text { Code } \\
\text { Block }\end{array}$ & Input & $\begin{array}{l}\text { Option } \\
\text { al }\end{array}$ & String & \\
\hline \begin{tabular}{|l|} 
Output \\
Feature \\
Class
\end{tabular} & Output & $\begin{array}{l}\text { Derive } \\
\text { d }\end{array}$ & \begin{tabular}{|l} 
Table \\
View or \\
Raster \\
Layer
\end{tabular} & $\begin{array}{l}\text { C:LMyDocs100MIPLDOC_LESA.gdb IStudyAr } \\
\text { ea_Union }\end{array}$ \\
\hline
\end{tabular}

Messages: 
Executing (Calculate Proportion): CalculateField

C:IMyDocsI00MIPIDOC_LESA.gdblStudyArea_Union Proportion

"[Shape_Area] / [TotalArea]" VB \#

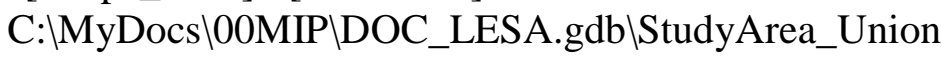

Start Time: Sun Jul 19 07:42:13 2009

Executed (Calculate Proportion) successfully.

End Time: Sun Jul 19 07:42:13 2009 (Elapsed Time: 0.00 seconds)

\section{Calculate UnitAcres}

Tool Name:Calculate Field

Tool Source:C:|Program Files\ArcGIS\ArcToolbox\Toolboxes\Data Management Tools.tbx|Fields\CalculateField

Parameters:

\begin{tabular}{|c|c|c|c|c|}
\hline Name & $\begin{array}{c}\text { Directi } \\
\text { on }\end{array}$ & Type & $\begin{array}{l}\text { Data } \\
\text { Type }\end{array}$ & Value \\
\hline $\begin{array}{l}\text { Input } \\
\text { Table }\end{array}$ & Input & $\begin{array}{l}\text { Requir } \\
\text { ed }\end{array}$ & \begin{tabular}{|l|} 
Table \\
View or \\
Raster \\
Layer
\end{tabular} & 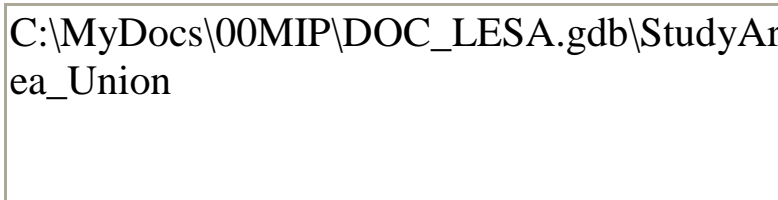 \\
\hline $\begin{array}{l}\text { Field } \\
\text { Name }\end{array}$ & Input & $\begin{array}{l}\text { Requir } \\
\text { ed }\end{array}$ & Field & UnitAcres \\
\hline $\begin{array}{l}\text { Expressi } \\
\text { on }\end{array}$ & Input & $\begin{array}{l}\text { Requir } \\
\text { ed }\end{array}$ & \begin{tabular}{|l} 
SQL \\
Expressi \\
on
\end{tabular} & !shape.area@ acres! \\
\hline $\begin{array}{l}\text { Expressi } \\
\text { on Type }\end{array}$ & Input & $\begin{array}{l}\text { Option } \\
\text { al }\end{array}$ & String & PYTHON_9.3 \\
\hline $\begin{array}{l}\text { Code } \\
\text { Block }\end{array}$ & Input & $\begin{array}{l}\text { Option } \\
\text { al }\end{array}$ & String & \\
\hline $\begin{array}{l}\text { Output } \\
\text { Feature } \\
\text { Class }\end{array}$ & Output & $\begin{array}{l}\text { Derive } \\
\text { d }\end{array}$ & \begin{tabular}{|l|} 
Table \\
View or \\
Raster \\
Layer
\end{tabular} & $\begin{array}{l}\text { C:IMyDocs } 100 M I P\left|D O C \_L E S A . g d b\right| S t u d y A r \\
\text { ea_Union }\end{array}$ \\
\hline
\end{tabular}

\section{Messages:}

Executing (Calculate UnitAcres): CalculateField

C:IMyDocsI00MIPIDOC_LESA.gdbIStudyArea_Union UnitAcres

!shape.area@acres! PYTHON_9.3 \#

C:IMyDocsI00MIPIDOC_LESA.gdb|StudyArea_Union

Start Time: Sun Jul 19 07:42:13 2009

Executed (Calculate UnitAcres) successfully.

End Time: Sun Jul 19 07:42:14 2009 (Elapsed Time: 1.00 seconds) 


\section{Add Field}

Tool Name:Add Field

Tool Source:C:\Program Files\ArcGIS $\backslash A r c T o o l b o x \backslash T o o l b o x e s \backslash D a t a$ Management Tools.tbx\Fields \AddField

Parameters:

\begin{tabular}{|c|c|c|c|c|}
\hline Name & $\begin{array}{c}\text { Directio } \\
n\end{array}$ & Type & $\begin{array}{l}\text { Data } \\
\text { Type }\end{array}$ & Value \\
\hline $\begin{array}{l}\text { Input } \\
\text { Table }\end{array}$ & Input & $\begin{array}{l}\text { Require } \\
\text { d }\end{array}$ & $\begin{array}{l}\text { Table } \\
\text { View } \\
\text { or } \\
\text { Raster } \\
\text { Layer }\end{array}$ & $\begin{array}{l}\text { C:IMyDocs } \backslash 00 M I P \backslash D O C \_L E S A . g d b \backslash S t u d y A r e a \\
\text { _Union }\end{array}$ \\
\hline $\begin{array}{l}\text { Field } \\
\text { Name }\end{array}$ & Input & $\begin{array}{l}\text { Require } \\
\text { d }\end{array}$ & String & Bin \\
\hline $\begin{array}{l}\text { Field } \\
\text { Type }\end{array}$ & Input & $\begin{array}{l}\text { Require } \\
\text { d }\end{array}$ & String & TEXT \\
\hline $\begin{array}{l}\text { Field } \\
\text { Precision }\end{array}$ & Input & $\begin{array}{l}\text { Option } \\
\text { al }\end{array}$ & Long & \\
\hline $\begin{array}{l}\text { Field } \\
\text { Scale }\end{array}$ & Input & $\begin{array}{l}\text { Option } \\
\text { al }\end{array}$ & Long & \\
\hline $\begin{array}{l}\text { Field } \\
\text { Length }\end{array}$ & Input & $\begin{array}{l}\text { Option } \\
\text { al }\end{array}$ & Long & \\
\hline $\begin{array}{l}\text { Field } \\
\text { Alias }\end{array}$ & Input & $\begin{array}{l}\text { Option } \\
\text { al }\end{array}$ & String & \\
\hline $\begin{array}{l}\text { Field } \\
\text { IsNullabl } \\
\text { e }\end{array}$ & Input & $\begin{array}{l}\text { Option } \\
\text { al }\end{array}$ & $\begin{array}{l}\text { Boolea } \\
n\end{array}$ & true \\
\hline $\begin{array}{l}\text { Field } \\
\text { IsRequir } \\
\text { ed }\end{array}$ & Input & $\begin{array}{l}\text { Option } \\
\text { al }\end{array}$ & $\begin{array}{l}\text { Boolea } \\
n\end{array}$ & false \\
\hline $\begin{array}{l}\text { Field } \\
\text { Domain }\end{array}$ & Input & $\begin{array}{l}\text { Option } \\
\text { al }\end{array}$ & String & \\
\hline $\begin{array}{l}\text { Output } \\
\text { Feature } \\
\text { Class }\end{array}$ & Output & $\begin{array}{l}\text { Derive } \\
\mathrm{d}\end{array}$ & $\begin{array}{l}\text { Table } \\
\text { View } \\
\text { or } \\
\text { Raster } \\
\text { Layer }\end{array}$ & $\begin{array}{l}\text { C:IMyDocs } 100 M I P \backslash D O C \_L E S A . g d b \backslash \text { StudyArea } \\
\text { _Union }\end{array}$ \\
\hline
\end{tabular}

Messages:

Executing (Add Field): AddField

C:IMyDocs\00MIP\DOC_LESA.gdb\StudyArea_Union Bin TEXT \# \# \# \# 
NULLABLE NON_REQUIRED \#

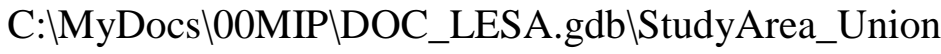

Start Time: Sun Jul 19 07:42:14 2009

Adding Bin to C:MyDocs100MIPIDOC_LESA.gdb\StudyArea_Union...

Executed (Add Field) successfully.

End Time: Sun Jul 19 07:42:14 2009 (Elapsed Time: 0.00 seconds)

\section{Make Feature Layer}

Tool Name:Make Feature Layer

Tool Source:C:Program Files\ArcGIS\ArcToolbox\Toolboxes\Data Management Tools.tbx $\mid$ Layers and Table Views\MakeFeatureLayer

\section{Parameters:}

\begin{tabular}{|c|c|c|c|c|}
\hline Name & $\begin{array}{c}\text { Directi } \\
\text { on }\end{array}$ & Type & $\begin{array}{l}\text { Data } \\
\text { Type }\end{array}$ & Value \\
\hline $\begin{array}{l}\text { Input } \\
\text { Features }\end{array}$ & Input & $\begin{array}{l}\text { Requir } \\
\text { ed }\end{array}$ & $\begin{array}{l}\text { Feature } \\
\text { Layer }\end{array}$ & $\begin{array}{l}\text { C:IMyDocs } 100 M I P \backslash D O C \_L E S A . g d b \mid S t u d y A r \\
\text { ea_Union }\end{array}$ \\
\hline $\begin{array}{l}\text { Output } \\
\text { Layer }\end{array}$ & Output & $\begin{array}{l}\text { Requir } \\
\text { ed }\end{array}$ & $\begin{array}{l}\text { Feature } \\
\text { Layer }\end{array}$ & ProjectSize \\
\hline $\begin{array}{l}\text { Expressi } \\
\text { on }\end{array}$ & Input & $\begin{array}{l}\text { Option } \\
\text { al }\end{array}$ & $\begin{array}{l}\text { SQL } \\
\text { Expressi } \\
\text { on }\end{array}$ & \\
\hline $\begin{array}{l}\text { Workspa } \\
\text { ce or } \\
\text { Feature } \\
\text { Dataset }\end{array}$ & Input & $\begin{array}{l}\text { Option } \\
\text { al }\end{array}$ & $\begin{array}{l}\text { Workspa } \\
\text { ce or } \\
\text { Feature } \\
\text { Dataset }\end{array}$ & \\
\hline $\begin{array}{l}\text { Field } \\
\text { Info }\end{array}$ & Input & $\begin{array}{l}\text { Option } \\
\text { al }\end{array}$ & $\begin{array}{l}\text { Field } \\
\text { Info }\end{array}$ & $\begin{array}{l}\text { FID_StudyArea FID_StudyArea VISIBLE } \\
\text { NONE;Id Id VISIBLE NONE;totalarea } \\
\text { totalarea VISIBLE NONE;Shape_Length } \\
\text { Shape_Length VISIBLE NONE;Shape_Area } \\
\text { Shape_Area VISIBLE NONE;FID_Soils_Clip } \\
\text { FID_Soils_Clip VISIBLE NONE;MUSYM } \\
\text { MUSYM VISIBLE NONE;PSU_soil } \\
\text { PSU_soil VISIBLE NONE;Acres Acres } \\
\text { VISIBLE NONE;LCC_class LCC_class } \\
\text { VISIBLE NONE;LCC_rating LCC_rating } \\
\text { VISIBLE NONE;Storie_Index Storie_Index } \\
\text { VISIBLE NONE;Shape_Length_1 } \\
\text { Shape_Length_1 VISIBLE } \\
\text { NONE;Shape_Area_1 Shape_Area_1 } \\
\text { VISIBLE NONE;Proportion Proportion } \\
\text { VISIBLE NONE;UnitAcres UnitAcres } \\
\text { VISIBLE NONE;LCCScore LCCScore }\end{array}$ \\
\hline
\end{tabular}




\begin{tabular}{|l|l|}
\hline \multicolumn{1}{|l|}{} & VISIBLE NONE;StorieScore StorieScore \\
VISIBLE NONE;Shape_length_12 \\
Shape_length_12 VISIBLE \\
NONE;Shape_area_12 Shape_area_12 \\
VISIBLE NONE;Shape_length Shape_length \\
VISIBLE NONE;Shape_area Shape_area \\
VISIBLE NONE;Bin Bin VISIBLE NONE \\
\hline
\end{tabular}

\section{Messages:}

Executing (Make Feature Layer): MakeFeatureLayer

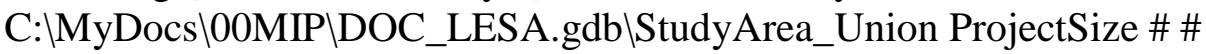
"FID_StudyArea FID_StudyArea VISIBLE NONE;Id Id VISIBLE NONE; totalarea totalarea VISIBLE NONE;Shape_Length Shape_Length VISIBLE NONE;Shape_Area Shape_Area VISIBLE NONE;FID_Soils_Clip FID_Soils_Clip VISIBLE NONE;MUSYM MUSYM VISIBLE NONE;PSU_soil PSU_soil VISIBLE NONE;Acres Acres VISIBLE NONE;LCC_class LCC_class VISIBLE NONE;LCC_rating LCC_rating VISIBLE NONE;Storie_Index Storie_Index VISIBLE NONE;Shape_Length_1 Shape_Length_1 VISIBLE NONE;Shape_Area_1 Shape_Area_1 VISIBLE NONE;Proportion Proportion VISIBLE NONE;UnitAcres UnitAcres VISIBLE NONE;LCCScore LCCScore VISIBLE NONE;StorieScore StorieScore VISIBLE NONE;Shape_length_12 Shape_length_12 VISIBLE NONE;Shape_area_12 Shape_area_12 VISIBLE NONE;Shape_length Shape_length VISIBLE NONE;Shape_area Shape_area VISIBLE NONE;Bin Bin VISIBLE NONE"

Start Time: Sun Jul 19 07:42:14 2009

Executed (Make Feature Layer) successfully.

End Time: Sun Jul 19 07:42:14 2009 (Elapsed Time: 0.00 seconds)

\section{Make Feature Layer PSI}

Tool Name:Make Feature Layer

Tool Source:C:\Program Files\ArcGIS\ArcToolbox\Toolboxes\Data Management Tools.tbx\Layers and Table Views\MakeFeatureLayer

\section{Parameters:}

\begin{tabular}{|l|l|l|l|l|l|}
\hline \multicolumn{1}{|c|}{ Name } & Direction & \multicolumn{1}{c|}{ Type } & Data Type & \multicolumn{1}{c|}{ Value } \\
\hline $\begin{array}{l}\text { Input } \\
\text { Features }\end{array}$ & Input & Required & $\begin{array}{l}\text { Feature } \\
\text { Layer }\end{array}$ & ProjectSize \\
\hline $\begin{array}{l}\text { Output } \\
\text { Layer }\end{array}$ & Output & Required & $\begin{array}{l}\text { Feature } \\
\text { Layer }\end{array}$ & PSI \\
\hline Expression & Input & Optional & $\begin{array}{l}\text { SQL } \\
\text { Expression }\end{array}$ & LCC_rating >=80 \\
\hline Workspace & Input & Optional & Workspace & \\
\hline
\end{tabular}




\begin{tabular}{|c|c|c|c|c|}
\hline $\begin{array}{l}\text { or Feature } \\
\text { Dataset }\end{array}$ & & & $\begin{array}{l}\text { or Feature } \\
\text { Dataset }\end{array}$ & \\
\hline Field Info & Input & Optional & Field Info & $\begin{array}{l}\text { FID_StudyArea FID_StudyArea } \\
\text { VISIBLE NONE;Id Id VISIBLE } \\
\text { NONE;totalarea totalarea VISIBLE } \\
\text { NONE;Shape_Length Shape_Length } \\
\text { VISIBLE NONE;Shape_Area } \\
\text { Shape_Area VISIBLE } \\
\text { NONE;FID_Soils_Clip } \\
\text { FID_Soils_Clip VISIBLE } \\
\text { NONE;MUSYM MUSYM } \\
\text { VISIBLE NONE;PSU_soil } \\
\text { PSU_soil VISIBLE NONE;Acres } \\
\text { Acres VISIBLE NONE;LCC_class } \\
\text { LCC_class VISIBLE } \\
\text { NONE;LCC_rating LCC_rating } \\
\text { VISIBLE NONE;Storie_Index } \\
\text { Storie_Index VISIBLE } \\
\text { NONE;Shape_Length_1 } \\
\text { Shape_Length_1 VISIBLE } \\
\text { NONE;Shape_Area_1 } \\
\text { Shape_Area_1 VISIBLE } \\
\text { NONE;Proportion Proportion } \\
\text { VISIBLE NONE;UnitAcres } \\
\text { UnitAcres VISIBLE } \\
\text { NONE;LCCScore LCCScore } \\
\text { VISIBLE NONE;StorieScore } \\
\text { StorieScore VISIBLE } \\
\text { NONE;Shape_length_12 } \\
\text { Shape_length_12 VISIBLE } \\
\text { NONE;Shape_area_12 } \\
\text { Shape_area_12 VISIBLE } \\
\text { NONE;Shape_Length Shape_Length } \\
\text { VISIBLE NONE;Shape_Area } \\
\text { Shape_Area VISIBLE NONE;Bin } \\
\text { Bin VISIBLE NONE }\end{array}$ \\
\hline
\end{tabular}

\section{Messages:}

Executing (Make Feature Layer PSI): MakeFeatureLayer ProjectSize PSI "LCC_rating >= 80" \# "FID_StudyArea FID_StudyArea VISIBLE NONE;Id Id VISIBLE NONE; totalarea totalarea VISIBLE NONE;Shape_Length Shape_Length VISIBLE NONE;Shape_Area Shape_Area VISIBLE NONE;FID_Soils_Clip FID_Soils_Clip VISIBLE NONE;MUSYM MUSYM VISIBLE NONE;PSU_soil PSU_soil VISIBLE NONE;Acres Acres VISIBLE NONE;LCC_class LCC_class 
VISIBLE NONE;LCC_rating LCC_rating VISIBLE NONE;Storie_Index Storie_Index VISIBLE NONE;Shape_Length_1 Shape_Length_1

VISIBLE NONE;Shape_Area_1 Shape_Area_1 VISIBLE

NONE;Proportion Proportion VISIBLE NONE;UnitAcres UnitAcres

VISIBLE NONE;LCCScore LCCScore VISIBLE NONE;StorieScore

StorieScore VISIBLE NONE;Shape_length_12 Shape_length_12

VISIBLE NONE;Shape_area_12 Shape_area_12 VISIBLE

NONE;Shape_Length Shape_Length VISIBLE NONE;Shape_Area

Shape_Area VISIBLE NONE;Bin Bin VISIBLE NONE"

Start Time: Sun Jul 19 07:42:14 2009

Executed (Make Feature Layer PSI) successfully.

End Time: Sun Jul 19 07:42:14 2009 (Elapsed Time: 0.00 seconds)

\section{Calculate Bin Field I}

Tool Name:Calculate Field

Tool Source:C:\Program Files\ArcGIS\ArcToolbox \Toolboxes\Data Management Tools.tbx \Fields\CalculateField

Parameters:

\begin{tabular}{|l|l|l|l|l||}
\hline \multicolumn{1}{|c|}{ Name } & Direction & \multicolumn{1}{c|}{ Type } & \multicolumn{1}{c|}{ Data Type } & Value \\
\hline Input Table & Input & Required & Table View or Raster Layer & PSI \\
\hline Field Name & Input & Required & Field & Bin \\
\hline Expression & Input & Required & SQL Expression & "I" \\
\hline Expression Type & Input & Optional & String & VB \\
\hline Code Block & Input & Optional & String & \\
\hline Output Feature Class & Output & Derived & Table View or Raster Layer & PSI \\
\hline
\end{tabular}

\section{Messages:}

Executing (Calculate Bin Field I): CalculateField PSI Bin "I" VB \# PSI

Start Time: Sun Jul 19 07:42:14 2009

WARNING 000405: No records within table

Executed (Calculate Bin Field I) successfully.

End Time: Sun Jul 19 07:42:14 2009 (Elapsed Time: 0.00 seconds)

\section{Make Feature Layer PSJ}

Tool Name:Make Feature Layer

Tool Source:C:IProgram Files\ArcGIS\ArcToolbox\Toolboxes\Data Management

Tools.tbx \Layers and Table Views\MakeFeatureLayer

Parameters:

\begin{tabular}{|l|l|l|l|l|l|}
\hline Name & Direction & \multicolumn{1}{|c|}{ Type } & Data Type & & Value \\
\hline Input & Input & Required & Feature & ProjectSize \\
\hline
\end{tabular}




\begin{tabular}{|c|c|c|c|c|}
\hline Features & & & Layer & \\
\hline $\begin{array}{l}\text { Output } \\
\text { Layer }\end{array}$ & Output & Required & $\begin{array}{l}\text { Feature } \\
\text { Layer }\end{array}$ & PSJ \\
\hline Expression & Input & Optional & $\begin{array}{l}\text { SQL } \\
\text { Expression }\end{array}$ & $\begin{array}{l}\text { "LCC_rating" <=70 AND } \\
\text { "LCC_rating" >=60 }\end{array}$ \\
\hline $\begin{array}{l}\text { Workspace } \\
\text { or Feature } \\
\text { Dataset }\end{array}$ & Input & Optional & $\begin{array}{l}\text { Workspace } \\
\text { or Feature } \\
\text { Dataset }\end{array}$ & \\
\hline Field Info & Input & Optional & Field Info & $\begin{array}{l}\text { FID_StudyArea FID_StudyArea } \\
\text { VISIBLE NONE;Id Id VISIBLE } \\
\text { NONE;totalarea totalarea VISIBLE } \\
\text { NONE;Shape_Length Shape_Length } \\
\text { VISIBLE NONE;Shape_Area } \\
\text { Shape_Area VISIBLE } \\
\text { NONE;FID_Soils_Clip } \\
\text { FID_Soils_Clip VISIBLE } \\
\text { NONE;MUSYM MUSYM } \\
\text { VISIBLE NONE;PSU_soil } \\
\text { PSU_soil VISIBLE NONE;Acres } \\
\text { Acres VISIBLE NONE;LCC_class } \\
\text { LCC_class VISIBLE } \\
\text { NONE;LCC_rating LCC_rating } \\
\text { VISIBLE NONE;Storie_Index } \\
\text { Storie_Index VISIBLE } \\
\text { NONE;Shape_Length_1 } \\
\text { Shape_Length_1 VISIBLE } \\
\text { NONE;Shape_Area_1 } \\
\text { Shape_Area_1 VISIBLE } \\
\text { NONE;Proportion Proportion } \\
\text { VISIBLE NONE;UnitAcres } \\
\text { UnitAcres VISIBLE } \\
\text { NONE;LCCScore LCCScore } \\
\text { VISIBLE NONE;StorieScore } \\
\text { StorieScore VISIBLE } \\
\text { NONE;Shape_length_12 } \\
\text { Shape_length_12 VISIBLE } \\
\text { NONE;Shape_area_12 } \\
\text { Shape_area_12 VISIBLE } \\
\text { NONE;Shape_Length Shape_Length } \\
\text { VISIBLE NONE;Shape_Area } \\
\text { Shape_Area VISIBLE NONE;Bin } \\
\text { Bin VISIBLE NONE }\end{array}$ \\
\hline
\end{tabular}

\section{Messages:}


Executing (Make Feature Layer PSJ): MakeFeatureLayer ProjectSize PSJ ""LCC_rating" <=70 AND "LCC_rating" >=60" \# "FID_StudyArea FID_StudyArea VISIBLE NONE;Id Id VISIBLE NONE; totalarea totalarea VISIBLE NONE;Shape_Length Shape_Length VISIBLE NONE;Shape_Area Shape_Area VISIBLE NONE;FID_Soils_Clip FID_Soils_Clip VISIBLE NONE;MUSYM MUSYM VISIBLE NONE;PSU_soil PSU_soil VISIBLE NONE;Acres Acres VISIBLE NONE;LCC_class LCC_class VISIBLE NONE;LCC_rating LCC_rating VISIBLE NONE;Storie_Index Storie_Index VISIBLE NONE;Shape_Length_1 Shape_Length_1 VISIBLE NONE;Shape_Area_1 Shape_Area_1 VISIBLE NONE;Proportion Proportion VISIBLE NONE;UnitAcres UnitAcres VISIBLE NONE;LCCScore LCCScore VISIBLE NONE;StorieScore StorieScore VISIBLE NONE;Shape_length_12 Shape_length_12 VISIBLE NONE;Shape_area_12 Shape_area_12 VISIBLE NONE;Shape_Length Shape_Length VISIBLE NONE;Shape_Area Shape_Area VISIBLE NONE;Bin Bin VISIBLE NONE"

Start Time: Sun Jul 19 07:42:14 2009

Executed (Make Feature Layer PSJ) successfully.

End Time: Sun Jul 19 07:42:14 2009 (Elapsed Time: 0.00 seconds)

\section{Calculate Bin Field J}

Tool Name:Calculate Field

Tool Source:C:\Program Files\ArcGIS $\backslash A r c T o o l b o x \backslash T o o l b o x e s \backslash D a t a$ Management Tools.tbx\Fields\CalculateField

\section{Parameters:}

\begin{tabular}{|l|l|l|l|l||}
\hline \multicolumn{1}{|c|}{ Name } & Direction & \multicolumn{1}{c|}{ Type } & \multicolumn{1}{c|}{ Data Type } & Value \\
\hline Input Table & Input & Required & Table View or Raster Layer & PSJ \\
\hline Field Name & Input & Required & Field & Bin \\
\hline Expression & Input & Required & SQL Expression & "J" \\
\hline Expression Type & Input & Optional & String & VB \\
\hline Code Block & Input & Optional & String & \\
\hline Output Feature Class & Output & Derived & Table View or Raster Layer & PSJ \\
\hline
\end{tabular}

\section{Messages:}

Executing (Calculate Bin Field J): CalculateField PSJ Bin "J" VB \# PSJ

Start Time: Sun Jul 19 07:42:14 2009

Executed (Calculate Bin Field J) successfully.

End Time: Sun Jul 19 07:42:14 2009 (Elapsed Time: 0.00 seconds)

\section{Make Feature Layer PSK}


Tool Name:Make Feature Layer

Tool Source:C:IProgram Files\ArcGIS\ArcToolbox \Toolboxes\Data Management

Tools.tbx \Layers and Table Views\MakeFeatureLayer

Parameters:

\begin{tabular}{|c|c|c|c|c|}
\hline Name & Direction & Type & Data Type & Value \\
\hline \begin{tabular}{|l|} 
Input \\
Features
\end{tabular} & Input & Required & $\begin{array}{l}\text { Feature } \\
\text { Layer }\end{array}$ & ProjectSize \\
\hline $\begin{array}{l}\text { Output } \\
\text { Layer }\end{array}$ & Output & Required & $\begin{array}{l}\text { Feature } \\
\text { Layer }\end{array}$ & PSK \\
\hline Expression & Input & Optional & $\begin{array}{l}\text { SQL } \\
\text { Expression }\end{array}$ & $\begin{array}{l}\text { "LCC_rating" }<=50 \text { AND } \\
\text { "LCC_rating" > }=10\end{array}$ \\
\hline $\begin{array}{l}\text { Workspace } \\
\text { or Feature } \\
\text { Dataset }\end{array}$ & Input & Optional & $\begin{array}{l}\text { Workspace } \\
\text { or Feature } \\
\text { Dataset }\end{array}$ & \\
\hline Field Info & Input & Optional & Field Info & $\begin{array}{l}\text { FID_StudyArea FID_StudyArea } \\
\text { VISIBLE NONE;Id Id VISIBLE } \\
\text { NONE;totalarea totalarea VISIBLE } \\
\text { NONE;Shape_Length Shape_Length } \\
\text { VISIBLE NONE;Shape_Area } \\
\text { Shape_Area VISIBLE } \\
\text { NONE;FID_Soils_Clip } \\
\text { FID_Soils_Clip VISIBLE } \\
\text { NONE;MUSYM MUSYM } \\
\text { VISIBLE NONE;PSU_soil } \\
\text { PSU_soil VISIBLE NONE;Acres } \\
\text { Acres VISIBLE NONE;LCC_class } \\
\text { LCC_class VISIBLE } \\
\text { NONE;LCC_rating LCC_rating } \\
\text { VISIBLE NONE;Storie_Index } \\
\text { Storie_Index VISIBLE } \\
\text { NONE;Shape_Length_1 } \\
\text { Shape_Length_1 VISIBLE } \\
\text { NONE;Shape_Area_1 } \\
\text { Shape_Area_1 VISIBLE } \\
\text { NONE;Proportion Proportion } \\
\text { VISIBLE NONE;UnitAcres } \\
\text { UnitAcres VISIBLE } \\
\text { NONE;LCCScore LCCScore } \\
\text { VISIBLE NONE;StorieScore } \\
\text { StorieScore VISIBLE } \\
\text { NONE;Shape_length_12 } \\
\text { Shape_length_12 VISIBLE } \\
\text { NONE;Shape_area_12 }\end{array}$ \\
\hline
\end{tabular}




\begin{tabular}{|l|l|l|}
\hline \multicolumn{1}{|l|}{} & $\begin{array}{l}\text { Shape_area_12 VISIBLE } \\
\text { NONE;Shape_Length Shape_Length } \\
\text { VISIBLE NONE;Shape_Area } \\
\text { Shape_Area VISIBLE NONE;Bin } \\
\text { Bin VISIBLE NONE }\end{array}$ \\
\hline
\end{tabular}

\section{Messages:}

Executing (Make Feature Layer PSK): MakeFeatureLayer ProjectSize PSK "'LCC_rating" <=50 AND "LCC_rating" >=10" \# "FID_StudyArea FID_StudyArea VISIBLE NONE;Id Id VISIBLE NONE;totalarea totalarea VISIBLE NONE;Shape_Length Shape_Length VISIBLE NONE;Shape_Area Shape_Area VISIBLE NONE;FID_Soils_Clip FID_Soils_Clip VISIBLE NONE;MUSYM MUSYM VISIBLE NONE;PSU_soil PSU_soil VISIBLE NONE;Acres Acres VISIBLE NONE;LCC_class LCC_class VISIBLE NONE;LCC_rating LCC_rating VISIBLE NONE;Storie_Index Storie_Index VISIBLE NONE;Shape_Length_1 Shape_Length_1 VISIBLE NONE;Shape_Area_1 Shape_Area_1 VISIBLE NONE;Proportion Proportion VISIBLE NONE;UnitAcres UnitAcres VISIBLE NONE;LCCScore LCCScore VISIBLE NONE;StorieScore StorieScore VISIBLE NONE;Shape_length_12 Shape_length_12 VISIBLE NONE;Shape_area_12 Shape_area_12 VISIBLE NONE;Shape_Length Shape_Length VISIBLE NONE;Shape_Area Shape_Area VISIBLE NONE;Bin Bin VISIBLE NONE"

Start Time: Sun Jul 19 07:42:14 2009

Executed (Make Feature Layer PSK) successfully.

End Time: Sun Jul 19 07:42:15 2009 (Elapsed Time: 1.00 seconds)

\section{Calculate Field K}

Tool Name:Calculate Field

Tool Source:C:\Program Files\ArcGIS $\backslash A r c T o o l b o x \backslash T o o l b o x e s \backslash D a t a$ Management Tools.tbx \Fields\CalculateField

\section{Parameters:}

\begin{tabular}{|l|l|l|l|l|}
\hline \multicolumn{1}{|c|}{ Name } & Direction & \multicolumn{1}{c|}{ Type } & \multicolumn{1}{c|}{ Data Type } & Value \\
\hline Input Table & Input & Required & Table View or Raster Layer & PSK \\
\hline Field Name & Input & Required & Field & Bin \\
\hline Expression & Input & Required & SQL Expression & S"K" \\
\hline Expression Type & Input & Optional & String & VB \\
\hline Code Block & Input & Optional & String & \\
\hline Output Feature Class & Output & Derived & Table View or Raster Layer & PSK \\
\hline
\end{tabular}

\section{Messages:}


Executing (Calculate Field K): CalculateField PSK Bin "K" VB \# PSK

Start Time: Sun Jul 19 07:42:15 2009

Executed (Calculate Field K) successfully.

End Time: Sun Jul 19 07:42:15 2009 (Elapsed Time: 0.00 seconds)

\section{Summary Statistics (4)}

Tool Name:Summary Statistics

Tool Source:C:|Program Files\ArcGIS\ArcToolbox\Toolboxes\Analysis

Tools.tbxlStatistics|Statistics

Parameters:

\begin{tabular}{|c|c|c|c|c|}
\hline Name & $\begin{array}{c}\text { Directio } \\
n\end{array}$ & Type & $\begin{array}{l}\text { Data } \\
\text { Type }\end{array}$ & Value \\
\hline $\begin{array}{l}\text { Input } \\
\text { Table }\end{array}$ & Input & $\begin{array}{l}\text { Require } \\
\text { d }\end{array}$ & $\begin{array}{l}\text { Table } \\
\text { View } \\
\text { or } \\
\text { Raster } \\
\text { Layer }\end{array}$ & ProjectSize \\
\hline $\begin{array}{l}\text { Output } \\
\text { Table }\end{array}$ & Output & $\begin{array}{l}\text { Require } \\
\text { d }\end{array}$ & Table & $\begin{array}{l}\text { C:LMyDocs } 100 \text { MIPIDOC_LESA.gdb } \backslash \text { OutStatsT } \\
\text { able }\end{array}$ \\
\hline $\begin{array}{l}\text { Statistic } \\
\text { s } \\
\text { Field(s) }\end{array}$ & Input & $\begin{array}{l}\text { Require } \\
\text { d }\end{array}$ & $\begin{array}{l}\text { Value } \\
\text { Table }\end{array}$ & UnitAcres SUM \\
\hline $\begin{array}{l}\text { Case } \\
\text { field }\end{array}$ & Input & $\begin{array}{l}\text { Optiona } \\
1\end{array}$ & $\begin{array}{l}\text { Multipl } \\
\text { e Value }\end{array}$ & Bin \\
\hline
\end{tabular}

\section{Messages:}

Executing (Summary Statistics (4)): Statistics ProjectSize

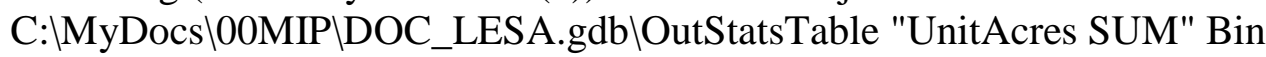

Start Time: Sun Jul 19 07:42:15 2009

Executed (Summary Statistics (4)) successfully.

End Time: Sun Jul 19 07:42:15 2009 (Elapsed Time: 0.00 seconds)

\section{Add Fields Project Size}

Tool Name:Add FieldsPS

Tool Source:C:LMyDocs100MIPIToolSharelLESA Tools.tbx\AddFieldsPrjSz

\section{Parameters:}

\begin{tabular}{|l|c|c|l|l|}
\hline Name & $\begin{array}{c}\text { Directio } \\
n\end{array}$ & Type & $\begin{array}{l}\text { Data } \\
\text { Type }\end{array}$ & \multicolumn{1}{|c|}{ Value } \\
\hline \begin{tabular}{l|l|l|l|} 
Input \\
Layer
\end{tabular} & Input & $\begin{array}{l}\text { Require } \\
\text { d }\end{array}$ & $\begin{array}{l}\text { Tabl } \\
\text { e } \\
\text { View }\end{array}$ & C:LyDocs lo0MIPLDOC_LESA.gdblOutStatsTab \\
\hline
\end{tabular}




\begin{tabular}{|c|c|c|c|c|}
\hline $\begin{array}{l}\text { Outpu } \\
\text { t } \\
\text { Layer }\end{array}$ & Output & Derived & $\begin{array}{l}\text { Tabl } \\
\text { e } \\
\text { View }\end{array}$ & $\begin{array}{l}\text { C:IMyDocs\00MIP\DOC_LESA.gdb\OutStatsTab } \\
\text { le }\end{array}$ \\
\hline
\end{tabular}

\section{Messages:}

Executing (Add Fields Project Size): AddFieldsPrjSz

C:MyDocs $100 M I P \backslash D O C \_L E S A . g d b \backslash O u t S t a t s T a b l e$

C:IMyDocs $100 M I P \backslash D O C \_L E S A . g d b \backslash O u t S t a t s T a b l e$

Start Time: Sun Jul 19 07:42:16 2009

Running script AddFieldsPrjSz...

Input layer: C:IMyDocsI00MIP|DOC_LESA.gdb\OutStatsTable

Added field PSscore.

Added field FactorPS.

Added field WeightPS.

Completed script AddFieldsPrjSz...

Executed (Add Fields Project Size) successfully.

End Time: Sun Jul 19 07:42:17 2009 (Elapsed Time: 1.00 seconds)

\section{Make Table View}

Tool Name:Make Table View

Tool Source:C:|Program Files\ArcGIS\ArcToolbox|Toolboxes\Data Management Tools.tbx Layers and Table Views\MakeTableView

Parameters:

\begin{tabular}{|l|l|l|l|l|}
\hline \multicolumn{1}{|c|}{ Name } & $\begin{array}{l}\text { Directio } \\
\boldsymbol{n}\end{array}$ & \multicolumn{1}{|c|}{ Type } & $\begin{array}{l}\text { Data } \\
\text { Type }\end{array}$ & \multicolumn{1}{|c|}{ Value } \\
\hline \begin{tabular}{l|l|l|l|} 
Input \\
Table
\end{tabular} & Input & $\begin{array}{l}\text { Require } \\
\text { d }\end{array}$ & $\begin{array}{l}\text { Table } \\
\text { View or } \\
\text { Raster } \\
\text { Layer }\end{array}$ & $\begin{array}{l}\text { C:IMyDocsIOOMIPIDOC_LESA.gdb\OutStat } \\
\text { sTable }\end{array}$ \\
\hline $\begin{array}{l}\text { Table } \\
\text { Name }\end{array}$ & Output & $\begin{array}{l}\text { Require } \\
\text { d }\end{array}$ & $\begin{array}{l}\text { Table } \\
\text { View or } \\
\text { Raster } \\
\text { Layer }\end{array}$ & OutStatsTable_View \\
\hline $\begin{array}{l}\text { Expressio } \\
\text { n }\end{array}$ & Input & $\begin{array}{l}\text { Option } \\
\text { al }\end{array}$ & $\begin{array}{l}\text { SQL } \\
\text { Expressi } \\
\text { on }\end{array}$ & NOT "Bin" IS null \\
\hline $\begin{array}{l}\text { Output } \\
\text { Workspa } \\
\text { ce }\end{array}$ & Input & $\begin{array}{l}\text { Option } \\
\text { al }\end{array}$ & $\begin{array}{l}\text { Workspa } \\
\text { ce }\end{array}$ & \\
\hline Field Info & Input & Option & Field & Bin Bin VISIBLE NONE;FREQUENCY \\
\hline
\end{tabular}




\begin{tabular}{|l|l|l|}
\hline al Info & $\begin{array}{l}\text { FREQUENCY VISIBLE } \\
\text { NONE;SUM_UnitAcres SUM_UnitAcres } \\
\text { VISIBLE NONE }\end{array}$ \\
\hline
\end{tabular}

\section{Messages:}

Executing (Make Table View): MakeTableView

C:\MyDocs $100 M I P \backslash D O C \_L E S A . g d b \backslash O u t S t a t s T a b l e$ OutStatsTable_View

"NOT "Bin" IS null" \# "Bin Bin VISIBLE NONE;FREQUENCY

FREQUENCY VISIBLE NONE;SUM_UnitAcres SUM_UnitAcres

VISIBLE NONE"

Start Time: Sun Jul 19 07:42:18 2009

Executed (Make Table View) successfully.

End Time: Sun Jul 19 07:42:18 2009 (Elapsed Time: 0.00 seconds)

\section{Calculate PS Scores for I, J, K}

Tool Name:Calculate Field

Tool Source:C:IProgram Files\ArcGIS\ArcToolbox\Toolboxes\Data Management Tools.tbx\Fields\CalculateField

\section{Parameters:}

\begin{tabular}{|c|c|c|c|c|}
\hline Name & Direction & Type & Data Type & Value \\
\hline $\begin{array}{l}\text { Input } \\
\text { Table }\end{array}$ & Input & Required & $\begin{array}{l}\text { Table } \\
\text { View or } \\
\text { Raster } \\
\text { Layer }\end{array}$ & OutStatsTable_View \\
\hline $\begin{array}{l}\text { Field } \\
\text { Name }\end{array}$ & Input & Required & Field & PSscore \\
\hline Expression & Input & Required & $\begin{array}{l}\text { SQL } \\
\text { Expression }\end{array}$ & $\begin{array}{l}\text { getscore(float(!SUM_UnitAcres!), } \\
\text { !Bin!) }\end{array}$ \\
\hline $\begin{array}{l}\text { Expression } \\
\text { Type }\end{array}$ & Input & Optional & String & PYTHON_9.3 \\
\hline $\begin{array}{l}\text { Code } \\
\text { Block }\end{array}$ & Input & Optional & String & 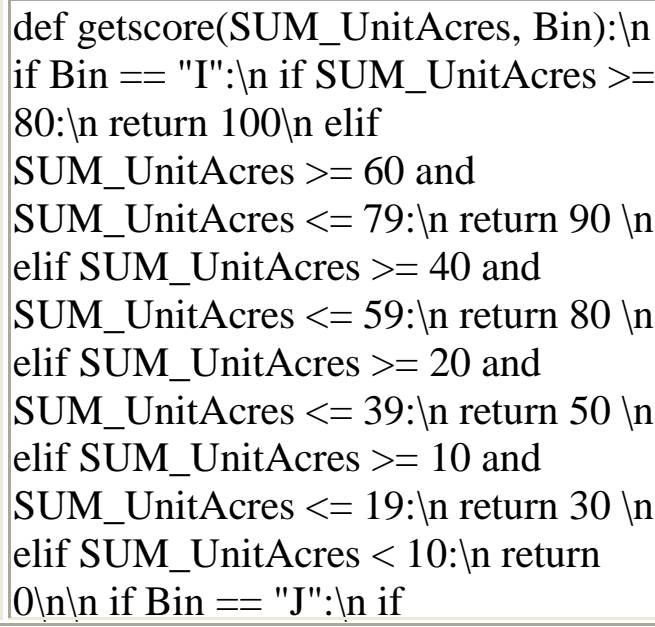 \\
\hline
\end{tabular}




\begin{tabular}{|c|c|c|c|c|}
\hline & & & & 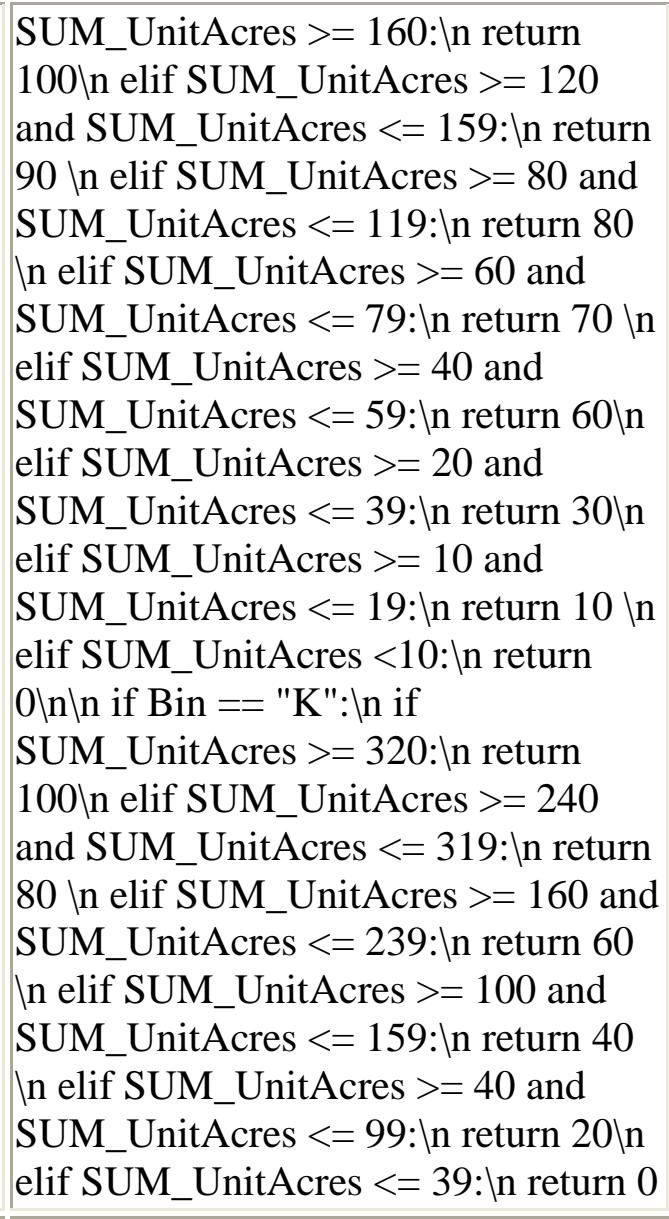 \\
\hline $\begin{array}{l}\text { Output } \\
\text { Feature } \\
\text { Class }\end{array}$ & Output & Derived & $\begin{array}{l}\text { Table } \\
\text { View or } \\
\text { Raster } \\
\text { Layer }\end{array}$ & OutStatsTable_View \\
\hline
\end{tabular}

\section{Messages:}

Executing (Calculate PS Scores for I, J, K): CalculateField

OutStatsTable_View PSscore getscore(float(!SUM_UnitAcres!), !Bin!)

PYTHON_9.3 "def getscore(SUM_UnitAcres, Bin): In if Bin == "I": In if

SUM_UnitAcres $>=80:$ :n return 100 \n elif SUM_UnitAcres $>=60$ and

SUM_UnitAcres $<=79:$ : n return 90 nn elif SUM_UnitAcres $>=40$ and

SUM_UnitAcres $<=59: \ln$ return $80 \backslash$ n elif SUM_UnitAcres $>=20$ and

SUM_UnitAcres $<=39:$ : return $50 \backslash$ n elif SUM_UnitAcres $>=10$ and

SUM_UnitAcres <= 19: In return 30 \n elif SUM_UnitAcres $<10:$ In

return $0 \backslash \mathrm{ln} \backslash \mathrm{n}$ if Bin == "J": $\ln$ if SUM_UnitAcres $>=160: \ln$ return 100 \n

elif SUM_UnitAcres $>=120$ and SUM_UnitAcres $<=159$ : In return $90 \backslash \mathrm{n}$

elif SUM_UnitAcres $>=80$ and SUM_UnitAcres $<=119$ : In return $80 \backslash \mathrm{n}$

elif SUM_UnitAcres $>=60$ and SUM_UnitAcres $<=79: \ln$ return $70 \mathrm{ln}$ elif SUM_UnitAcres $>=40$ and SUM_UnitAcres $<=59: \ln$ return 60 $\backslash \mathrm{n}$ elif

SUM_UnitAcres $>=20$ and SUM_UnitAcres $<=39:$ In return 30 ln elif 
SUM_UnitAcres >= 10 and SUM_UnitAcres <= 19: In return $10 \backslash n$ elif SUM_UnitAcres <10: In return 0 $\ln \backslash n$ if Bin == "K": In if SUM_UnitAcres $>=320:$ :n return 100 \n elif SUM_UnitAcres $>=240$ and SUM_UnitAcres

$<=319:$ :n return $80 \backslash \mathrm{n}$ elif SUM_UnitAcres $>=160$ and SUM_UnitAcres

$<=239:$ In return $60 \backslash$ n elif SUM_UnitAcres $>=100$ and SUM_UnitAcres

$<=159:$ :n return $40 \backslash$ n elif SUM_UnitAcres $>=40$ and SUM_UnitAcres

$<=99:$ In return 20\n elif SUM_UnitAcres $<=39$ : In return 0"

OutStatsTable_View

Start Time: Sun Jul 19 07:42:18 2009

Executed (Calculate PS Scores for I, J, K) successfully.

End Time: Sun Jul 19 07:42:18 2009 (Elapsed Time: 0.00 seconds)

\section{Export Highest Score}

Tool Name:Export Highest Score

Tool Source:C:IMyDocs\00MIP\ToolSharelLESA Tools.tbx\ExportHighest

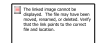

Parameters:

\begin{tabular}{|c|c|c|c|c|}
\hline Name & $\begin{array}{c}\text { Directio } \\
n\end{array}$ & Type & $\begin{array}{l}\text { Data } \\
\text { Type }\end{array}$ & Value \\
\hline $\begin{array}{l}\text { Input } \\
\text { Table }\end{array}$ & Input & $\begin{array}{l}\text { Require } \\
\text { d }\end{array}$ & \begin{tabular}{|l} 
Tabl \\
e \\
Vie \\
w
\end{tabular} & OutStatsTable_View \\
\hline $\begin{array}{l}\text { Field to } \\
\text { Compar } \\
\text { e }\end{array}$ & Input & $\begin{array}{l}\text { Require } \\
\text { d }\end{array}$ & Field & PSscore \\
\hline $\begin{array}{l}\text { Output } \\
\text { Table }\end{array}$ & Output & $\begin{array}{l}\text { Require } \\
\text { d }\end{array}$ & $\begin{array}{l}\text { Tabl } \\
\text { e }\end{array}$ & $\begin{array}{l}\text { C:MyDocs } \backslash \text { MOMIP\DOC_LESA.gdb\HighestPSF } \\
\text { actor }\end{array}$ \\
\hline
\end{tabular}

\section{Messages:}

Executing (Export Highest Score): ExportHighest OutStatsTable_View

PSscore C:IMyDocs \00MIP\DOC_LESA.gdb\HighestPSFactor

Start Time: Sun Jul 19 07:42:18 2009

Running script ExportHighest...

The highest score is 100

Operation complete

Completed script ExportHighest...

Executed (Export Highest Score) successfully.

End Time: Sun Jul 19 07:42:20 2009 (Elapsed Time: 2.00 seconds)

\section{Calculate Field}


Tool Name:Calculate Field

Tool Source:C: Program Files\ArcGIS\ArcToolbox\Toolboxes\Data Management Tools.tbx \Fields\CalculateField

Parameters:

\begin{tabular}{|c|c|c|c|c|}
\hline Name & $\begin{array}{c}\text { Directi } \\
\text { on }\end{array}$ & Type & $\begin{array}{l}\text { Data } \\
\text { Type }\end{array}$ & Value \\
\hline $\begin{array}{l}\text { Input } \\
\text { Table }\end{array}$ & Input & $\begin{array}{l}\text { Requir } \\
\text { ed }\end{array}$ & $\begin{array}{l}\text { Table } \\
\text { View or } \\
\text { Raster } \\
\text { Layer }\end{array}$ & 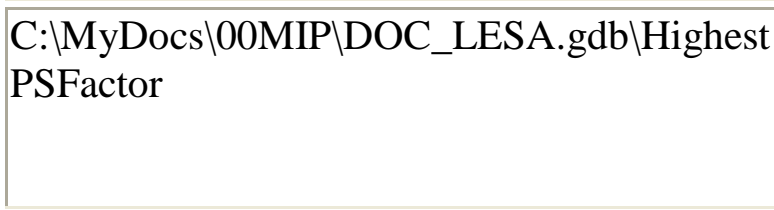 \\
\hline $\begin{array}{l}\text { Field } \\
\text { Name }\end{array}$ & Input & $\begin{array}{l}\text { Requir } \\
\text { ed }\end{array}$ & Field & FactorPS \\
\hline $\begin{array}{l}\text { Expressi } \\
\text { on }\end{array}$ & Input & $\begin{array}{l}\text { Requir } \\
\text { ed }\end{array}$ & $\begin{array}{l}\text { SQL } \\
\text { Expressi } \\
\text { on }\end{array}$ & [PSscore] \\
\hline $\begin{array}{l}\text { Expressi } \\
\text { on Type }\end{array}$ & Input & $\begin{array}{l}\text { Option } \\
\text { al }\end{array}$ & String & VB \\
\hline $\begin{array}{l}\text { Code } \\
\text { Block }\end{array}$ & Input & $\begin{array}{l}\text { Option } \\
\text { al }\end{array}$ & String & \\
\hline $\begin{array}{l}\text { Output } \\
\text { Feature } \\
\text { Class }\end{array}$ & Output & $\begin{array}{l}\text { Derive } \\
\mathrm{d}\end{array}$ & $\begin{array}{l}\text { Table } \\
\text { View or } \\
\text { Raster } \\
\text { Layer }\end{array}$ & $\begin{array}{l}\text { C:MyyDocs } \backslash 00 M I P \backslash D O C \_L E S A . g d b \backslash \text { Highest } \\
\text { PSFactor }\end{array}$ \\
\hline
\end{tabular}

\section{Messages:}

Executing (Calculate Field): CalculateField

C:IMyDocs $\backslash 00 M I P \backslash D O C \_L E S A . g d b \backslash H i g h e s t P S F a c t o r$ FactorPS [PSscore]

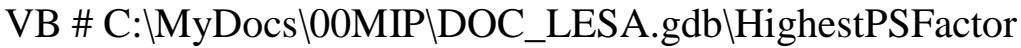

Start Time: Sun Jul 19 07:42:20 2009

Executed (Calculate Field) successfully.

End Time: Sun Jul 19 07:42:20 2009 (Elapsed Time: 0.00 seconds)

\section{Calculate Weight PS Field}

Tool Name:Calculate Field

Tool Source:C: Program Files $\backslash A r c G I S \backslash A r c T o o l b o x \backslash T o o l b o x e s \backslash D a t a$ Management Tools.tbx \Fields\CalculateField

Parameters:

\begin{tabular}{|l|l|l|l|l||}
\hline \multicolumn{1}{|c|}{ Name } & $\begin{array}{c}\text { Directi } \\
\text { on }\end{array}$ & Type & $\begin{array}{c}\text { Data } \\
\text { Type }\end{array}$ & \multicolumn{1}{|c|}{ Value } \\
\hline \begin{tabular}{l|l|l|l} 
Input \\
Table
\end{tabular} & Input & $\begin{array}{l}\text { Requir } \\
\text { ed }\end{array}$ & $\begin{array}{l}\text { Table } \\
\text { View or }\end{array}$ & $\begin{array}{l}\text { C:MyDocs } \\
\text { PSFactor }\end{array}$ \\
\hline
\end{tabular}




\begin{tabular}{|l|l|l|l|l|l|}
\hline & & & $\begin{array}{l}\text { Raster } \\
\text { Layer }\end{array}$ & \\
\hline $\begin{array}{l}\text { Field } \\
\text { Name }\end{array}$ & Input & $\begin{array}{l}\text { Requir } \\
\text { ed }\end{array}$ & Field & WeightPS \\
\hline $\begin{array}{l}\text { Expressi } \\
\text { on }\end{array}$ & Input & $\begin{array}{l}\text { Requir } \\
\text { ed }\end{array}$ & $\begin{array}{l}\text { SQL } \\
\text { Expressi } \\
\text { on }\end{array}$ & [FactorPS] $* 0.15$ \\
\hline $\begin{array}{l}\text { Expressi } \\
\text { on Type }\end{array}$ & Input & $\begin{array}{l}\text { Option } \\
\text { al }\end{array}$ & String & VB \\
\hline $\begin{array}{l}\text { Code } \\
\text { Block }\end{array}$ & Input & $\begin{array}{l}\text { Option } \\
\text { al }\end{array}$ & String & \\
\hline $\begin{array}{l}\text { Output } \\
\text { Feature } \\
\text { Class }\end{array}$ & Output & $\begin{array}{l}\text { Derive } \\
\text { d }\end{array}$ & $\begin{array}{l}\text { Table } \\
\text { View or } \\
\text { Raster } \\
\text { Layer }\end{array}$ & $\begin{array}{l}\text { C:LMyDocs } \\
\text { PSFactor }\end{array}$ \\
\hline
\end{tabular}

\section{Messages:}

Executing (Calculate Weight PS Field): CalculateField C:IMyDocs $\backslash 00 M I P \backslash D O C \_L E S A . g d b \backslash$ HighestPSFactor WeightPS

"[FactorPS] *0.15" VB \#

C:MyDocs\00MIP\DOC_LESA.gdb\HighestPSFactor

Start Time: Sun Jul 19 07:42:20 2009

Executed (Calculate Weight PS Field) successfully.

End Time: Sun Jul 19 07:42:20 2009 (Elapsed Time: 0.00 seconds) 


\section{Appendix K - Manual Methodology}

The manual workflow for preparing the LESA model consisted of the following steps:

To score the LCC and Storie Index factors, launch the NRCS web soil survey, delineate the study area and view the results for LCC and Storie Index. Record the results in Table 1A of the instruction manual. Calculate the LCC and Storie totals (Columns $\mathrm{F}$ and $\mathrm{H}$ of Table 1A) and record results in Line 1 and 2 of Table 8, Final LESA Worksheet.

To score the Project Size factor, refer back to Table 1A and transfer the acres of each soil unit based on its LCC rating to column (bin) I, J, or K of Table 1B. Sum each column and determine the score for each column based on the criteria in Table 3. Compare the three candidate scores and select the single highest score. Record the highest single score in Table $1 \mathrm{~B}$ and Line 3 of the Table 8.

To score the Water Availability Factor launch ArcMap and delineate the study area. Use the study area to clip the water layer. Use the total area of the study area and the total area of the clipped water layer to calculate the proportion of water infrastructure present and record in column $\mathrm{C}$ of Table 4 . Record the proportion in Line 4 of Table 8.

To score the Surrounding Agricultural Lands factor draw a bounding box around the study area and buffer the study area by .25 miles. Clip the FMMP land use layer to the buffered bounding box. Select agricultural land uses from the FMMP layer and calculate the percent of agricultural lands. Refer to Table 6 to determine the score for the percentage and record in Line 5 of Table 8. To score the Surrounding Protected Lands repeat the procedure above using the protected layer. Record the results in Line 6 of Table 8.

The final overall score for the property is calculated by weighing each factor score, summing the weighted scores, and recording the result in Line 7 of the Table 8 . Line 7 is the overall weighted score for the property. 


\section{Appendix L - Instruction Manual}

\section{GIS-Enabled LESA Model Instructions}

Introduction: The GIS enabled LESA model is a prototype project to automate the workflow Of the California Agricultural Land Evaluation and Site Assessment Model. It was prepared on behalf of other California Department of Conservation, Division of Land Resource Protection, Farmland Mapping and Monitoring Program (FMMP).

This application requires an ESRI ArcInfo license to operate. This is the application should be copied to a read/write workspace prior modeling. The following directions were prepared for running the project from the $\mathrm{C}$ : drive.

Note: An animated demonstration is provided on the project disc.

\section{Contents}

Step 1-Open LESA Model Project......................................................................................... 113

Step 2-Define the study area by editing new feature ............................................... 113

Step 2a-Define the study area by importing a pre-existing feature .............................. 114

Step 3-Run the complete model from the Open Model dialog box .............................. 114

Step 3a-Run the complete model from the Edit Model window. ................................. 114

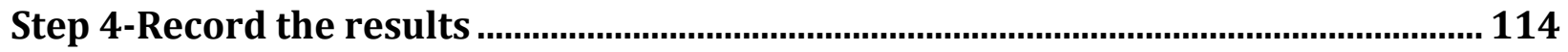

Step 5-Create a ModelBuilder model report..................................................................... 115

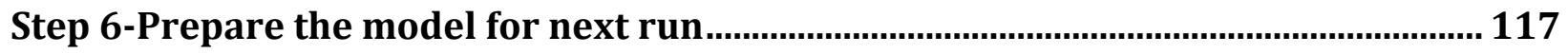


Step 1-Open LESA Model Project

Copy project workspace to the C: drive

\begin{tabular}{|c|c|c|}
\hline Address $\square$ C: $\backslash 0$ LESA Project Workspace & & \\
\hline Folders & $x$ & Name - \\
\hline $\begin{array}{l}{[3 \text { Desktop }} \\
\square \text { My Documents } \\
\square 0 \text { Local Disk (C:) } \\
0 \text { LESA Project Workspace } \\
\square \text { Python Scripts } \\
\square \text { ToolShare }\end{array}$ & $\hat{\Lambda}$ & $\begin{array}{l}\square \text { LESA File Geodatabase.gdb } \\
\text { P Python Scripts } \\
\text { ToolShare } \\
\text { (wiw)LESA Project Report.docx } \\
\text { ArcGISDiagrammer.zip } \\
\text { alESA Model.mxd }\end{array}$ \\
\hline
\end{tabular}

Launch ArcInfo ArcMap, browse to the project workspace, and select the LESA model .mxd to open project.

Step 2-Define the study area by editing new feature

The study area for each model run must be defined prior to running the model.

To begin an edit session, select Editor>Start Editing, and select the LESA file geodatabase, and to set the target layer to study area.

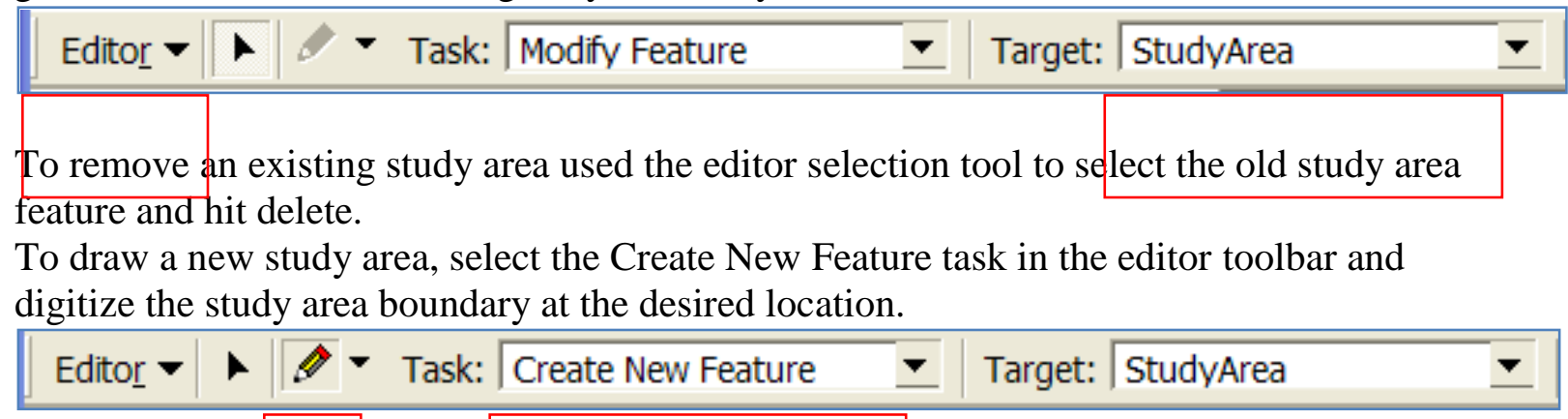

To save the study area, select Editor> Save Edits, then Editor>Stop Editing 
Step 2a-Define the study area by importing a pre-existing feature

Access the Open Model dialog box (step 3). Use the browse button to navigate to the data layer representing the study area and select. This will replace the default study area layer for a single run.

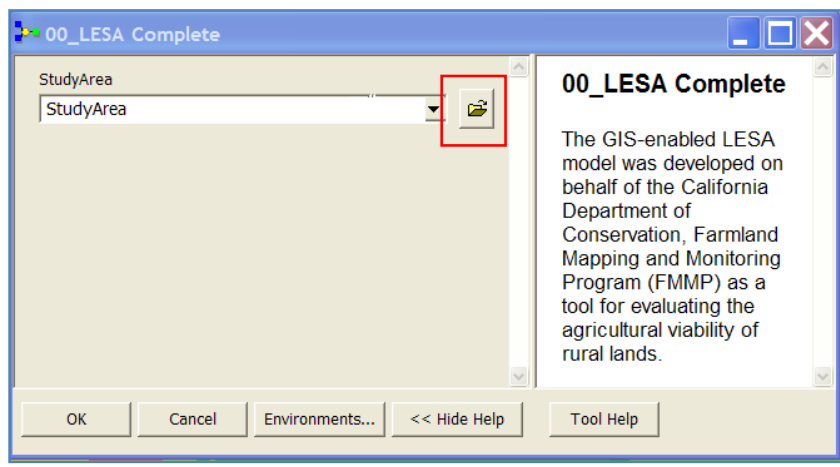

Step 3-Run the complete model from the Open Model dialog box

Select Complete LESA model from the LESA Tools toolbox. Right click and select Open to access the Open Model dialog box. Select Ok to run the model. Close the progress window when the model is complete.

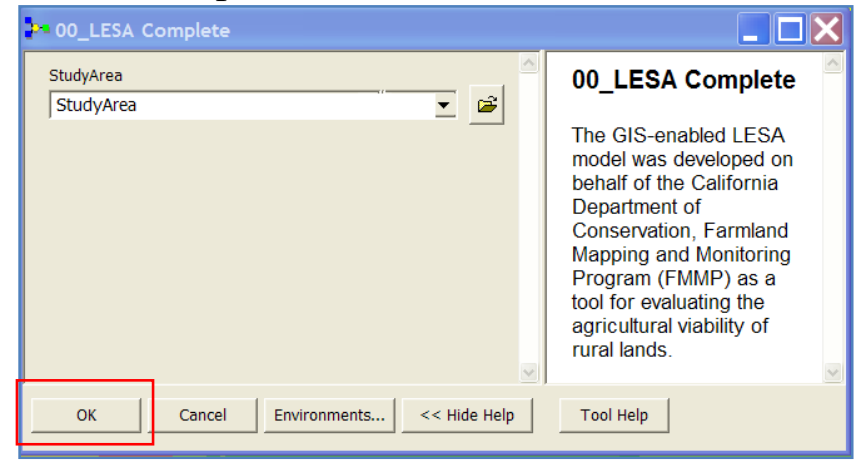

Step 3a-Run the complete model from the Edit Model window.

Select Complete LESA model from the LESA Tools Toolbox. Right click and select Edit to open the Edit Model window. Select Model>Run Entire Model to run the model or select the Run button. Close the progress window when the model is complete.

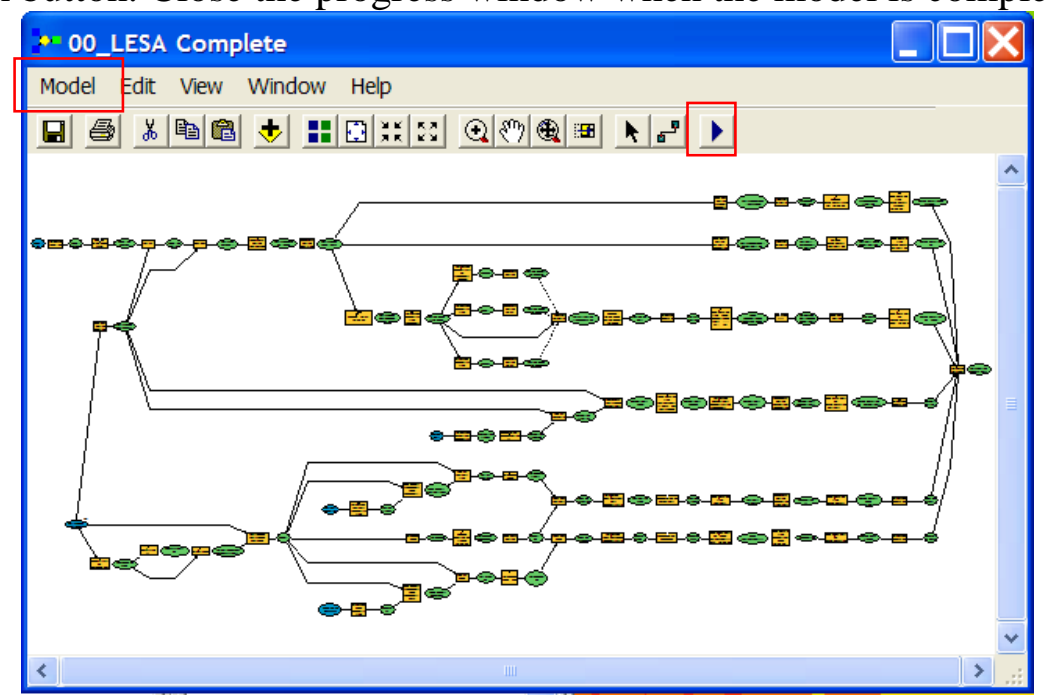

Step 4-Record the results 
Select the Source tab at the bottom of the ArcMap table of contents to display tables. Right click on the QueryTable1 table and select open to view contents. Record the contents of the bottom row of the table in the corresponding cell in Table 8 of the 1997 instruction manual.

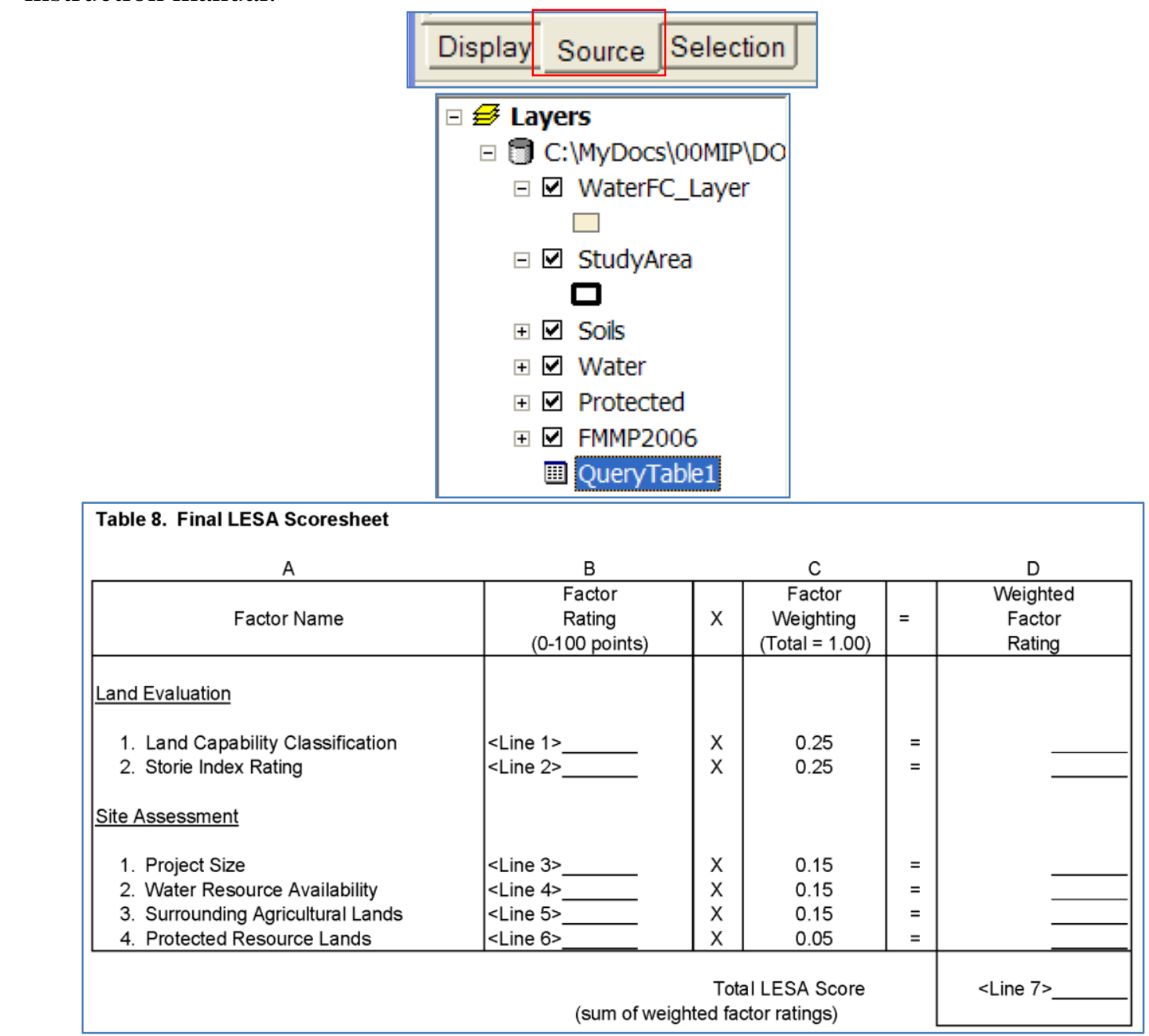

Step 5-Create a ModelBuilder model report

At the conclusion of a model run a report can be generated that provides a list of variables and processes in its collapsed form, or detailed information about the model in its expanded form. From the Edit Model window (step 3a) select Model $>$ Report and choose either view or save the model report. 


\begin{tabular}{|c|}
\hline Model Edit View Window \\
\hline Run \\
\hline Run Entire Model \\
\hline Validate Entire Model \\
\hline Save \\
\hline Delete Intermediate Data \\
\hline Print Setup... \\
\hline Print Preview... \\
\hline Print... \\
\hline \begin{tabular}{l|l} 
Report... &
\end{tabular} \\
\hline $\begin{array}{l}\text { Model Properties... } \\
\text { Diagram Properties... }\end{array}$ \\
\hline
\end{tabular}




\section{Step 6-Prepare the model for next run}

Once the model has been run and the results recorded in the summary table, the model should be prepared for the next run. It is recommended that the following steps be performed at the beginning of a new run to ensure any previous results have been cleared from the project.

Open the Edit Model window (step 3a).

Select Model>Delete Intermediate Data: this removes any temporary data created during a previous run.

\begin{tabular}{|l|}
\hline Model Edit View Window \\
Run \\
Run Entire Model \\
Validate Entire Model \\
Save \\
\hline Delete Intermediate Data \\
\hline
\end{tabular}

Select Model>Validate Model: This resets the model and prepares it for another run by checking the model variables (inputs) ensure it is valid for the tool associated with it. Select Model>Save: Select save to save the model after deleting intermediate data and validation. 